\title{
GIOVANO PALMA
}

\section{PRESSÕES E FLUXO EM SILOS ESBELTOS $(\mathrm{h} / \mathrm{d} \geq 1,5)$}

Dissertação apresentada à Escola de Engenharia de São Carlos da Universidade de São Paulo, como parte dos requisitos para obtenção do Título de Mestre em Engenharia de Estruturas.

Orientador: Prof. Tit. Carlito Calil Junior

São Carlos

2005 


\section{AGRADECIMENTOS}

A Deus por cuidar de mim e mostrar o melhor caminho a seguir.

A Universidade Federal de Santa Maria por ter proporcionado minha formação na graduação.

A Escola de Engenharia de São Carlos da Universidade de São Paulo por ter proporcionado o desenvolvimento da pesquisa de mestrado.

A minha família por apoiar-me em todos os instantes, e mesmo longe, estar sempre presente.

A Deise por estar junto comigo em todos os momentos, sempre me apoiando e fortalecendo.

Ao Prof. Calil pela amizade demonstrada, excelente orientação e incentivo a pesquisa e busca do conhecimento.

A todos meus colegas que me acompanharam ao longo destes anos de vivência acadêmica. Em especial, o colega Andrés Cheung pela amizade e companheirismo na pesquisa.

Aos professores e funcionários do Departamento de Engenharia de Estruturas, em especial do Laboratório de Madeiras e Estruturas de Madeira. 
"A ciência sem Deus, incha, é orgulho. Quanto mais acredito na ciência, mais acredito em Deus" Albert Einsten 


\section{RESUMO}

PALMA, G. (2005). Pressões e fluxo em silos esbeltos ( $h / d \geq 1,5)$. São Carlos, 2005. Exame de Dissertação (Mestrado) - Escola de Engenharia de São Carlos, Universidade de São Paulo.

A maioria dos silos existentes no mundo não apresenta condições ideais de operação devido ao insuficiente conhecimento das pressões, do fluxo e do grande número de variáveis que afetam o comportamento dos produtos armazenados. Isso explica também, a grande quantidade de acidentes e colapsos em silos. Uma análise dos principais códigos normativos indica a existência de divergências entre eles, principalmente quando se referem à determinação das pressões exercidas pelo produto armazenado sobre a estrutura, o mesmo ocorrendo entre as teorias propostas por pesquisadores. Este trabalho tem por finalidade apresentar um estudo teórico das pressões e fluxo em silos verticais esbeltos $(h / d \geq 1,5)$ exercidas pelo produto armazenado. Para isso, um estado da arte das teorias de pressões e fluxo propostas pelos mais importantes pesquisadores e normas internacionais sobre o assunto foi desenvolvida. Como exemplo de aplicação, foram analisadas as pressões em um silo vertical esbelto com fundo cônico, para as situações de fluxo de massa e fluxo de funil, para dois produtos granulares. Com base nos resultados obtidos, foi elaborada uma proposta de norma brasileira para a determinação das pressões exercidas pelo produto armazenado para essas unidades, tendo em vista que o Brasil ainda não possui uma norma específica para o projeto e construção de silos. Além disso, foi desenvolvido um programa computacional de cálculo das pressões.

Palavras Chave: Pressões, fluxo, silos esbeltos, estruturas de armazenamento. 


\section{ABSTRACT}

PALMA, G. (2005). Pressure and flow in slender silos ( $h / d \geq 1,5)$. São Carlos, 2005. Exame de Dissertação (Mestrado) - Escola de Engenharia de São Carlos, Universidade de São Paulo.

Silos are structures that usually present process and failures problems due to insufficient knowledge of bulk solids pressures and flow. An analysis of the principal international theories and standards shows divergences, mainly in the pressures determination due to the storage of bulk solids. This work presents a theoretical study of the pressures and flow in slender vertical silos $(h / d \geq 1,5)$ due the storage of the bulk solids. An state of the art of the theories of pressures and flow proposed by the most important researchers and international standards on the subject is presented. As a practical example, the pressures were determined in a slender vertical silo with conical bottom, for mass and funnel flow patterns and for two granular materials. Based on the study, a proposal of Brazilian standard was elaborated for the determination of the pressures due the bulk solids for slender silos, considering that Brazil doesn't still have a specific standard for the design and construction of silos. A software for pressures determination was also developed.

Keywords: Pressures, flow, slender silos, storage structures. 


\section{LISTA DE FIGURAS}

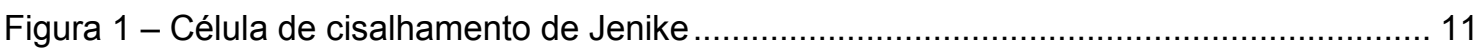

Figura 2 - Gráfico do Lugar geométrico de deslizamento ......................................................... 11

Figura 3 - Gráfico da Determinação do ângulo de atrito ...................................................... 12

Figura 4 - Determinação do atrito com a parede na célula de Jenike. ...................................... 14

Figura 5 - Lugar geométrico de deslizamento com a parede ................................................. 14

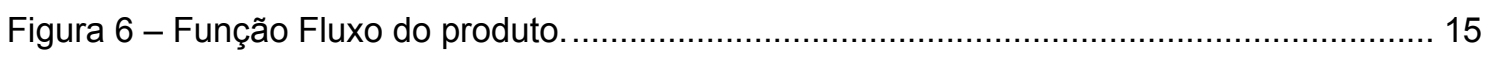

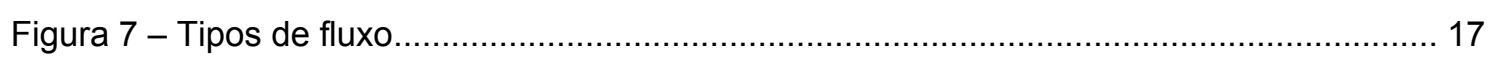

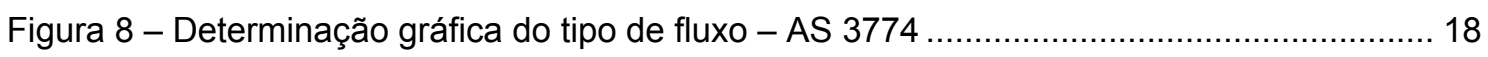

Figura 9 - Determinação gráfica do tipo de fluxo - DIN 1055-6, ISO 11697, EUROCODE 1 .... 18

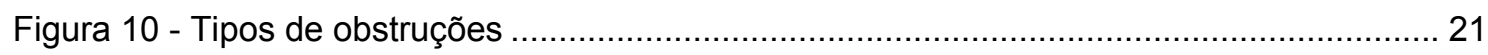

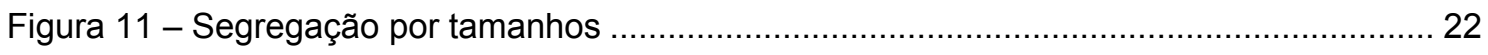

Figura 12 - Análise para formação de obstrução em abóbada em silos com fluxo de massa. . 23

Figura 13 - Função fluxo do produto armazenado e fator fluxo da tremonha............................ 24

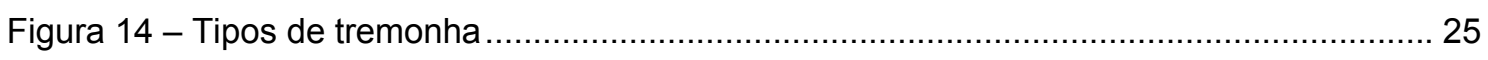

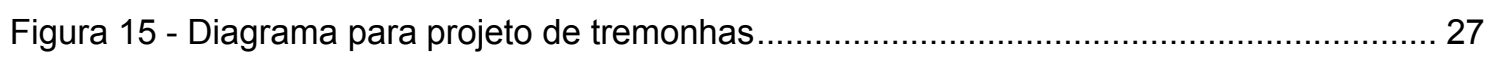

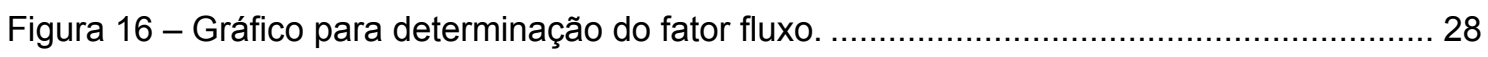

Figura 17 - Determinação da função $\mathrm{H}(\alpha)$ para tremonhas cônicas e em cunha....................... 30

Figura 18 - Formas de bocas de descarga para silos com fluxo de funil ................................ 31

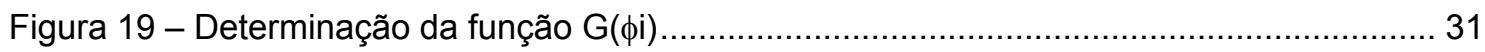

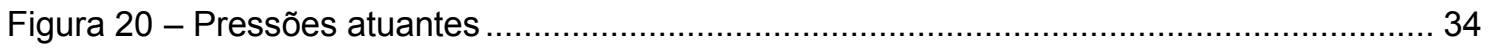

Figura 21 - Razão da pressão de fluxo pela pressão inicial ................................................ 37

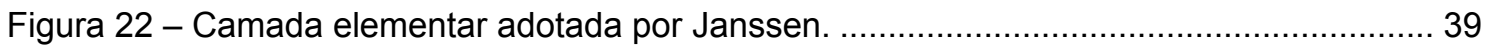

Figura 23 - Pico de pressão em tremonhas com fluxo de massa.......................................... 47

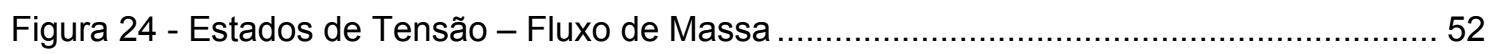

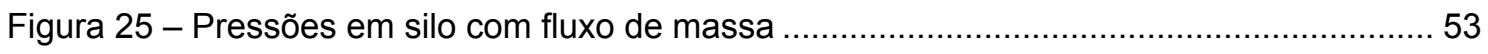

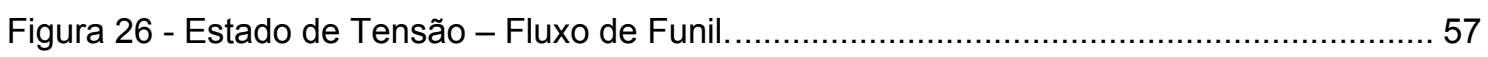

Figura 27 - Distribuição das pressões em silos com fundo plano conforme norma AS $3774 \ldots 62$

Figura 28 - Pressões sobre a tremonha conforme normas ISO, EUROCODE 1 e DIN 1055-6.66

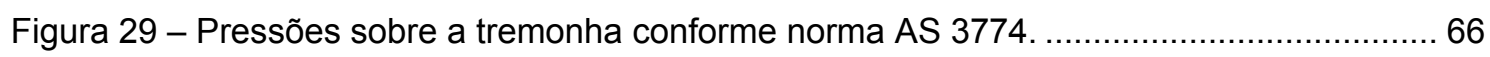

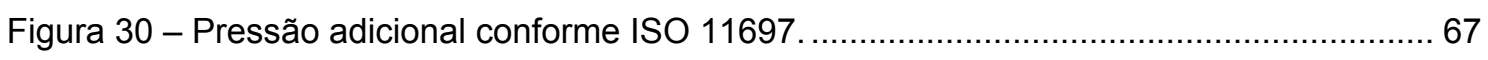

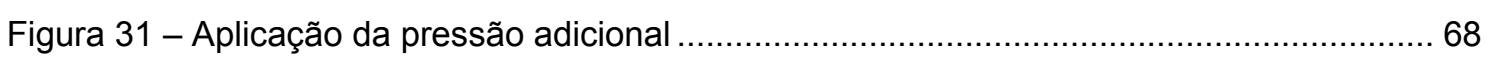

Figura 32 - Distribuição da pressão de descarga excêntrica................................................... 70

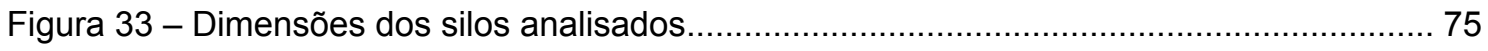

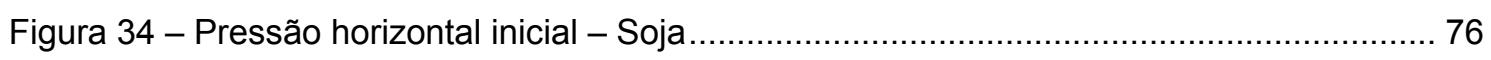

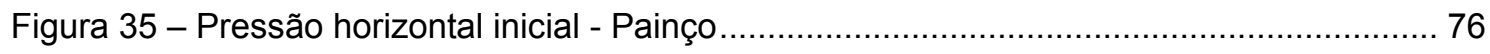

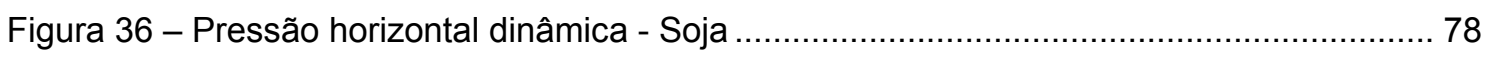

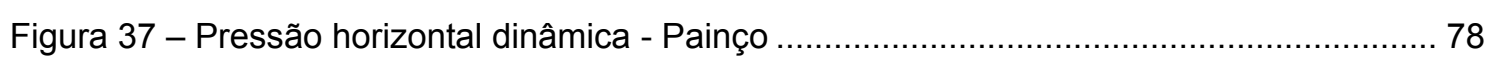

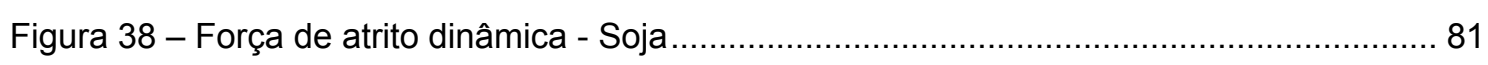

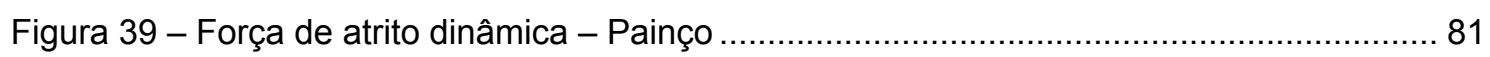




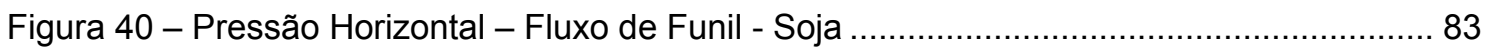

Figura 41 - Pressão Horizontal - Fluxo de Funil - Painço …...................................................... 83

Figura 42 - Tela do programa para cálculo de pressões ...................................................... 86 


\section{LISTA DE TABELAS}

TABELA 1 - Emprego do limite inferior e superior das propriedades físicas dos produtos........ 10

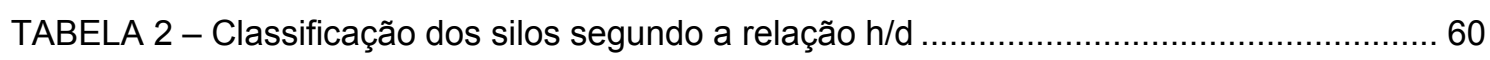

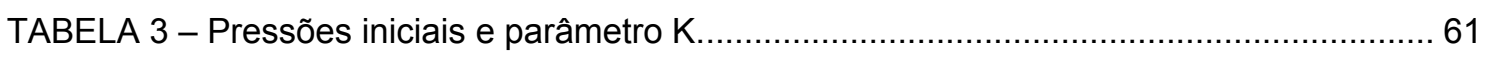

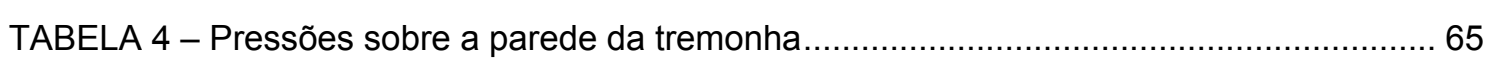

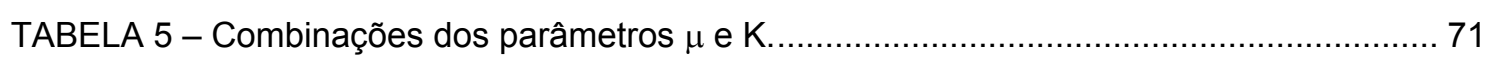

TABELA 6 - Níveis de carregamentos utilizados nos ensaios............................................. 73

TABELA 7 - Valores das propriedades físicas dos produtos ................................................ 73

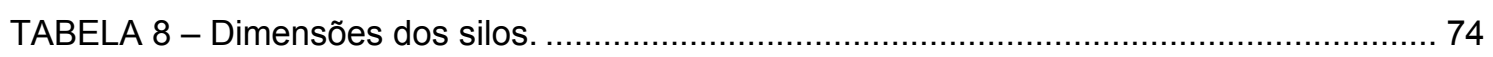

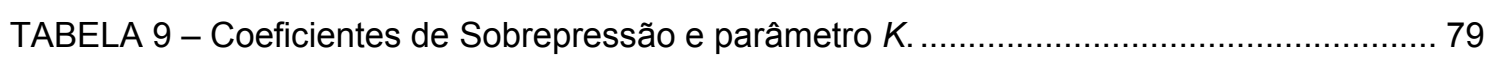

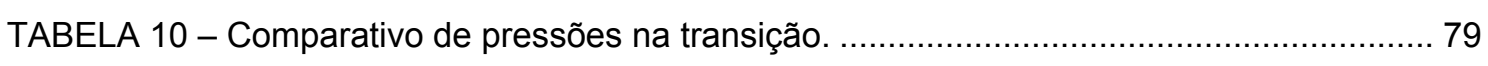

TABELA 11 - Pressão na transição: EUROCODE versus Normas e Teorias. ............................ 80

TABELA 12 - Força de Atrito norma EUROCODE versus Normas e Teorias ............................ 82

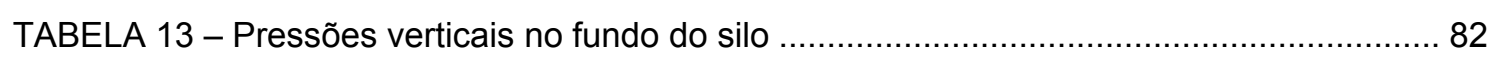

TABELA 14 - Relação entre pressões na transição: fluxo massa versus fluxo funil ................... 84 


\section{LISTA DE SÍMBOLOS}

\section{LETRAS MINÚSCULAS}

$\alpha$

$\alpha_{s}$

$\phi_{\mathrm{e}}$

$\phi_{e, 1}$

$\phi_{\mathrm{e}, \mathrm{u}}$

$\phi_{\mathrm{i}}$

$\phi_{\mathrm{i}, t}$

$\phi_{\mathrm{i}, \mathrm{u}}$

$\phi_{\mathrm{r}}$

$\phi_{\mathrm{w}}$

$\phi_{\mathrm{w}, \mathrm{I}}$

$\phi_{\mathrm{w}, \mathrm{u}}$

$\gamma$

$\gamma_{\mathrm{i}}$

$\gamma_{u}$

$\mu$

$\mu_{1}$

$\mu_{\mathrm{u}}$

$\tau$

$\sigma$

d

b

$\mathrm{h}_{\mathrm{c}}$

$\mathrm{h}_{\mathrm{cob}}$

$\mathrm{h}_{\mathrm{cn}}$

$\mathrm{h}_{\mathrm{t}}$

$p_{h}$

$p_{v}$

$p_{w}$

$p_{n}$

$p_{t}$

Ângulo de inclinação da parede da tremonha com a vertical

Ângulo de inclinação com o eixo central do cone formado no fluxo de funil

Efetivo ângulo de atrito interno do produto (valor médio)

Valor inferior do efetivo ângulo de atrito interno do produto

Valor superior do efetivo ângulo de atrito interno do produto

Ângulo de atrito interno (valor médio)

Valor inferior do ângulo de atrito interno do produto

Valor superior do ângulo de atrito interno do produto

Ângulo de repouso do produto

Ângulo de atrito do produto com a parede (valor médio)

Valor inferior do ângulo de atrito do produto com a parede

Valor superior do ângulo de atrito do produto com a parede

Peso específico do produto

Valor inferior da densidade do produto

$\left[\mathrm{FL}^{-3}\right]$

Valor superior da densidade do produto

$\left[\mathrm{FL}^{-3}\right]$

Coeficiente de atrito do produto com a parede (valor médio)

Valor inferior do coeficiente de atrito do produto com parede

Valor superior do coeficiente de atrito do produto com parede

Tensão de Cisalhamento

Tensão Normal

Altura efetiva do silo

Diâmetro do silo

Dimensão da boca de saída

Altura do corpo do silo

Altura da cobertura do silo

Altura da tremonha

$$
\text { Pressão horizontal (normal) à parede do corpo do silo }
$$


$\mathrm{p}_{\mathrm{s}} \quad$ Pressão aplicada na transição em silos com fluxo de massa

$\left[\mathrm{FL}^{-2}\right]$

$\mathrm{p}_{\mathrm{p}} \quad$ Pressão adicional

$\left[\mathrm{FL}^{-2}\right]$

z Ordenada a partir do nível de referência

[L]

z' Ordenada a partir do vértice da tremonha

[L]

$r \quad$ Coordenada radial em silos cilíndricos

\section{LETRAS MAIÚSCULAS}

A Área da sessão transversal de um silo $\left[\mathrm{L}^{2}\right]$

K Razão entre as pressões horizontal e vertical (valor médio) [1]

$\mathrm{K}_{\mathrm{u}} \quad$ Valor superior de $\mathrm{K}$

$\mathrm{K}_{\mathrm{I}} \quad$ Valor inferior de $\mathrm{K}$

$\mathrm{P}_{\mathrm{w}} \quad$ Força de compressão sobre a parede por unidade de perímetro $\quad\left[\mathrm{FL}^{-1}\right]$

$\cup \quad$ Perímetro da seção A [L]

\section{LISTA DE INDICES}

e Estático ou inicial ou carregamento

d Dinâmico ou descarga [1]

$\mathrm{t}$ Tremonha [1]

tr Transição [1]

c Corpo do silo [1]

b Base do silo [1]

ex Excêntrico [1]

tal Talude [1]

cn Cone [1]

cob Cobertura [1]

\section{LISTA DE ABREVIATURAS E SIGLAS}

ABNT

ANSI

AS

DIN

ENV

ISO
Associação Brasileira de Normas Técnicas

American National Standard Institute

Australian Standard

Deutsche Industrie Norm

EUROCODE - European Committee for Standardization International Organization for Standardization 


\section{SUMÁRIO}

AGRADECIMENTOS

EPÍGRAFE

RESUMO

ABSTRACT

LISTA DE FIGURAS V V

LISTA DE TABELAS vii

LISTA DE SIMBOLOS viii

LISTA DE ÍNDICES $\quad$ ix

LISTA DE ABREVIATURAS E SIGLAS ix

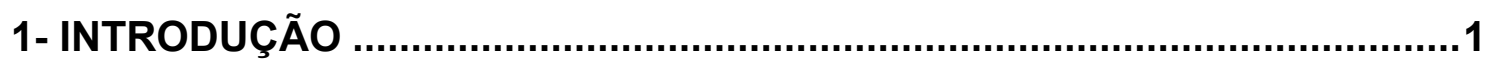

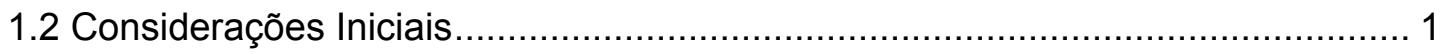

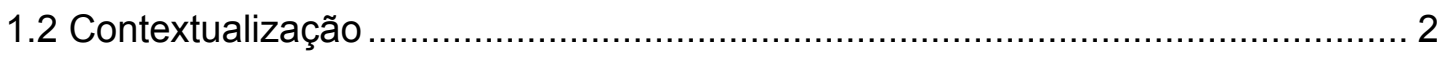

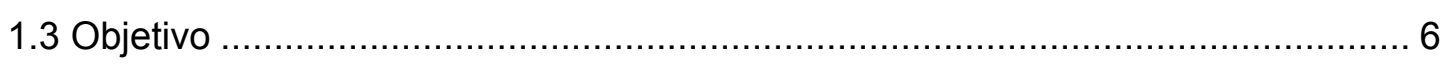

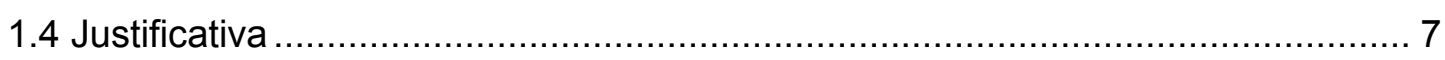

2 - PROPRIEDADES FÍSICAS DOS PRODUTOS ARMAZENADOS................8

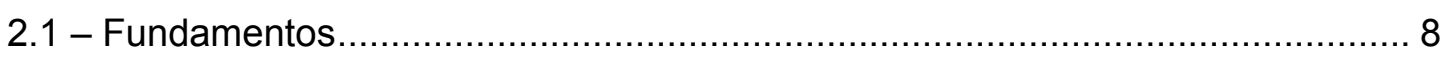

2.2 - Determinação das propriedades físicas ............................................... 10

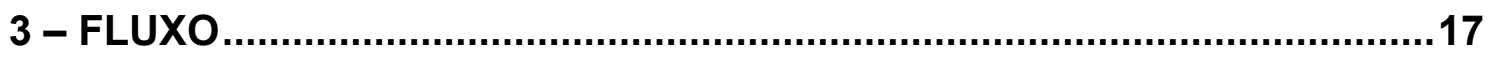

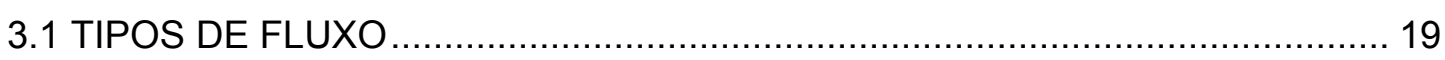

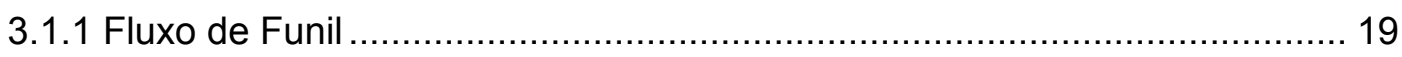

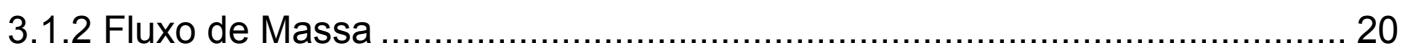

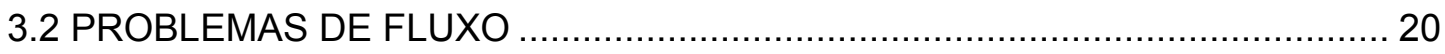

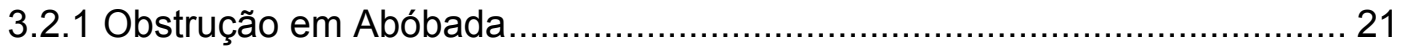

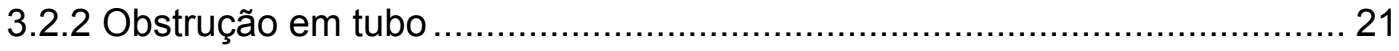

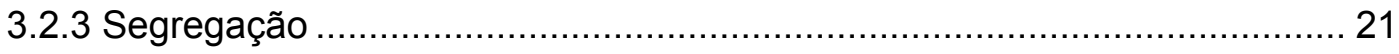

3.2.4 Tempo de armazenamento em excesso ................................................ 22

3.3 REQUISITOS PARA EVITAR OBSTRUÇÕES DE FLUXO ............................. 22

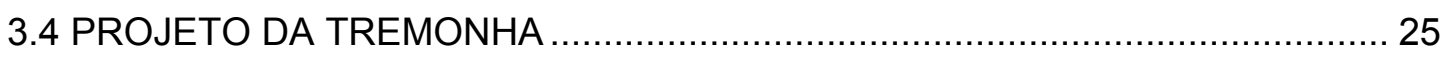

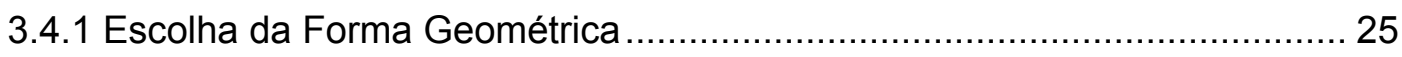

3.4.2 Determinação da Inclinação das Paredes................................................... 26

3.4.3 Determinação do Fator Fluxo da tremonha $(f f)$.................................... 28

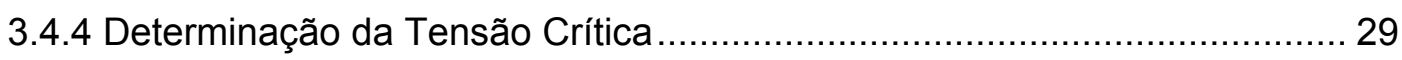

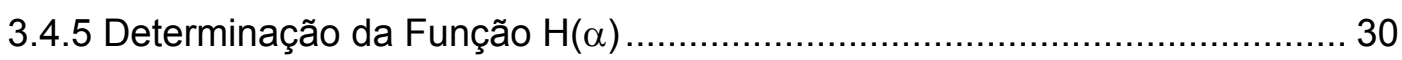

3.4.6 Determinação da dimensão mínima da boca de descarga ........................ 30 
4 - AÇÕES

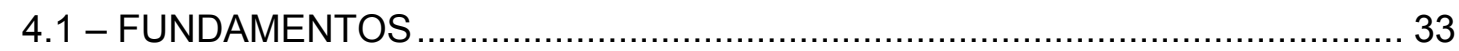

4.2 PRESSÕES ESTÁTICAS E PRESSÕES DE FLUXO....................................... 35

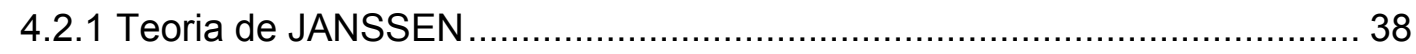

4.2.2 Teoria de WALKER apud GAYLORD \& GAYLORD ............................... 40

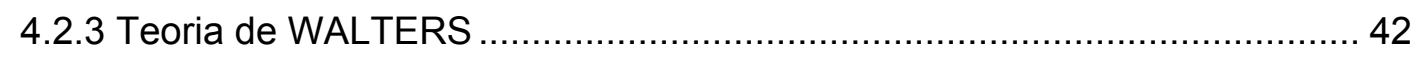

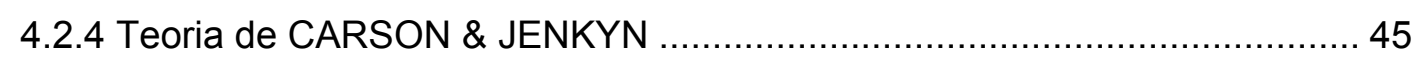

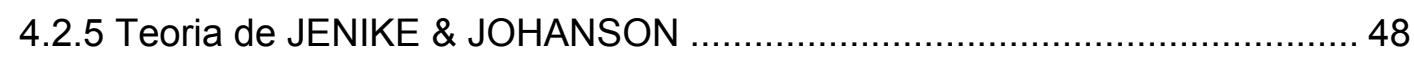

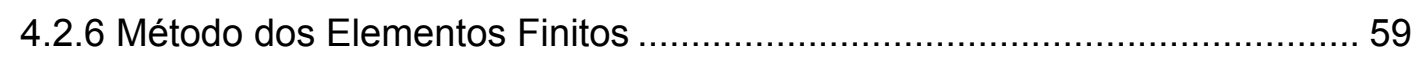

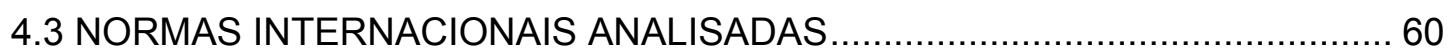

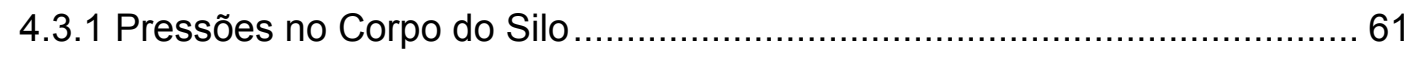

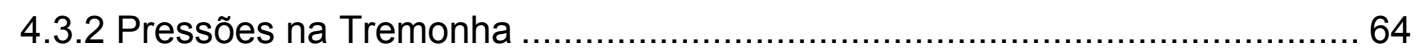

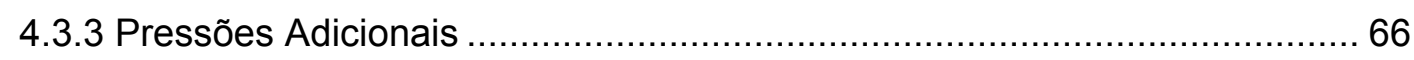

4.3.4 - Combinações de Carregamento .......................................................... 70

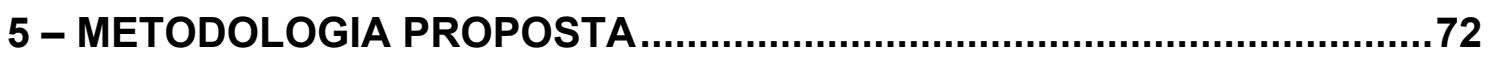

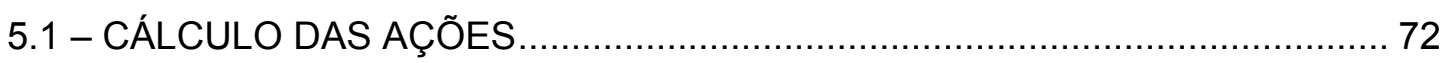

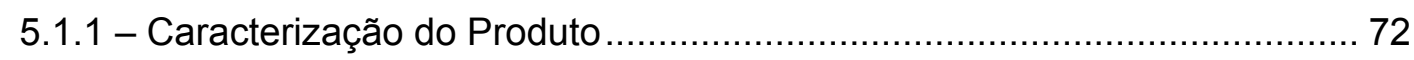

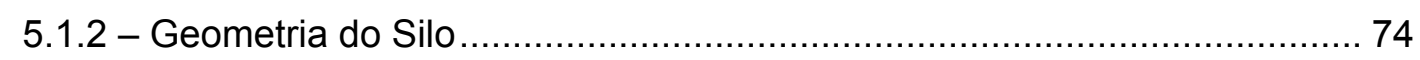

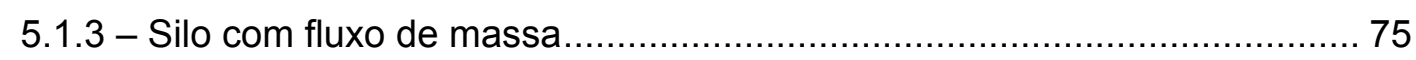

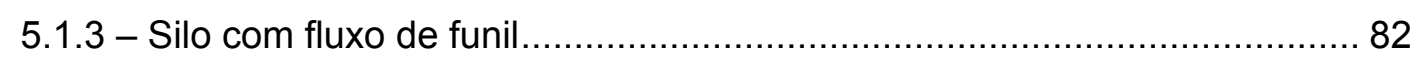

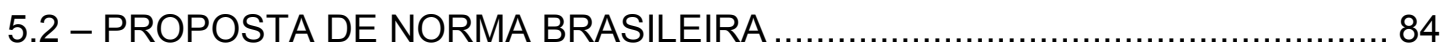

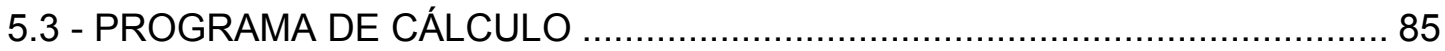

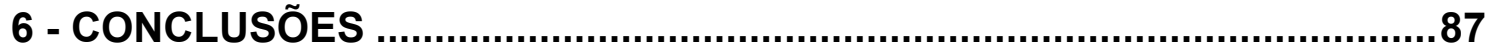

7 - REFERÊNCIAS

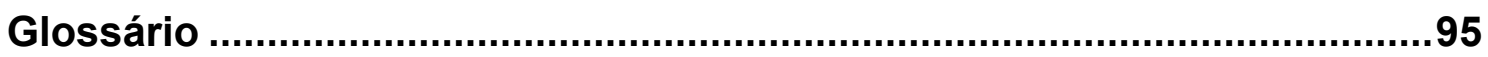

Proposta de Norma Brasileira para Silos Verticais Esbeltos.....................97 


\section{1- INTRODUÇÃO}

\subsection{Considerações Iniciais}

Silos são construções destinadas ao armazenamento de produtos granulares ou pulverulentos a granel, tipicamente utilizados na indústria, agricultura, siderurgia e portos entre outros. Podem ser construídos com os mais diversos materiais, como concreto armado, aço, madeira, argamassa armada, etc., porém os mais utilizados atualmente na agricultura são os silos metálicos com chapa corrugada.

O armazenamento de produtos em silos é considerado uma solução de grande viabilidade devido à economia de espaço físico, mão-de-obra e custo de transporte, assim como a possibilidade de conservação do produto ensilado.

A demanda por silos pode ser explicada devido às necessidades de cooperativas, produtores e indústrias em armazenar grandes quantidades de produtos e materiais em espaços reduzidos. A estocagem torna-se importante também em termos econômicos, na medida em que permite um maior controle do escoamento da safra e abastecimento, reduzindo a necessidade de importação e também das especulações de mercado.

No Brasil, a necessidade de ampliação da rede armazenadora se torna cada vez mais necessária, tendo em vista que conforme o terceiro levantamento da safra elaborado pela Companhia Nacional de Abastecimento (Conab) (2004), a produção brasileira de grãos baterá um novo recorde, com um volume de 130,8 milhões de toneladas na safra 2003/2004, o que representa um acréscimo de $6,2 \%$ sobre a colheita anterior (123,2 milhões de toneladas). A estimativa indica um crescimento de 3,1 milhões de hectares na área plantada em relação ao período anterior, totalizando 47 milhões de hectares. 
Estima-se que este ritmo de crescimento da área cultivada provocará um salto na produção agrícola em longo prazo, tanto que se for mantido o crescimento neste nível, espera-se que nos próximos 15 ou 20 anos teremos mais de 30 milhões de hectares disponíveis para o plantio de grãos. Existe também a expectativa de que os avanços tecnológicos da pecuária de corte e leite vão permitir essa transferência de área hoje destinada a pastagem para o cultivo de grãos.

Portanto, num país como o Brasil, onde a produção de grãos aumenta a cada ano acarretando o projeto e construção de novos silos todos os dias, o correto conhecimento da determinação das ações que atuam sobre as paredes e fundo do silo torna-se cada vez mais essencial. Além disso, para projetar um silo com segurança, economia e eficiência, é necessário que o projetista conheça as máximas pressões possíveis de atuar sobre as paredes do silo durante sua vida operacional.

As pressões atuantes são diretamente dependentes das propriedades físicas dos produtos armazenados, do padrão de fluxo e da forma geométrica do silo, entre outras.

Os silos verticais podem ser classificados pela geometria em dois tipos: baixos e esbeltos. Os silos baixos correspondem às unidades de relação altura/diâmetro ou altura/lado menor que 1,5 e os silos esbeltos maior que 1,5 .

\subsection{Contextualização}

Os primeiros silos altos foram construídos entre 1870 e 1880. Naquela época, os calculistas pensavam que os produtos armazenados se comportavam como líquidos, projetando as estruturas para pressões equivalentes aos líquidos. Foi quando em 1881, ROBERTS (1884) efetuando ensaios em modelos de escala reduzida, estabeleceu a primeira teoria sobre silos, determinando que as pressões nas paredes não aumentavam linearmente com a profundidade, mas que alguma parcela do peso do produto armazenado é transferida para as paredes por atrito. Como resultado, as pressões no fundo e nas paredes na parte mais baixa de um silo, são menores que as exercidas por um líquido.

JANSSEN (1895), no ano de 1895, estabelece pela primeira vez a equação para o cálculo de pressões em um silo, ao considerar o equilíbrio de forças em uma parte elementar da massa ensilada. Sua teoria mudou em poucos anos o conceito de cálculo de pressões em silos, sendo até hoje utilizada, inclusive pelas normas internacionais. 
Esta teoria serviu de base para as primeiras normas de cálculo e para as pesquisas posteriores que se realizaram. Nos anos seguintes, uma grande transição para o campo experimental foi realizada por PRANTE e JAMIESON apud JENIKE (1968).

As propriedades dos produtos armazenados e dos líquidos são tão diferentes que os mecanismos de fluxo destas fases são completamente distintos. Segundo JENIKE (1964) duas diferenças fundamentais existem:

produtos armazenados podem transferir esforços de cisalhamento sob condições estáticas pois tem ângulo de atrito estático maior que zero, enquanto que os líquidos não;

muitos produtos armazenados, quando consolidados, isto é, após uma pressão ter sido aplicada sobre eles, adquirem resistência devido a coesão e mantém a sua forma sobre pressão, enquanto que os líquidos não;

Contudo, em 1930 devido aos refinamentos nos materiais de construção e nos métodos de cálculo estrutural, levando a uma redução dos coeficientes de segurança, ocorreram falhas em um grande número de silos projetados de acordo com a teoria de JANSSEN. Estas falhas produziram várias dúvidas sobre a validade da teoria de JANSSEN e incentivaram novas investigações sobre o comportamento dos produtos granulares em silos.

Pesquisadores de vários países começaram novos estudos em modelos reduzidos e em silos em escala real. PRANTE et al apud JENIKE (1968), concluíram que as pressões nos silos não eram constantes, mas variavam entre a condição inicial de carregamento e a condição de fluxo. Unanimidade foi obtida no que diz respeito que as pressões laterais críticas em silos ocorriam durante a descarga do silo e as pressões de fluxo podiam exceder as pressões iniciais por um fator de até 3 vezes.

Na década de quarenta, na França, os irmãos M. REIMBERT e A. REIMBERT (1979), conduzindo ensaios em modelos reduzidos, observaram que a relação entre a pressão horizontal e a pressão vertical variava com a altura do material e a forma do silo. Em 1976 conduzindo novos experimentos em silos em escala real e com diferentes geometrias, obtiveram resultados demonstrando que as pressões de fluxo excediam as iniciais por um fator 2 vezes maior.

Para o estudo das pressões de descarga dos silos foram muito importantes as contribuições de WALKER (1966), WALTERS (1973) e JENIKE et al $(1968,1973,1977,1985,1987)$, que reforçou a idéia de que as pressões ativas se desenvolviam inicialmente durante o carregamento do produto no silo e que pressões passivas ocorriam durante a descarga. 
Na década de setenta, importantes investigações em modelos reduzidos foram feitas na Espanha por RAVENET (1992). No final dessa mesma década, JOFRIET apud AYUGA (1995) no Canadá, inicia os primeiros estudos utilizando o método dos elementos finitos.

Nos anos seguintes, atenção especial foi dada a determinação das propriedades físicas dos produtos armazenados e também adaptação das normas aos últimos avanços científicos.

Atualmente, segundo AYUGA (1995), estão se diversificando os trabalhos de pesquisa, mas coexistem três grupos claramente diferenciados: os que estudam as ações e deformações em silos reais ou em modelos reduzidos; os que se dedicam a melhorar os modelos de comportamento dos materiais e os que avançam no estudo dos esforços estruturais, tanto estáticos como dinâmicos e no estudo dos detalhes, normalmente baseando-se no método dos elementos finitos.

No Brasil, o Departamento de Engenharia de Estruturas (SET), da Escola de Engenharia de São Carlos (EESC), da Universidade de São Paulo (USP), possui uma linha de pesquisa com o intuito de aprimorar o conhecimento, comprovar as teorias existentes e desenvolver tecnologia própria na área de silos. Até o momento foram desenvolvidos os seguintes trabalhos de Mestrado e Doutorado:

CALIL (1978), em sua dissertação de Mestrado "Estudo dos Silos de Madeira a Nível de Fazendas", propõe como alternativa para o pequeno produtor a construção de tais estruturas nas propriedades agrícolas, utilizando madeira tanto como material estrutural quanto de revestimento.

CALIL (1984), em sua tese de Doutorado "Sobrepresiones en las Paredes de los Silos para Almacenamiento de Productos Pulverulentos Cohesivos", realiza estudo em modelos reduzidos, determinando os tipos de fluxo de materiais armazenados, a intensidade das pressões de carregamento e descarga para produtos granulares e para produtos pulverulentos.

FORTES FILHO (1985), em sua dissertação de Mestrado "Uma Introdução ao Estudo dos Silos", aborda a problemática dos silos de maneira ampla e suficientemente profunda para as aplicações correntes, apoiando-se em uma análise de estudos teóricos e experimentais realizados por diversos autores.

VAZ (1987), em sua dissertação de Mestrado "Silos Verticais de Madeira Compensada", apresenta uma proposta de silos de madeira compensada de seção hexagonal para o pequeno produtor. 
COUTO (1989), em sua dissertação de Mestrado "Contribuição ao Estudo dos Silos de Argamassa Armada para o Armazenamento de Cereais", propõe uma metodologia de dosagem para argamassa armada, verificando sua viabilidade construtiva em dois silos protótipos cilíndricos.

ESTEVES (1989), em sua dissertação de Mestrado "Silos Metálicos de Chapa Corrugada", apresenta estudo teórico e experimental destas unidades com vistas a caracterização dos materiais e das ligações utilizadas, além de propor uma metodologia de ensaio para a avaliação dos componentes estruturais.

CALIL (1990), em sua tese de Livre - Docência "Recomendações de Fluxo e de Cargas para o Projeto de Silos Verticais", realiza o estudo das teorias e práticas que envolvem as várias fases de carregamento e fluxo de produtos armazenados, propondo recomendações para o armazenamento destes produtos em silos.

SILVA (1993)*, em sua tese de Doutorado "Estudo da Variabilidade de Pressões em Silos" estuda as pressões em silos sob o ponto de vista probabilístico, com ênfase na análise da variabilidade das propriedades dos produtos armazenados e na variabilidade das pressões.

MILANI (1993), em sua tese de Doutorado "Determinação das Propriedades de Produtos Armazenados para Projeto de Pressões e Fluxo em Silos", apresenta uma metodologia de ensaio para a determinação das propriedades de produtos armazenados, com base em estudos teóricos e experimentais utilizando o equipamento de translação "Jenike Shear Cell".

FASSONI (1994), em sua dissertação de Mestrado "Sistema Construtivo Modular em Madeira para Silos Horizontais", apresenta proposta de projeto de silo horizontal de madeira utilizando peças maciças e chapas de compensado, com ênfase na pré-fabricação.

GOMES (1994), em sua dissertação de Mestrado "Silos para Armazenamento de Laranjas", propõe o projeto e detalhes construtivos de um silo protótipo, utilizando madeiras de reflorestamento para o armazenamento de laranjas, tanto em nível de fazendas, como de indústrias.

MANFRIN (1994), em sua dissertação de Mestrado "Um Estudo dos Silos para Açúcar: Propriedades Físicas do Material Armazenado, Recomendações Construtivas, Normativas e Análise Estrutural", analisa as condições ideais que o açúcar deve apresentar para uma adequada armazenagem, bem como avalia a distribuição dos esforços solicitantes a partir do confronto entre uma análise discreta, tratando a estrutura como um conjunto de pilares e vigas curvas, e de outra contínua, na qual a estrutura da parede é tratada como casca.

* Tese apresentada à Escola Politécnica da Universidade de São Paulo sob orientação do Prof. Dr. Carlito Calil Junior. 
NASCIMENTO (1996), em sua tese de Doutorado "Estudo de Silos Prismáticos para Fábricas de Ração", desenvolve estudo teórico e experimental de painéis metálicos com conformação ziguezague horizontal, fornecendo subsídios técnicos para projetos de silos prismáticos metálicos para uso industrial.

ARAÚJO (1997), em sua tese de Doutorado "Estudo Teórico Experimental de Tremonhas Piramidais para Silos Metálicos Elevados", realiza estudos para a determinação dos esforços em tremonhas enrijecidas e não enrijecidas por análise analítica, numérica e experimental, confrontando os métodos utilizados.

ANDRADE Jr. (1998), em sua dissertação de Mestrado "Análise Estrutural das Chapas Metálicas de Silos e de Reservatórios Cilíndricos", procura dispor conceitos claros e distintos do comportamento e dos fenômenos de perda de estabilidade do equilíbrio de reservatórios e silos metálicos, bem como estabelece configurações estruturais que apresentam maiores riscos a perda da estabilidade da estrutura e fornece relações de diâmetro/espessura e de diâmetro/altura em que é possível evitar os problemas advindos da perda de estabilidade do equilíbrio.

GOMES (2000), em sua tese de doutorado "Estudo Teórico e Experimental das Ações em Silos Horizontais", compara resultados teóricos com os obtidos por meio de medições diretas das pressões em um modelo piloto e um silo horizontal em escala real, com a relação entre as pressões horizontais e verticais, K. Com base nos resultados obtidos, propõe um novo método de cálculo fundamentado em um modelo empírico para a determinação das pressões horizontais nessas unidades.

FREITAS (2001) em sua tese de doutorado "Estudo teórico e experimental das pressões em silos cilíndricos de baixa relação altura/diâmetro e fundo plano", realiza ensaios em um silo protótipo e um silo piloto. Com base nos resultados experimentais propõe modelos empíricos para a determinação das pressões horizontais e verticais no fundo plano do silo para esse tipo de unidade armazenadora.

ANDRADE Jr. (2002) em sua tese de doutorado "Ação do Vento em Silos Cilíndricos de baixa relação altura/diâmetro", realiza estudos teóricos e experimentais em modelos aerodinâmicos e aeroelásticos sobre as ações do vento em silos, determinando coeficientes aerodinâmicos no costado e na cobertura.

\subsection{Objetivo}

Dando continuidade nas pesquisas do SET, este trabalho tem por finalidade o estudo teórico das pressões e fluxo em silos verticais esbeltos $(h / d \geq 1,5)$ exercidas por produtos não coesivos. 
Para isso, as pressões foram analisadas segundo as teorias de pressões e fluxo propostas pelos mais importantes pesquisadores e normas internacionais em um silo vertical esbelto com fundo cônico, para as situações de fluxo de massa e fluxo de funil, para dois produtos granulares.

Com base no estudo, foram propostas recomendações para a determinação das pressões devidas ao produto armazenado para essas unidades e elaborado um programa computacional de cálculo das pressões.

\subsection{Justificativa}

A maioria dos silos existentes no mundo não apresenta condições ideais de operação, seus projetos ainda são complexos e, muitas vezes, rodeados de incertezas, pois diversas são as variáveis que afetam o comportamento estrutural. Uma forte razão para isso é o insuficiente conhecimento das pressões e do comportamento de fluxo dos produtos armazenados. Isso explica, também, a grande quantidade de acidentes e colapsos de silos.

Uma análise das principais normas internacionais indica a existência de divergências entre elas, principalmente quando se referem à determinação das pressões exercidas pelo produto armazenado sobre a estrutura. Devido as normas serem baseadas geralmente em teorias existentes, torna-se necessário também examinar essas teorias. A maioria dessas teorias existentes, as quais diferem consideravelmente, baseia-se no comportamento de tensões do produto armazenado no silo. Portanto, se faz necessário uma comparação entre teorias e normas.

Do mesmo modo, a correta determinação dos picos de pressões que ocorrem na descarga, ainda não é completamente conhecida, tanto que as normas adotam coeficientes de segurança parciais para levar em consideração esses efeitos.

Além disso, o Brasil ainda não possui uma norma específica para o projeto e construção de silos, sendo neste trabalho inseridos os estudos que contribuirão para a elaboração da primeira norma de ações em silos do Brasil. 


\section{2 - PROPRIEDADES FÍSICAS DOS PRODUTOS ARMAZENADOS}

\section{1 - Fundamentos}

A primeira etapa para o cálculo das ações em silos é o estudo das propriedades do produto a ser armazenado. Para isso, torna-se necessário à caracterização do produto que consiste em determinar as propriedades físicas, também chamadas de propriedades de fluxo. Estas propriedades se referem ao comportamento do produto e surgem das forças que atuam sobre as partículas individualmente. A importância em determinar as propriedades do produto reside no fato de que elas influenciam no padrão de fluxo, pressões atuantes, geometria e rugosidade da parede da célula de armazenamento e dispositivo de descarga (tremonha) entre outros.

As propriedades de fluxo normalmente determinadas são as seguintes:

- $\quad$ densidade $-\rho$

- granulometria

- $\quad$ ângulo de atrito interno - $\phi_{\mathrm{i}}$

- $\quad$ efetivo ângulo de atrito interno - $\phi_{\mathrm{e}}$

- $\quad$ ângulo de atrito com a parede - $\phi_{\mathrm{w}}$

- $\quad$ Função Fluxo - FF

- $\quad$ fator fluxo da tremonha - $f f$.

As normas internacionais apresentam tabelas com os valores das propriedades de fluxo para alguns produtos e também métodos e equipamentos para sua determinação. Como esses valores variam muito entre as norma, recomenda-se, sempre que possível, realizar ensaios para caracterização de cada produto a ser armazenado. 
Devido à importância do assunto, diversos pesquisadores vem desenvolvendo pesquisas na área objetivando um melhor entendimento do comportamento dessas propriedades nas fases de carregamento, armazenagem e descarga, assim como, de padronizar os procedimentos para a determinação das propriedades.

Importantes contribuições foram dadas por JENIKE (1964), que em 1952 começou a investigar a possibilidade de utilizar os equipamentos de teste da mecânica dos solos para medir as propriedades de fluxo. Devido aos níveis de tensões em silos serem mais baixos do que nos solos, estes dispositivos em sua versão original apresentaram resultados insatisfatórios para os produtos armazenados. Diante disso, Jenike desenvolveu um aparelho de cisalhamento direto, conhecido internacionalmente pelo nome de "Jenike Shear Tester", apropriado para a caracterização dos produtos armazenados, sendo utilizado por muitos pesquisadores e códigos normativos. Segundo SCHWEDES (1981), a principal razão desta popularidade, é certamente a versatilidade do aparelho de Jenike, pois permite a determinação da Função Fluxo, ângulo de atrito interno, ângulo de atrito com a parede e o efeito do tempo de consolidação.

Com o intuito de avaliar a confiabilidade e reprodutibilidade das medidas das propriedades de fluxo, um grupo denominado "Working Party on the Mechanics of Particulate Solids (WPMPS)" da Federação Européia de Engenheiros Químicos, coordenou vários ensaios com o aparelho de Jenike. Após detalhada análise dos resultados experimentais e da experiência dos membros da WPMPS, foi elaborado um novo procedimento padrão de teste, o qual fornece instruções detalhadas para a operação do aparelho de Jenike, que recebeu o nome de "Standart Shear Testing Technique for Particulate Solids Using the Jenike Shear Cell (1989) “.

No Brasil, MILANI (1993) desenvolveu um importante trabalho com base em estudos teóricos e experimentais utilizando o equipamento de Jenike, propondo uma metodologia de ensaio para a determinação das propriedades dos produtos armazenados.

Segundo ROTTER et al. (1998) apud FREITAS (2001), uma descrição completa de todas as propriedades de fluxo é atualmente impossível, pois ainda não são conhecidos todos os parâmetros que deveriam ser medidos, nem como algumas das propriedades conhecidas deveriam ser medidas.

REIMBERT (1979) afirma que as condições do processo de armazenamento não conseguem ser controladas como nos ensaios de laboratório, portanto, o estabelecimento de faixas de variação (limites superior e inferior) das propriedades do 
produto torna-se necessário para que se possam estabelecer as combinações de parâmetros que resultam nas maiores solicitações.

Conforme FREITAS (2001), tendo em vista que as propriedades dos produtos armazenados em silos variam durante a vida útil do silo e considerando o critério de dimensionamento dos estados limites, CALIL JR (1997) propõe, de acordo com a norma australiana AS (1996), que, em termos de projeto, deverão ser determinados dois limites para cada parâmetro, de modo a delimitar a sua faixa de variação e, com isso, obter-se as combinações mais desfavoráveis para cada caso. Estes limites são o menor valor possível (limite inferior) e o maior valor possível (limite superior) para o parâmetro considerado durante a vida útil do silo. A tabela 1 apresenta o emprego adequado dos limites das principais propriedades de acordo com o objetivo.

TABELA 1 - Emprego do limite inferior e superior das propriedades físicas dos produtos.

\begin{tabular}{|c|c|c|c|c|c|}
\hline \multicolumn{2}{|c|}{$\begin{array}{l}\text { APLICAÇÃO DA } \\
\text { PROPRIEDADE }\end{array}$} & $\begin{array}{c}\text { Peso } \\
\text { específico } \\
\text { do produto }\end{array}$ & $\begin{array}{l}\text { Ângulo de } \\
\text { atrito com a } \\
\text { parede }\left(\phi_{w}\right)\end{array}$ & $\begin{array}{l}\text { Ângulo de } \\
\text { atrito } \\
\text { interno }\left(\phi_{i}\right)\end{array}$ & $\begin{array}{l}\text { Relação entre a } \\
\text { pressão horizontal } \\
\text { e vertical (K) }\end{array}$ \\
\hline \multirow{2}{*}{ Tipo de fluxo } & Funil & Inferior & Superior & Inferior & - \\
\hline & Massa & Inferior & Inferior & Superior & - \\
\hline \multirow{2}{*}{\multicolumn{2}{|c|}{$\begin{array}{c}\text { Cálculo da máxima pressão } \\
\text { horizontal na parede do silo, } p_{\mathrm{h}} \\
\text { Cálculo da máxima pressão } \\
\text { vertical, } \mathrm{p}_{\mathrm{v}}\end{array}$}} & Superior & Inferior & Inferior & Superior \\
\hline & & Superior & Inferior & Superior & Inferior \\
\hline \multicolumn{2}{|c|}{$\begin{array}{c}\text { Força máxima de atrito na } \\
\text { parede do silo, } p_{w}\end{array}$} & Superior & Superior & Inferior & Superior \\
\hline \multicolumn{2}{|c|}{$\begin{array}{c}\text { Força vertical máxima na } \\
\text { tremonha }\end{array}$} & Superior & Inferior & Superior & Inferior \\
\hline
\end{tabular}

\section{2 - Determinação das propriedades físicas}

Para determinação das propriedades físicas dos produtos armazenados usamse os chamados testes de cisalhamento. Um dos aparelhos mais versátil e utilizado por muitos pesquisadores e normas internacionais é o proposto por Jenike, sendo equipado com: uma célula de cisalhamento de forma cilindrica, a qual é colocada sobre a base da máquina; um pendural com pesos, para aplicação de uma carga vertical por gravidade na célula; um suporte de carga acionado eletro-mecanicamente, o qual promove a ação do cisalhamento movendo-se horizontalmente numa velocidade de $3 \mathrm{~mm} / \mathrm{s}$; uma célula de carga para medir a força de cisalhamento e um registrador para indicação desta força. A figura 1 mostra a célula de cisalhamento do aparelho de Jenike (Jenike Shear Tester). 


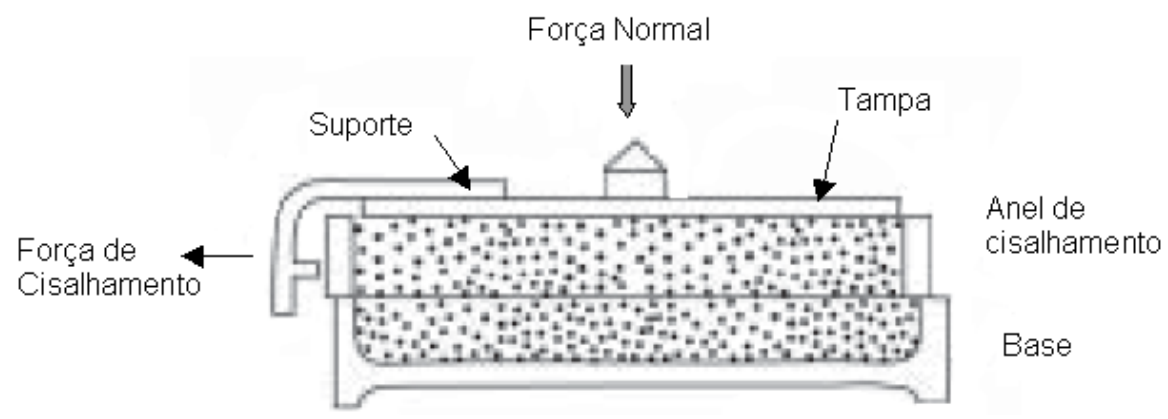

Figura 1 - Célula de cisalhamento de Jenike

Inicialmente a tensão de cisalhamento e a densidade do produto aumentam com o tempo t como indicado no diagrama da figura 2(a). Após um certo tempo, a densidade e a tensão de cisalhamento $\tau_{\text {pre }}$ que são função da tensão normal $\sigma_{\text {pre, }}$ tornam-se constantes. A deformação do produto armazenado nesta condição (densidade e tensões normais e de cisalhamento constantes), chama-se de estado de fluxo estável. Quando o estado de fluxo estável é alcançado, diz-se que a amostra está consolidada criticamente (circulo de tensão A da figura 2 (b)). No processo de pré-cisalhamento ("preshear”) o produto é colocado num estado de consolidação definido e sua importância é para a definição do plano de cisalhamento. $O$ précisalhamento é parado assim que o estado de fluxo estável é alcançado. Os valores

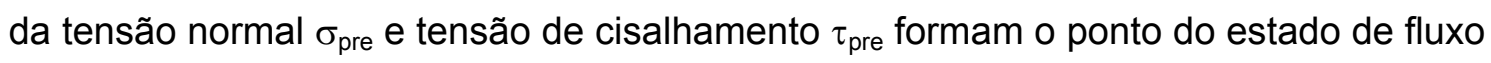
estável mostrado no diagrama $\sigma$ versus $\tau$ (figura 2(b)).

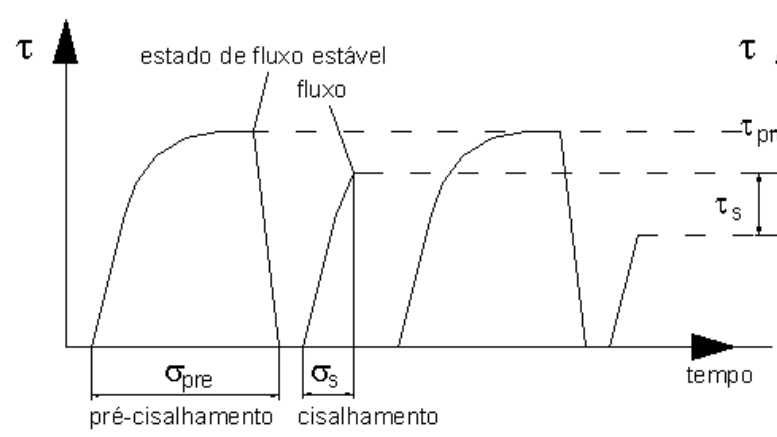

(a)

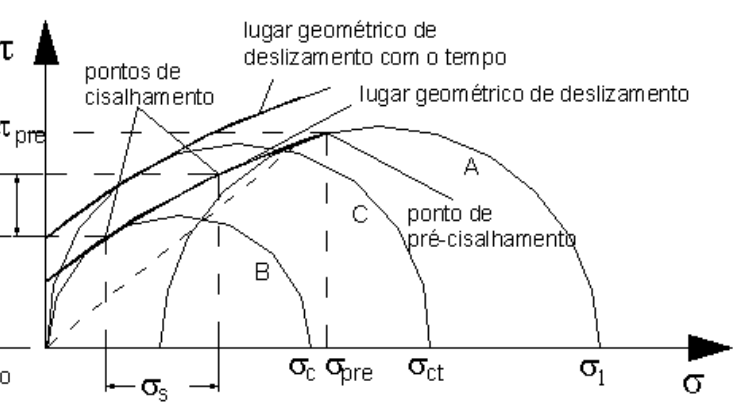

(b)

Figura 2 - Gráfico do Lugar geométrico de deslizamento

Posteriormente, a amostra é cisalhada com uma redução da tensão normal $\sigma_{\mathrm{s}}<\sigma_{\text {pre }}$. Nota-se que a força de cisalhamento aumenta rapidamente, alcançando um valor máximo, representando a tensão de cisalhamento e depois diminui. Este processo é chamado de cisalhamento ("shear"). Sob tensões representadas pelo círculo $\mathrm{B}$, o ponto de ruptura (deslizamento) é alcançado e o produto inicia o fluxo. $\mathrm{O}$ ponto de deslizamento do produto armazenado é chamado de "yield locus". Todos os círculos de tensões que são tangenciais ao lugar geométrico de deslizamento 
representam estados de tensões em que o produto inicia o fluxo. Em resumo, o lugar geométrico de deslizamento nada mais é que a envoltória de todos os círculos de tensões que representam os estados de tensões no qual o produto entra em fluxo.

O inicio do fluxo está associado a uma diminuição da densidade e uma correspondente redução da tensão de cisalhamento (figura 2) As tensões normais e de cisalhamento fornecem um ponto sobre o lugar geométrico de deslizamento no diagrama $\sigma$ versus $\tau$. Se várias amostras do produto são pré-cisalhadas sob iguais tensões normais $\sigma_{\text {pre }}$ mas cisalhadas sob diferentes tensões normais $\sigma_{s}<\sigma_{\text {pre }}$, pode ser determinado o lugar geométrico de deslizamento no diagrama $\sigma$ versus $\tau$.

Em resumo, o teste de cisalhamento constitui-se de duas fases. A primeira é a preparação da amostra para obtenção do fluxo de estado estável e do précisalhamento para definição do lugar geométrico de deslizamento. Na segunda fase do teste, a determinação real das tensões de cisalhamento é realizada com diferentes valores de tensões normais menores que os utilizados na primeira fase, determinando as tensões de cisalhamento necessárias para o deslizamento (ruptura) do produto.

Conforme explicado, os parâmetros que descrevem as propriedades de fluxo podem ser determinados através do lugar geométrico de deslizamento (figuras 2 e 3). A tensão de consolidação $\sigma_{1}$ é igual a tensão principal maior do círculo de Mohr que é tangencial ao lugar geométrico de deslizamento. Este círculo de tensões representa as tensões na amostra no final do procedimento de consolidação (tensões no estado de fluxo estável). A tensão inconfinada $\sigma_{\mathrm{c}}$ resulta do círculo de tensões que é tangente ao lugar geométrico de deslizamento e que passa através da origem (tensão principal menor $\sigma_{2}=0$ ).

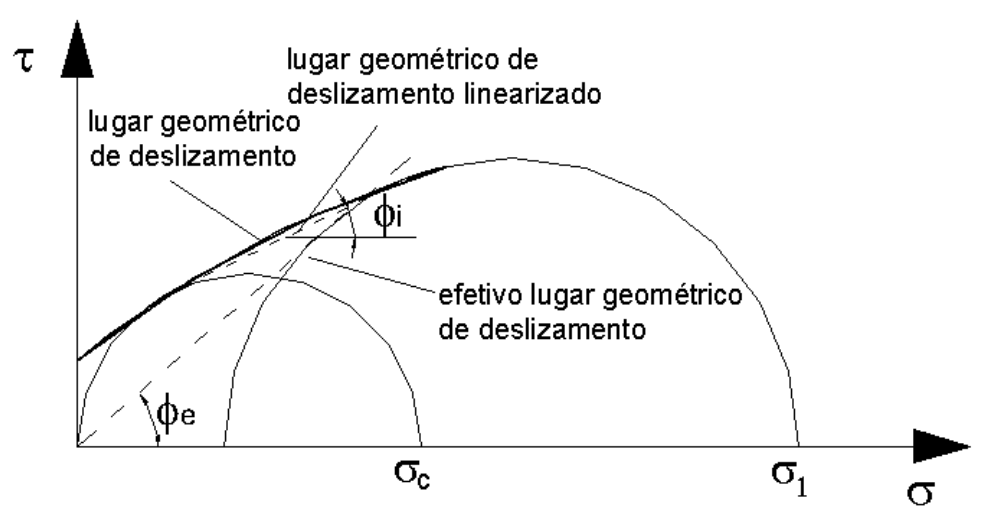

Figura 3 - Gráfico da Determinação do ângulo de atrito

Como explicado, a linha que tangencia os círculos é chamada de lugar geométrico de deslizamento e o ângulo que forma com o eixo $\sigma$ é chamado de ângulo de atrito interno $\phi_{\mathrm{i}}$. Já a linha tangente ao maior círculo de Mohr e passando pela 
origem é chamada de efetivo lugar geométrico de deslizamento e o ângulo que forma com o eixo $\sigma$ é chamado de efetivo ângulo de atrito interno $\phi_{\mathrm{e}}$.

O ângulo de atrito interno $\phi_{i}$ é definido como a inclinação local do lugar geométrico dos estados de deslizamento. Devido a inclinação do lugar geométrico de deslizamento seguir a forma curva ao invés de reta, o ângulo de atrito interno varia ao longo do lugar geométrico de deslizamento. Para a maioria das aplicações é suficiente um ângulo de atrito interno. Neste caso, o ângulo de atrito interno é definido pela inclinação do lugar geométrico de deslizamento linearizado. A linearização do lugar geométrico de deslizamento resulta da tangente comum a ambos os círculos de tensões de Mohr mostrados na figura 3. Cabe salientar, que para produtos de fluxo livre (sem coesão) o lugar geométrico de deslizamento passa pela origem, portanto $\phi_{\mathrm{i}}=\phi_{\mathrm{e}}$.

Se forem esperadas influências causadas por temperatura, umidade e período de armazenamento, então os testes de cisalhamento devem ser realizados de acordo com estas condições. Para a medição do efeito da consolidação com o tempo pode-se usar a célula de cisalhamento de Jenike com o auxílio da bancada de consolidação. Após a obtenção do estado de fluxo estável e pré-cisalhamento, a amostra é armazenada por um determinado tempo t sob tensão normal $\sigma=\sigma_{1}$. Posteriormente, a amostra é cisalhada por uma tensão normal $\left(\sigma_{\mathrm{s}}<\sigma_{\text {pre }}\right)$ da mesma maneira que aquelas usadas para determinar um ponto sobre o lugar geométrico de deslizamento mostrado na figura 2. É sabido que produtos que ganham resistência com o tempo de armazenamento, adquirem maior resistência ao cisalhamento. Portanto no diagrama $\sigma$ versus $\tau$, o lugar geométrico de deslizamento com o tempo fica acima do lugar geométrico de deslizamento (figura 2).

A determinação do atrito do produto armazenado com a parede também pode ser obtida usando o aparelho de Jenike. Neste caso, a base da célula de cisalhamento é substituída por uma amostra do material de parede que será avaliado (figura 4). A força de cisalhamento ou a tensão de cisalhamento $\tau_{\mathrm{w}}$ que são necessárias para mover a célula de cisalhamento com o produto armazenado através do material da parede são medidas sob diferentes tensões normais $\sigma_{\mathrm{w}}$. 


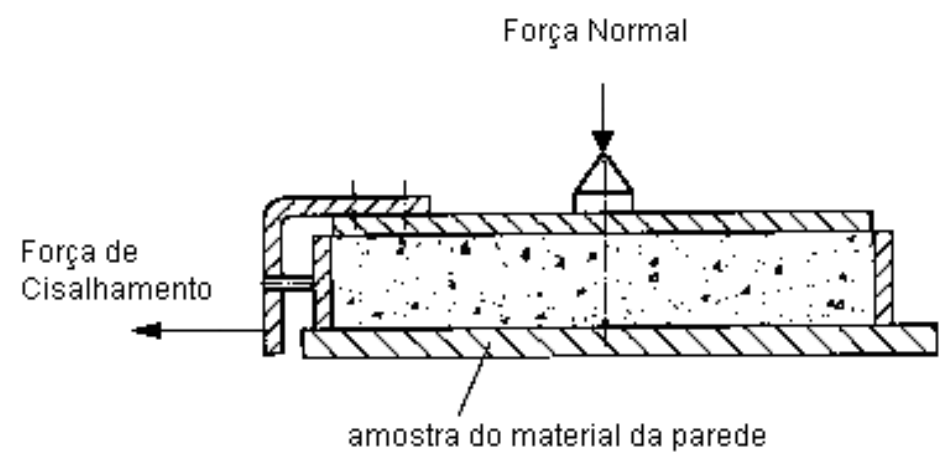

Figura 4 - Determinação do atrito com a parede na célula de Jenike.

Se os pares de valores medidos $\left(\sigma_{\mathrm{w}}, \tau_{\mathrm{w}}\right)$ são plotados num diagrama $\tau_{\mathrm{w}}$ versus $\sigma_{\mathrm{w}}$ (figura 5), então o resultado da união dos pontos medidos fornece o lugar geométrico de deslizamento com a parede. $O$ ângulo de atrito com a parede $\phi_{\mathrm{W}}$ resulta da inclinação do lugar geométrico de deslizamento com a parede com o eixo $\sigma$. Pode ser determinado pela relação:

$$
\phi_{w}=\operatorname{arctg}^{\tau_{w}} / \sigma_{w}
$$

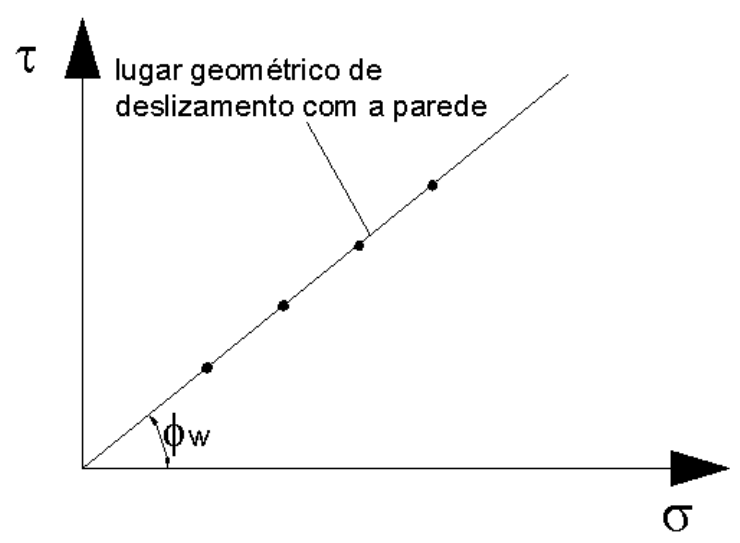

Figura 5 - Lugar geométrico de deslizamento com a parede

O ensaio para a determinação do ângulo de atrito com a parede permite que vários tipos de materiais de parede (concreto, aço, pvc) possam ser ensaiados. Com isto é possível decidir qual material ou tipo de acabamento da parede traria mais vantagens para o fluxo do produto.

Quanto mais consolidado está o produto armazenado, maior é a tensão de consolidação $\sigma_{1}$, maior a densidade $\rho$ e a tensão inconfinada de ruptura $\sigma_{c}$. A maioria dos produtos armazenados com granulometria fina apresentam tensão inconfinada de ruptura $\sigma_{\mathrm{c}}$ quando consolidados. Estes produtos são chamados de coesivos. Contudo, existem produtos que apresentam o valor de $\sigma_{\mathrm{c}}$ praticamente zero, mesmo para grandes consolidações. Esses produtos são chamados não coesivos ou de fluxo livre. 
Para cada tensão de consolidação, pode-se determinar uma densidade e um ponto de deslizamento do produto. A função $\sigma_{\mathrm{c}}=\mathrm{f}\left(\sigma_{1}\right)$ é chamada Função Fluxo do produto ( $F F$ ) (figura 6).

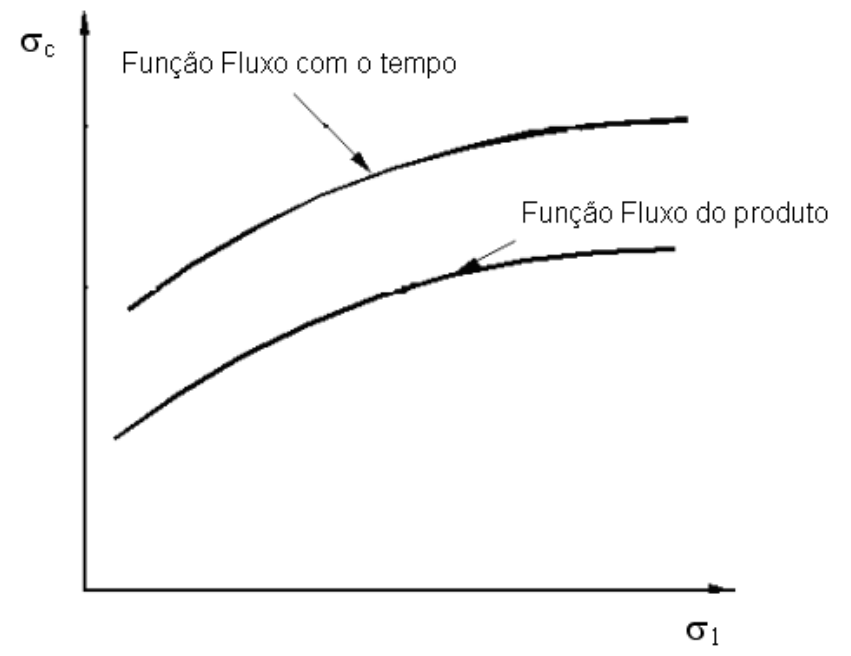

Figura 6 - Função Fluxo do produto.

Alguns produtos consolidam com o tempo quando armazenados em repouso. Assim, torna-se necessário à determinação da Função Fluxo com o tempo $\left(F F_{\mathrm{t}}\right)$ (figura 6). Para isto, a amostra destes produtos é solicitada por uma tensão de consolidação por um determinado tempo. No caso da consolidação com o tempo do produto armazenado, a tensão inconfinada aumenta com a duração da consolidação. Então para cada período de armazenagem um yield locus com o tempo no diagrama $\sigma$ versus $\tau$ pode ser encontrado (figura 2 ). $O$ círculo de tensão $C$ da figura 2 , indica a tensão inconfinada de ruptura com o tempo $\sigma_{\mathrm{ct}}$ que pertence ao lugar geométrico de deslizamento com o tempo.

No projeto de um silo, a Função Fluxo e Função Fluxo com o tempo devem ser conhecidas para prevenir os problemas de fluxo. Para caracterizar o comportamento de fluxo dos produtos armazenados, a relação $F F$ da tensão de consolidação $\sigma_{1}$ pela tensão inconfinada de ruptura $\sigma_{c}$ é usada:

$$
F F=\sigma_{1} / \sigma_{c}
$$

FF é um indicativo da fluidez, que nada mais é do que a capacidade do produto armazenado fluir.

Vários números e curvas são necessários para definir com precisão a fluidez de um produto. Segundo PRESCOTT (2000), a fluidez não pode ser expressa por um valor único ou um índice. A fluidez é o resultado da combinação das propriedades físicas do produto que afetam o fluxo e o equipamento usado para manipulação, 
armazenagem ou processamento do produto. Porém, para uma rápida análise da fluidez do produto, pode-se tomar os seguintes valores limites da Função Fluxo apresentados por JENIKE (1964).

$$
\begin{array}{ll}
F F<2 & \text { produtos muito coesivos, não flui; } \\
2<F F<4 & \text { produtos coesivos; } \\
4<F F<10 & \text { produto que flui facilmente; } \\
F F>10 & \text { produto de fluxo livre. }
\end{array}
$$

Portanto, quanto maior o valor de $F F$, melhor é o fluxo do produto armazenado. Cada produto armazenado tem suas próprias Função Fluxo e Função Fluxo com o tempo. Produtos sem coesão, de fluxo livre, geralmente não causam problemas de fluxo.

Além disso, a capacidade de fluir (fluidez) de alguns produtos armazenados, geralmente grãos finos (partículas menores que $100 \mu \mathrm{m}$ ), torna-se pior com o aumento da umidade e do tempo de armazenamento, aumentando a possibilidade de ocorrência de obstruções de fluxo.

Outro importante parâmetro para o estudo da fluidez dos produtos armazenados é o fator de fluxo da tremonha $(f f)$ que diferentemente da Função Fluxo do produto ( $F F$ ), é uma propriedade do conjunto silo-produto, dependendo de algumas características de ambos. Para calcular o fator de fluxo do sistema é necessário conhecer: o efetivo ângulo de atrito interno do produto $\left(\phi_{\mathrm{e}}\right)$, o ângulo de atrito do produto com a parede $\left(\phi_{w}\right)$, a geometria e inclinação da tremonha $(\alpha)$.

O cálculo do fator de fluxo ( $f f$ ) supõe a solução das equações diferenciais representativas das tensões que surgem nos silos durante a descarga. Tais resoluções foram publicadas por Jenike, para silos de diferentes geometrias, na forma de gráficos denominados de gráficos de fatores de fluxo. Assim como a Função Fluxo $(F F)$, o fator fluxo da tremonha $(f f)$ também é usado para indicar a fluidez do produto armazenado. Porem, ao contrário da Função Fluxo, quanto mais baixo seu valor, melhor é a fluidez do produto. Para caracterizar o fator fluxo da tremonha, a relação $f f$ da tensão de consolidação $\sigma_{1}$ pela tensão atuando onde um arco estável imaginário, formado por partículas do produto, é sustentado pelas paredes da tremonha $\sigma_{1}{ }^{\prime}$ é usada (equação 3).

$$
f f=\sigma_{1} / \sigma_{1}{ }^{\prime}
$$




\section{3 - FLUXO}

Segundo JENIKE \& JOHANSON (1968) o fluxo acontece quando as pressões são tais que o cisalhamento ocorre sem destruir a isotropia do produto armazenado. Durante o fluxo a densidade do produto é uma função das pressões. Quando as pressões são constantes, o produto cisalha sob densidade constante. Quando as pressões aumentam, o produto compacta e a densidade também aumenta. Quando as pressões diminuem, o produto expande, a densidade diminui, e o fluxo pode prosseguir indefinidamente.

A descarga do produto armazenado por gravidade pode ocorrer conforme dois tipos principais de fluxo: por fluxo de massa e fluxo de funil (figura 7). $O$ tipo de fluxo que vai ocorrer depende principalmente das propriedades físicas do produto, assim como, da geometria e rugosidade da superfície da tremonha.

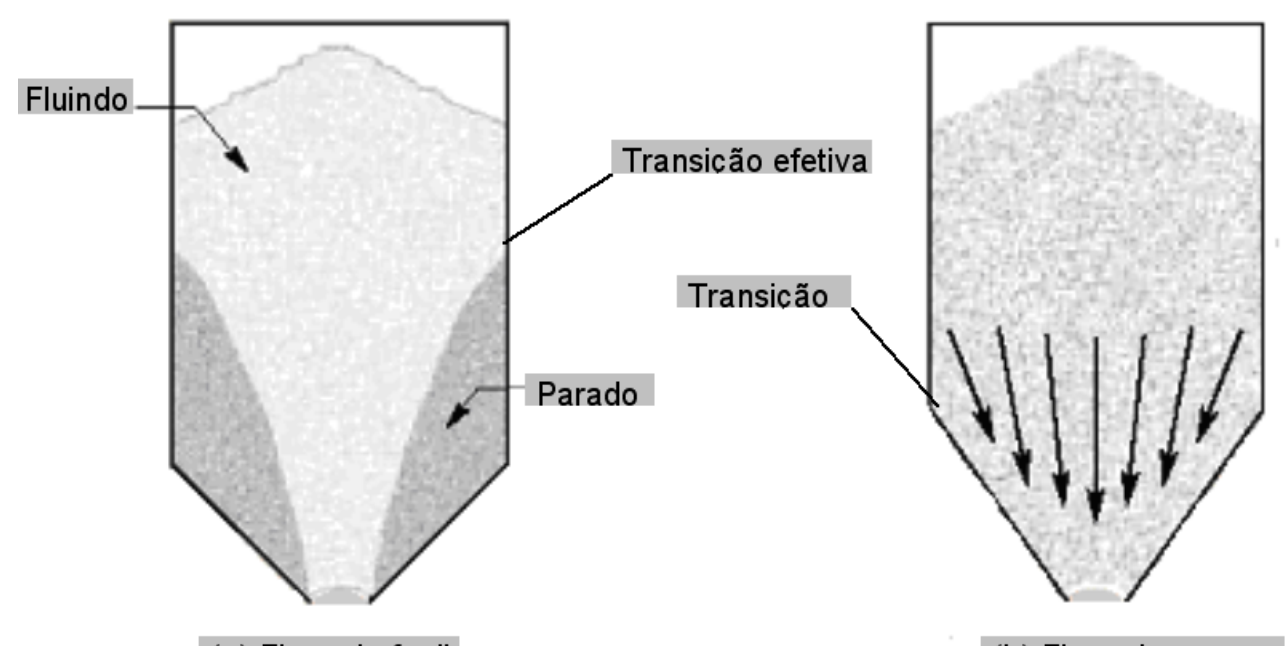

(a) Fluxo de funil

(b) Fluxo de massa

Figura 7 - Tipos de fluxo

Segundo CALIL Jr. (1990) o tipo de fluxo caracteriza o descarregamento do produto, o tipo de segregação, a formação ou não de zonas de produto sem movimento e se o silo pode ser esvaziado completamente. Determina também a distribuição das pressões nas paredes do silo e fundação, e a integridade e custo da construção. 
Conforme ROBERTS (1987d) o padrão de fluxo de um silo com fluxo de massa é razoavelmente fácil de ser reproduzido e determinado, enquanto que em um silo com fluxo de funil é mais difícil de investigar, especialmente se o silo tem várias bocas de descarga, carregamento excêntrico ou se o produto armazenado está propício a segregar. Portanto, a menos que haja razão para o contrário, devem ser projetados silos com formas geométricas simples e carregamento simétrico.

Cabe salientar, que a maioria das normas internacionais apresentam geralmente dois gráficos para determinação do tipo de fluxo que irá ocorrer no silo. Estes gráficos fornecem o tipo de fluxo em função do ângulo ou do coeficiente de atrito com a parede, da inclinação das paredes da tremonha e do tipo de tremonha (geralmente, cônicas ou em cunha).

A seguir são apresentados os gráficos para determinação do tipo de fluxo conforme as normas estudadas.
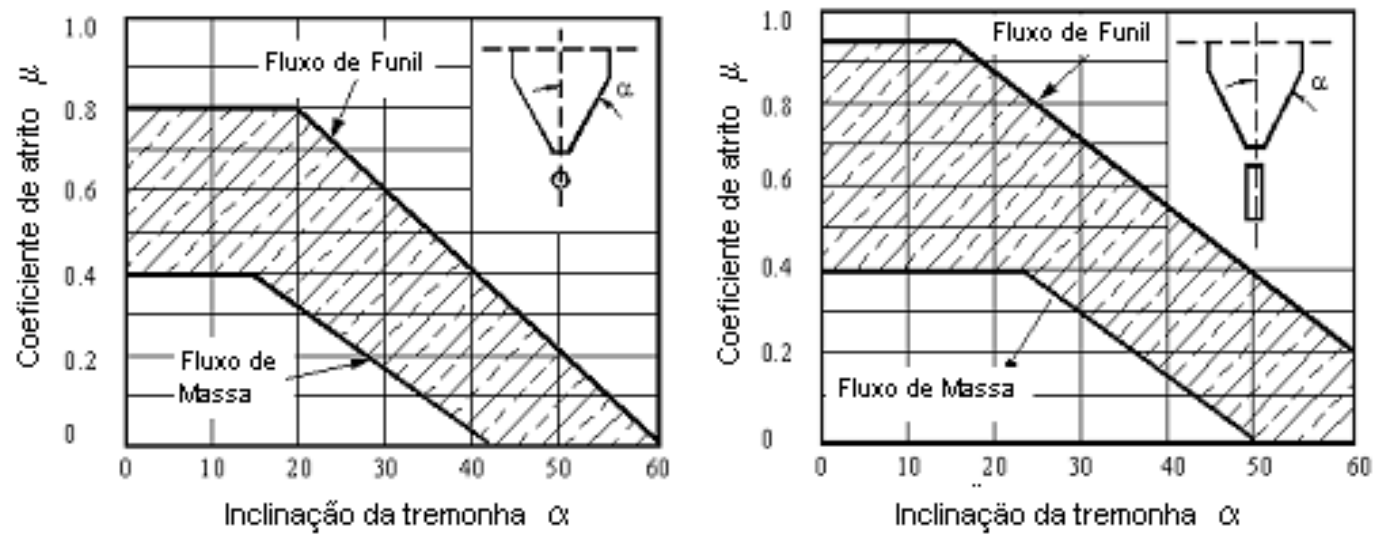

Figura 8 - Determinação gráfica do tipo de fluxo - AS 3774
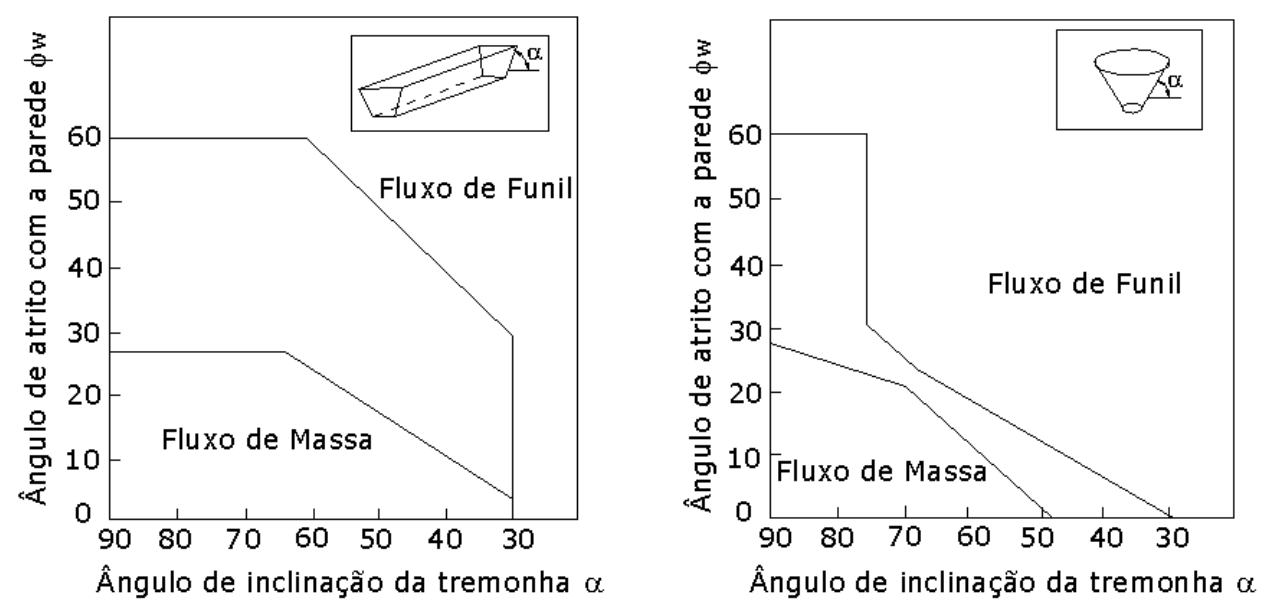

Figura 9 - Determinação gráfica do tipo de fluxo - DIN 1055-6, ISO 11697, EUROCODE 1 


\subsection{TIPOS DE FLUXO}

\subsubsection{Fluxo de Funil}

Caracteriza-se pela formação de um canal de fluxo, alinhado com a boca de descarga, cercado por uma zona na qual o produto permanece estático (zona parada ou estagnada).

Para produtos pouco coesivos, durante a descarga do silo, a parte mais alta que está em contato com as paredes vai desmoronando e alimentando o canal central. Entretanto, para produtos muito coesivos, a descarga pode até ser interrompida, ocorrendo a formação de um canal central vazio, cercado de produto estático. Normalmente para silos com relação altura/diâmetro < 1, o cone não toca a parede, ou seja, se estende até o topo.

Como durante a descarga o produto não se move todo de uma vez, a quantidade de material e a granulometria variam em função da duração da operação, portanto a vazão de fluxo do produto tende a ser irregular.

Se o produto armazenado tende a deteriorar com o tempo, então aqueles produtos acumulados próximo à parede (zonas estagnadas) serão os mais suscetíveis a degradação, podendo deteriorar-se devido à alteração de suas propriedades com o tempo.

Cabe salientar que silos com fluxo de funil apresentam, também, menores capacidades de armazenamento devido à formação das zonas estagnadas, que só conseguem ser removidas mediante o completo esvaziamento do silo. Para produtos que segregam no carregamento dos silos com fluxo de funil, a possibilidade de remistura na tremonha não existe.

Ainda, as paredes laterais estão sujeitas a menores pressões devido à zona estagnada. Contudo, devem ser esperadas altas pressões sobre as paredes na região em que o canal de fluxo encontra a parede (transição efetiva).

Como vantagens desse padrão de fluxo pode-se citar o menor desgaste das paredes devido ao atrito do produto com a parede ser desprezível, assim como, pressões menores nas paredes do silo em virtude da zona estagnada, excetuando a região de parede acima da transição efetiva. Permite, também, que altura do silo para uma mesma capacidade seja menor, pois a tremonha é de menor altura. 


\subsubsection{Fluxo de Massa}

Este padrão de fluxo é o ideal e deve ser obtido sempre que possível. Caracteriza-se pelo fato de que todas as partículas do produto armazenado estão em movimento durante a operação de descarga. Desde o instante inicial da descarga, nenhuma partícula permanece na sua posição original, todas elas se movem, o que impede a formação de zonas estagnadas.

Como o produto que entra primeiro no silo é o primeiro a sair, evita-se que produtos suscetíveis ao tempo de permanência se deteriorem (alterem suas propriedades). Permite, também, que o tempo de permanência do produto armazenado seja constante, fazendo com que ocorra renovação do produto.

Como todas as partículas estão em movimento na descarga, o fluxo é uniforme e pode ser controlado. Isto diminui a possibilidade de obstruções de fluxo e permite a determinação das pressões mais facilmente. Cabe salientar que as maiores pressões sobre as paredes estão localizadas próximas a transição do corpo do silo para a tremonha.

Ainda, devido ao fato do produto se mover todo de uma vez, existe a possibilidade de re-mistura na tremonha, o que permite maior homogeneização, diminuindo a segregação.

Outra vantagem é o fato de que o silo pode ser totalmente descarregado por gravidade, sem o auxilio de qualquer dispositivo de retirada. Isto permite que toda capacidade de armazenamento da unidade seja aproveitada. Geralmente, silos com fluxo de massa apresentam tremonhas com paredes lisas e com menor inclinação com a vertical.

\subsection{PROBLEMAS DE FLUXO}

A formação de uma obstrução de fluxo deve-se ao fato de que o produto armazenado adquire resistência suficiente para suportar seu próprio peso, devido à consolidação do produto. Existem basicamente dois tipos de obstruções de fluxo: abóbada e tubo. Admite-se que se durante a descarga do produto, nenhuma dessas duas obstruções ocorrerem, um fluxo satisfatório acontecerá.

Essas obstruções causam sérios danos aos silos e principalmente para a tremonha, pois quando rompem, atuam como um pistão, comprimindo o ar existente na tremonha, levando a danos na boca de descarga e paredes laterais. 


\subsubsection{Obstrução em Abóbada}

A figura 10 (a) mostra este tipo de obstrução. Geralmente a obstrução em arco forma-se logo acima da saída fazendo com que o fluxo seja interrompido. Para produtos finos e coesivos, a força de adesão existente entre as partículas é a principal razão para a formação da abóbada enquanto que para produtos maiores (grãos) a principal causa é o entrosamento entre as partículas.

\subsubsection{Obstrução em tubo}

A figura 10 (b) mostra esse tipo de obstrução. Normalmente ocorre em silos com fluxo de funil. Se a consolidação do produto aumenta com o tempo de armazenagem, o risco da formação do tubo também aumenta.

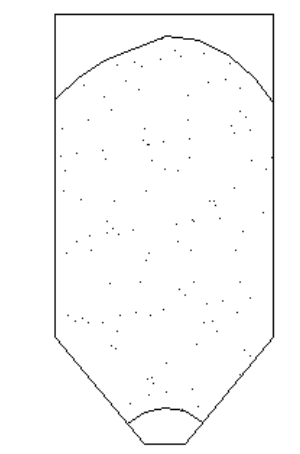

Obstrução em Abóbada

(a)

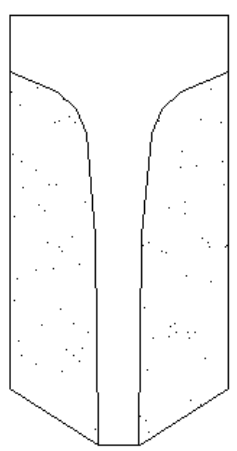

Obstrução em Tubo

(b)

Figura 10 - Tipos de obstruções

Outros problemas típicos que podem ocorrer na armazenagem dos produtos são:

\subsubsection{Segregação}

Este tipo de problema normalmente ocorre quando existe grande variação nas dimensões das partículas. A figura 11 apresenta um exemplo de segregação, onde as partículas maiores acumulam-se perto das paredes do silo, enquanto que as partículas menores acumulam-se próximas ao centro. No caso de silos com fluxo de funil, as partículas menores (localizadas no centro) seriam descarregadas primeiro enquanto que as maiores somente no final, causando problemas de heterogeneidade na 
descarga. No caso de silos com fluxo de massa, o produto não irá segregar na descarga.

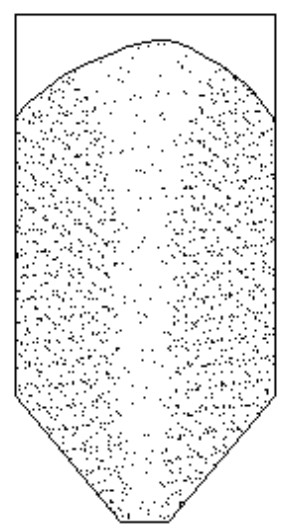

Segregaçăo

Figura 11 - Segregação por tamanhos

\subsubsection{Tempo de armazenamento em excesso}

Se o produto armazenado sofre deterioração em função do tempo de armazenagem, então para silos com fluxo de funil, o produto existente nas zonas estagnadas pode estragar. Isto ocorre principalmente no caso de armazenagem de alimentos ou outros produtos que alteram suas propriedades com o tempo.

Resumindo, enquanto que em um silo com fluxo de funil todos os problemas listados anteriormente podem ocorrer, num silo com fluxo de massa apenas a obstrução em abóbada é possível.

\subsection{REQUISITOS PARA EVITAR OBSTRUÇÕES DE FLUXO}

A dimensão da abertura de descarga de um silo deve ser suficientemente grande para que não ocorram obstruções durante a descarga do produto armazenado. Normalmente para silos com fluxo de massa, o objetivo é evitar a formação da obstrução em abóbada e para silos com fluxo de funil evitar a formação da obstrução em tubo.

Analisemos o que acontece com uma partícula do produto armazenado durante a operação de descarga em um silo com fluxo de massa (figura 12). Quando o produto foi depositado no topo do silo, a partícula estava inconsolidada, pois sobre ela não atuava nenhuma pressão. A medida que a partícula vai descendo, a consolidação 
aumenta e conseqüentemente a tensão de consolidação $\sigma_{1}$ também. Como pode ser visto na figura 12 (a), inicialmente a pressão aumenta com a profundidade, permanecendo constante a partir de uma certa altura. $\mathrm{Na}$ transição entre a parede vertical e a tremonha ocorre um pico de pressão. A partir deste ponto, a pressão vai diminuindo à medida que o produto vai sendo descarregado. Como resultado desta consolidação, a tensão inconfinada de ruptura $\sigma_{c}$ (resistência do produto) também aumenta. Por outro lado, a partícula do produto está solicitada todo tempo por uma tensão $\sigma_{1}{ }^{\prime}$, cuja intensidade depende da posição da partícula no silo. figura 12(a).

Como neste caso (figura 12(a)), em todo o momento a tensão $\sigma_{1}{ }^{\prime}$ a que está submetida a partícula é maior que a tensão inconfinada de ruptura $\sigma_{\mathrm{c}}$, não ocorre a formação de abóbada durante a descarga do produto.

No entanto, se a dimensão da abertura de descarga é diminuída de $b_{1}$ para $b_{2}$ (figura 12(b)) mantendo-se constantes as demais variáveis (inclinação da tremonha, produto, umidade...) de maneira que se a tensão inconfinada de ruptura $\sigma_{c}$ supere a tensão $\sigma_{1}$ ' ocorrerá a formação de abóbada. O ponto onde $\sigma_{\mathrm{c}}$ intercepta $\sigma_{1}$, , representa a dimensão de abertura crítica ou mínima para a qual não se forma obstrução em abóbada.
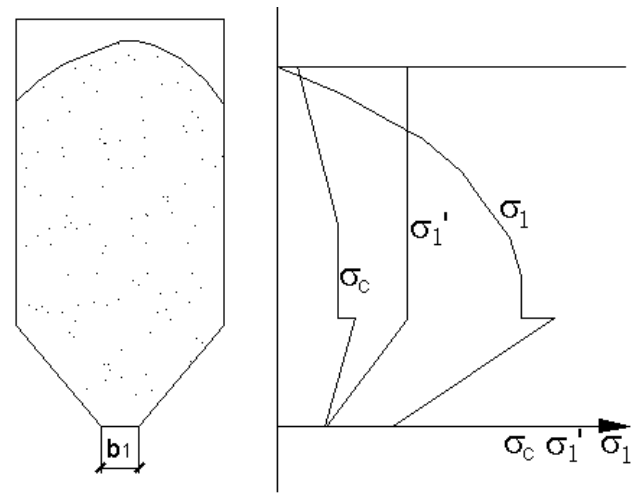

(a)

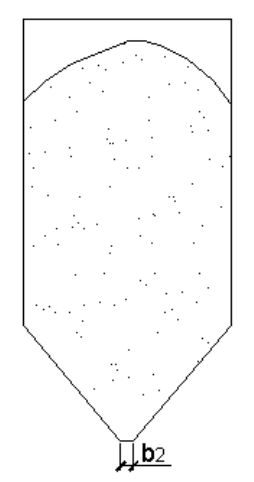

(b)

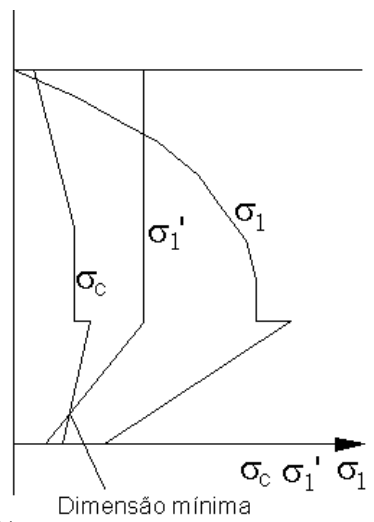

Figura 12 - Análise para formação de obstrução em abóbada em silos com fluxo de massa.

Para efeitos de projeto, o critério de fluxo ou não fluxo proposto por JENIKE apud ROBERTS (1987a) é o utilizado. Consiste em transladar o que foi discutido na figura 12 para a forma gráfica da figura 13. Nesta figura, a tensão inconfinada $\sigma_{\mathrm{c}}$, que representa a resistência do produto, é plotada contra a maior tensão de consolidação $\sigma_{1}$. A curva formada é chamada de função fluxo $(F F)$. A outra linha mostrada na figura 13, é chamada de fator fluxo ( $f f$ ); ela representa a condição de tensão no arco. Onde a linha $f f$ varia abaixo da curva de $F F$, as tensões na abóbada são insuficientes para causar o fluxo. Por outro lado, onde a linha de $f f$ varia acima da 
curva de $F F$, as tensões na abóbada excedem a resistência do produto e o fluxo ocorrerá. A intersecção da linha $f f$ com a curva $F F$ é o ponto crítico (tensão crítica) para calcular a dimensão $D$ da abertura da boca de descarga, ou seja, quando $\sigma_{c}=$ $\sigma_{1}$.

Se a função fluxo com o tempo $F F_{\mathrm{t}}$ fosse plotada na figura 13 , então o ponto de intersecção seria acima do ponto já determinado. Isto significa que aberturas de descarga maiores são necessárias para prevenir a obstrução em abóbada de produtos que aumentam a consolidação com o período de armazenagem.

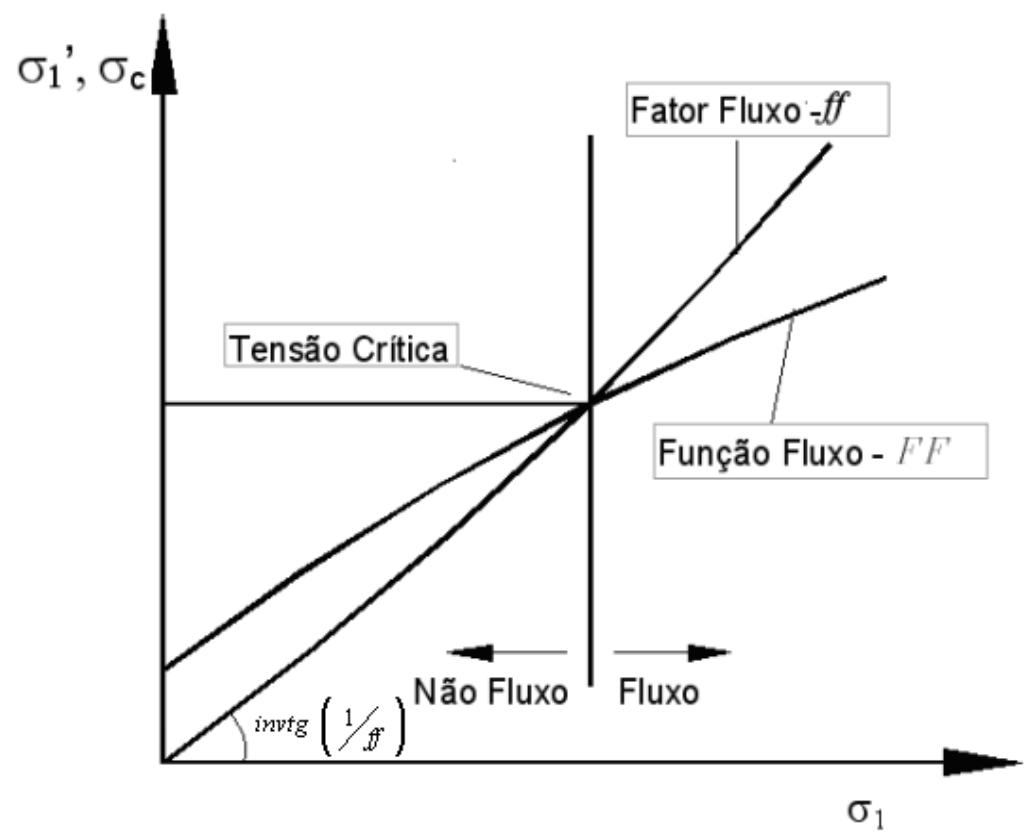

Figura 13 - Função fluxo do produto armazenado e fator fluxo da tremonha

Portanto para ocorrer fluxo por gravidade:

$$
F F>f f \text { ou seja, } \frac{\sigma_{1}}{\sigma_{c}}>\frac{\sigma_{1}}{\sigma_{1}{ }^{\prime}}
$$

Conforme CALIL Jr. (1990), caso o fator fluxo da tremonha variar sempre acima da função fluxo do produto armazenado, então a análise anterior não pode ser utilizada para determinar a dimensão mínima da boca de descarga. Produtos que apresentam este comportamento, geralmente não possuem coesão, portanto são de fluxo livre. Neste caso, a dimensão mínima da boca de descarga pode ser determinada em função do dispositivo de descarga ou, no caso de partículas grandes, por uma dimensão de boca de descarga, em média 8 vezes a dimensão da maior partícula para abertura circular, 9 vezes para abertura quadrada ou retangular e 4 vezes para aberturas em forma de canal com relação comprimento/largura maior que 6. 
Se o fator fluxo da tremonha variar sempre abaixo da função fluxo do produto, então o produto armazenado não fluirá somente por gravidade. Neste caso, pode-se substituir o material da parede da tremonha por um outro mais liso, ou mesmo, revestila com outro material, diminuindo a rugosidade das paredes. Se, mesmo assim, permanecer a situação de não fluxo, deverão ser usados dispositivos de descarga.

Para produtos que aumentam a consolidação com o tempo de armazenagem, caso o fator fluxo da tremonha interceptar somente a função fluxo do produto e não interceptar a função fluxo do produto com o tempo, então dispositivos mecânicos, como vibradores, deverão ser instalados para iniciar o fluxo e a abertura da boca de descarga será projetada com um fator de segurança para levar em conta os efeitos desfavoráveis da vibração. Segundo JENIKE (1964), isso é conseguido multiplicando o fator fluxo sem vibração por 1,5 obtendo uma tensão crítica maior e conseqüentemente, uma boca de descarga com maior dimensão.

\subsection{PROJETO DA TREMONHA}

O primeiro passo para projetar tanto um silo como uma tremonha é a determinação das propriedades físicas do produto armazenado. Isto pode ser realizado através de ensaios ou mediante consulta em tabelas apropriadas conforme explicado no capitulo anterior. O passo seguinte é a escolha da forma geométrica da tremonha.

\subsubsection{Escolha da Forma Geométrica}

A figura 14 apresenta algumas formas geométricas de tremonha.

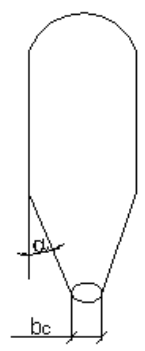

a) Cônica

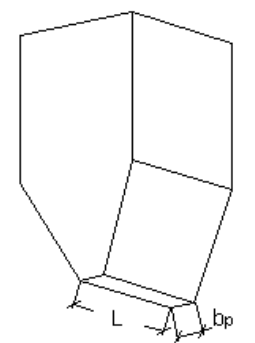

b) Cunha

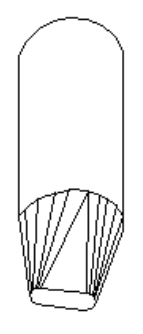

c) Transição

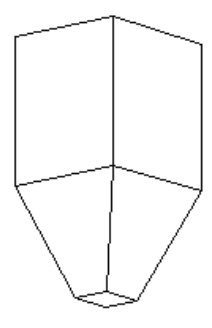

d) Piramidal

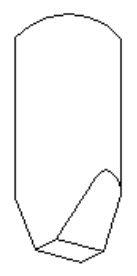

e) Bisel

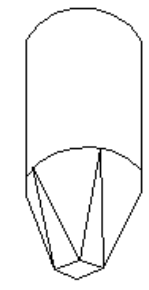

f) Saída Quadrada

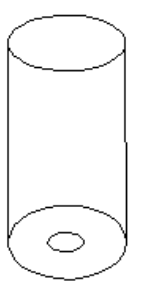

g) Fundo Plano

Figura 14 - Tipos de tremonha 
As formas (a), (b) e (c) são os tipos de tremonha mais utilizadas. Para um determinado produto o ângulo de inclinação $(\alpha)$ para uma tremonha cônica será normalmente menor que o ângulo de uma em cunha. Segundo JENIKE (1964) a tremonha em cunha permite inclinações um pouco maiores (geralmente de $8^{\circ}$ a $10^{\circ}$ ) para produtos com as mesmas propriedades. Portanto, a tremonha em cunha necessita menor altura quando comparada com a tremonha cônica. Além disso, a dimensão da boca de saída bc para a tremonha cônica é normalmente maior que a largura $b p$ para a tremonha em cunha. A desvantagem da tremonha em cunha é que abertura de descarga tem comprimento igual a largura do silo. O comprimento mínimo da abertura é $L=3 b p$, que na prática é muito menos que a largura do silo. Por esta razão, a tremonha em transição (forma c) vem sendo utilizada.

Segundo SCHULZE (1996), para se obter fluxo de massa com a tremonha piramidal (forma d), as arestas da mesma devem ser arredondadas internamente para que o produto supere o atrito com a parede nos dois lados que suportam a formação de zonas estagnadas. A forma em bisel (forma e) é simples e eficaz, mas tem a desvantagem do produto formar vazios dentro da tremonha, impedindo o fluxo. $O$ mesmo ocorre para a forma piramidal com saída quadrada (forma f). Tremonhas com fundo plano sempre apresentam fluxo de funil.

No caso de silos com fluxo de funil, o ângulo de inclinação da tremonha com a vertical é maior que para fluxo de massa. Portanto, a tremonha para este tipo de fluxo tem menor altura e pode ser usada em locais onde a altura do silo é limitada. Contudo, geralmente necessitam dispositivos promotores de fluxo como vibradores para restabelecer o fluxo, quando se forma, por exemplo, uma obstrução como tubo.

\subsubsection{Determinação da Inclinação das Paredes}

Tendo sido feita a escolha da forma geométrica da tremonha, determinados os ângulos de atrito com a parede e o efetivo ângulo de atrito interno, pode ser determinada a máxima inclinação da tremonha com a vertical, a qual assegura o fluxo de massa, com os diagramas mostrados na figura 15 para tremonha cônica e em cunha.

Os limites entre o fluxo de massa e fluxo de funil são o resultado da solução das equações propostas por JENIKE (1964). Nos diagramas a inclinação da tremonha é medida com a vertical. O efetivo ângulo de atrito interno é o parâmetro das linhas limites entre o fluxo de massa e o fluxo de funil. As linhas limites separam todos os pares de valores que conduzem ao fluxo de massa daqueles que conduzem ao fluxo de funil. 

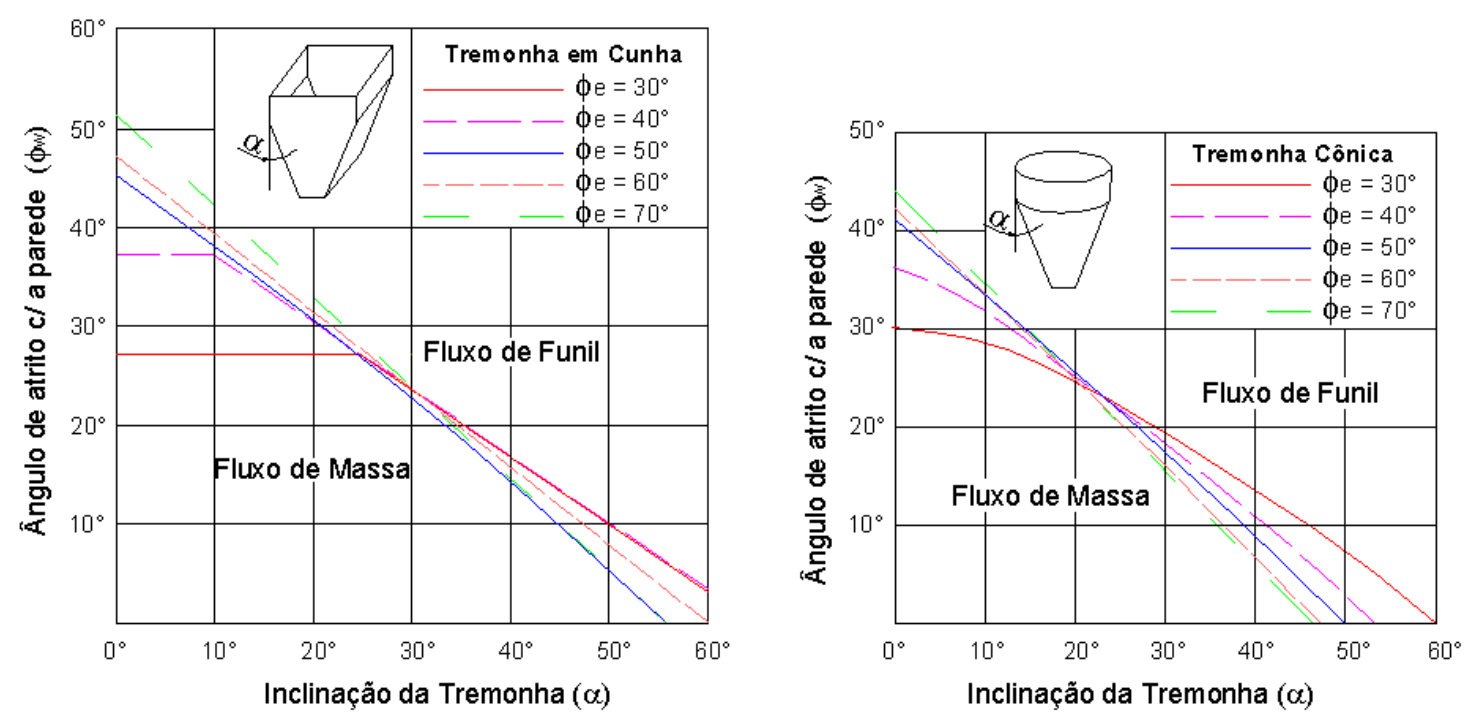

Figura 15 - Diagrama para projeto de tremonhas Fonte: SCHULZE, D. (1996)

JENIKE (1985) afirma que os gráficos publicados em 1964 predizem muito bem a inclinação da tremonha para fluxo de massa, embora resultados experimentais indiquem que os valores são um pouco conservadores. Já para silos com fluxo de funil, os valores apresentados nos gráficos predizem incorretamente o ângulo de inclinação de tremonhas de eixo simétrico.

McLEAN (1986) sugere o seguinte equacionamento para a determinação da inclinação máxima da tremonha para fluxo de massa:

- para tremonhas de eixo simétrico:

$$
\alpha_{c r i t}=0,5\left[180-\cos ^{-1}\left(\frac{\left(1-\operatorname{sen} \phi_{e}\right)}{2 \operatorname{sen} \phi_{e}}\right)-\left(\phi_{w}+\operatorname{sen}^{-1}\left(\frac{\operatorname{sen} \phi_{w}}{\operatorname{sen} \phi_{e}}\right)\right)\right]
$$

- para tremonhas em cunha:

$$
\alpha_{c r i t}=\frac{e^{3,75 \cdot(1,01)\left(\phi_{e}-30\right) / 10}-\phi_{w}}{0,725\left(\operatorname{tg} \phi_{e}\right)^{0,2}}
$$

Segundo GAYLORD \& GAYLORD (1984), para tremonhas em bisel e em cunha, o fluxo de massa ocorrerá se:

$$
\begin{aligned}
& \alpha \leq 60^{\circ}-1,33 \phi_{w} \\
& \phi_{w} \leq 0,9 \phi_{e} \\
& L \geq 6 . b_{p}
\end{aligned}
$$


Para tremonhas piramidais, GAYLORD \& GAYLORD (1984), sugerem que o ângulo $\alpha$ do canto da tremonha deve ser determinado como para tremonhas cônicas. Os ângulos das paredes de união $\alpha_{1}$ e $\alpha_{2}$ são relacionados com $\alpha$ por:

$$
\operatorname{tg}^{2} \alpha=\operatorname{tg}^{2} \alpha_{1}+\operatorname{tg}^{2} \alpha_{2}
$$

A inclinação de tremonhas com fluxo de funil não é diretamente afetada pelo padrão de fluxo, porém segundo CALIL Jr. (1990) pode-se usar o seguinte equacionamento como referência:

$$
\alpha=65-\phi_{w s}
$$

Com o objetivo de se levar em consideração possíveis instabilidades de fluxo, o ângulo de inclinação da tremonha $(\alpha)$ deve ser tomado pelo menos $3^{\circ}$ menor do que o determinado graficamente ou pelas equações (4) e (5). (CALIL Jr. (1990)).

\subsubsection{Determinação do Fator Fluxo da tremonha ( $f f)$}

Pode ser obtido graficamente através dos gráficos publicados por JENIKE (1964). Estes gráficos são função da forma geométrica e inclinação da tremonha, ângulo de atrito com a parede e efetivo ângulo de atrito interno. A figura 16 apresenta um destes gráficos.

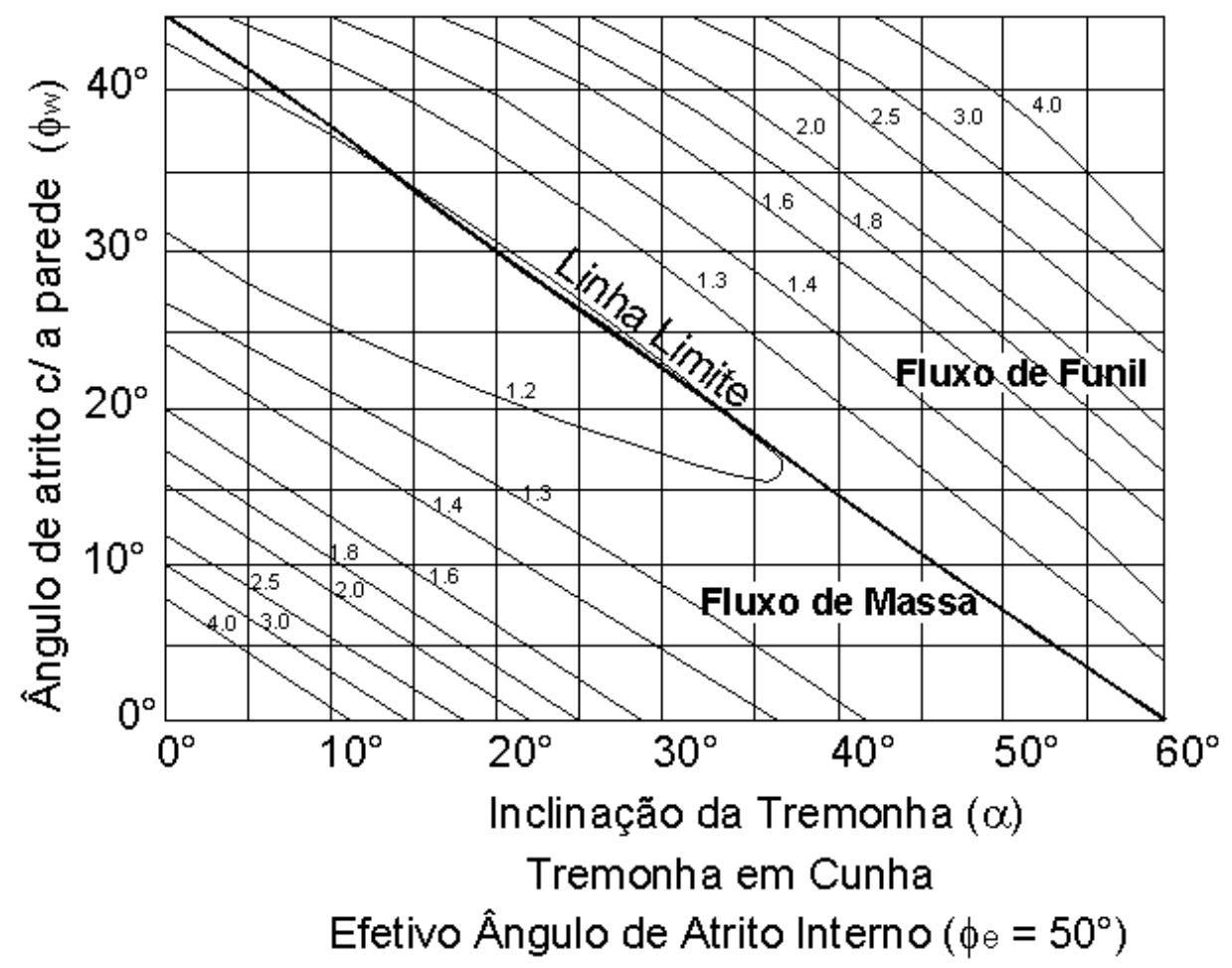

Figura 16 - Gráfico para determinação do fator fluxo.

Fonte: JENIKE, A. (1964) 
A seguir apresenta-se o equacionamento proposto por ENSTAD (1975) que permitem determinar o fator fluxo com boa aproximação.

\section{Equacionamento proposto por Enstad:}

$$
\begin{aligned}
& F(\alpha)=\left(\frac{65}{130+\alpha}\right)^{m}\left(\frac{200}{200+\alpha}\right)^{1-m} \\
& 2 \beta=\phi_{w s}+\operatorname{sen}^{-1}\left(\frac{\operatorname{sen} \phi_{w s}}{\operatorname{sen} \phi_{e s}}\right) \\
& \theta=\beta+\alpha \\
& X=\frac{2^{m} \operatorname{sen} \phi_{e s}}{1-\operatorname{sen} \phi_{e s}}\left[\frac{\operatorname{sen}(\beta+\theta)}{\cos (90-\alpha)}+1\right] \\
& Y=\frac{[2(1-\cos \theta)]^{m} \theta^{1-m} \cos (90-\alpha)+\operatorname{sen} \beta(\operatorname{sen} \theta)^{1+m}}{\left(1-\operatorname{sen} \phi_{e s}\right)(\operatorname{sen} \theta)^{2+m}} \\
& f f=\frac{Y\left(1+\operatorname{sen} \phi_{e s}\right)}{2(X-1) F(\alpha) \cos (90-\alpha)}
\end{aligned}
$$

Onde:

$$
\begin{aligned}
& \phi_{\mathrm{es}}=\text { valor superior do efetivo ângulo de atrito interno. } \\
& \phi_{\mathrm{ws}}=\text { valor superior do ângulo de atrito com a parede } \\
& \mathrm{m}=0 \text { para tremonhas retangulares, onde } \mathrm{L} \geq 30 \\
& \mathrm{~m}=1 \text { para tremonhas de eixo simétrico }
\end{aligned}
$$

Para tremonhas retangulares com $L \leq 30$, o valor de "m" será encontrado por interpolação entre 0 e 1.

\subsubsection{Determinação da Tensão Crítica}

Para a determinação da tensão crítica, plota-se num gráfico a tensão de consolidação $\sigma_{1}$ versus a tensão inconfinada $\sigma_{c}$. A união dos pontos fornece a curva da Função Fluxo do produto. Após, traça-se através da origem uma reta com inclinação invtg $\left(\frac{1}{f f}\right)$ obtendo o fator fluxo da tremonha. O ponto de intersecção entre a reta $f f$ e a curva $F F$ fornece a tensão crítica $\left(\sigma_{\text {crit }}\right)$. (figura 13 ) 


\subsubsection{Determinação da Função $H(\alpha)$}

Para determinar a dimensão da boca de descarga, JENIKE (1964) utiliza a função $H(\alpha)$ que não é conhecida explicitamente. Essa função depende da forma geométrica e da inclinação da tremonha. A figura 17 apresenta o gráfico para determinação do valor de $H(\alpha)$ para tremonhas cônicas e em cunha.

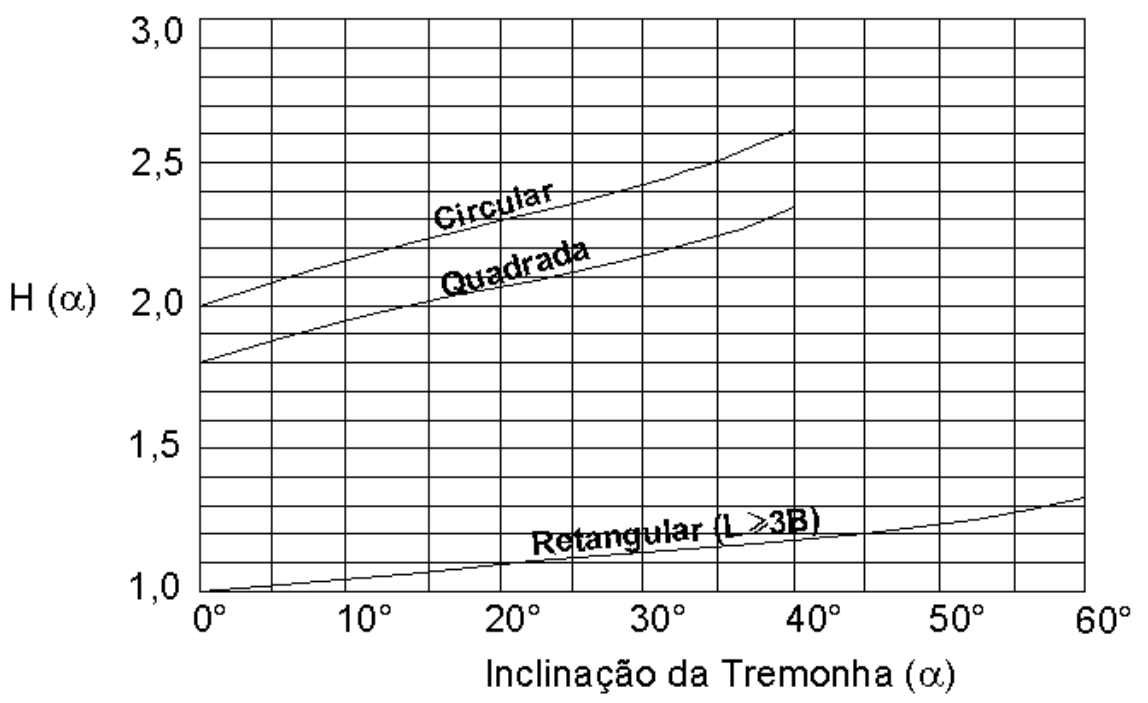

Figura 17 - Determinação da função $H(\alpha)$ para tremonhas cônicas e em cunha. Fonte: JENIKE, A. (1964)

\subsubsection{Determinação da dimensão mínima da boca de descarga}

\section{Silos com fluxo de massa}

A dimensão mínima da boca de descarga é dada por:

$$
b_{\min }=\frac{H(\alpha) * \sigma_{c r i t}}{\gamma_{i}}
$$

Com o intuito de evitar instabilidades que alterem o tipo de fluxo, JENIKE (1964) recomenda que a dimensão mínima da boca de descarga dada pela equação (17) seja majorada em $20 \%$.

Com boa aproximação, JENIKE \& JOHANSON apud GAYLORD \& GAYLORD (1984), sugerem as seguintes equações:

$$
\begin{aligned}
& b_{\min } \geq \frac{2,2 \sigma_{c r i t}}{\gamma_{i}}, \text { para bocas de descarga circulares; } \\
& b_{\min } \geq \frac{1,3 \sigma_{c r i t}}{\gamma_{i}}, \text { para bocas de descarga retangulares. }
\end{aligned}
$$




\section{Silos com fluxo de funil}

Para garantir que um fluxo satisfatório ocorrerá em um silo com fluxo de funil, é necessário que a dimensão da boca de descarga seja grande o suficiente para que não ocorram obstruções de fluxo em arco e tubo. Formas típicas de bocas de descarga são mostradas na figura 18.

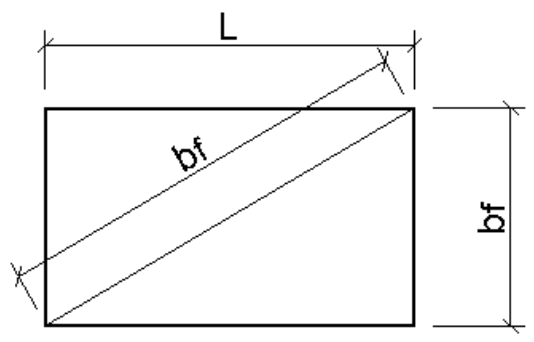

Retangular

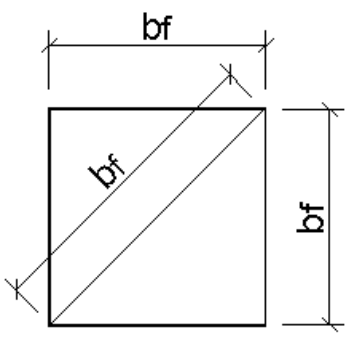

Quadrada

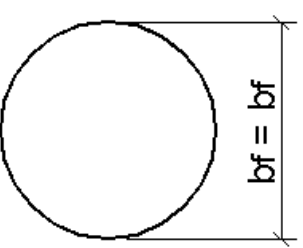

Circular

Figura 18 - Formas de bocas de descarga para silos com fluxo de funil

A dimensão mínima da boca de descarga é dada por:

$$
b_{f_{\text {min }}}=\frac{G\left(\phi_{i}\right) * \sigma_{c r i t}}{\gamma_{i}}
$$

A função $G\left(\phi_{i}\right)$ é denominada fator de tubo e pode ser determinada pelo gráfico proposto por JENIKE (1964). O valor desta função depende do ângulo de atrito interno. A figura 19 apresenta este gráfico.

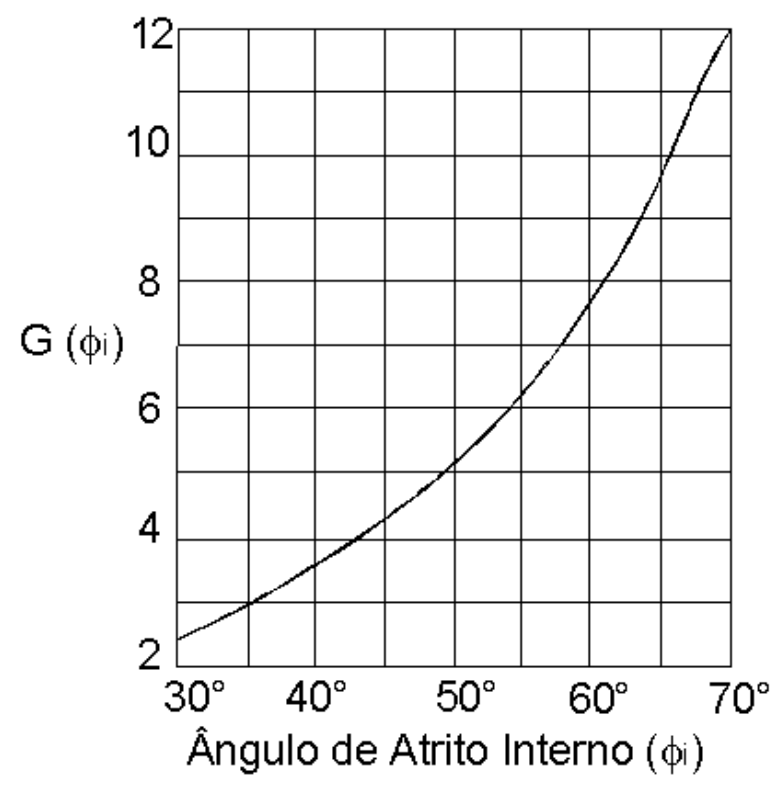

Figura 19 - Determinação da função $G(\phi i)$ Fonte: JENIKE, A. (1964) 
McLEAN apud CALIL Jr. (1990) propõe a seguinte expressão empírica para $\mathrm{G}\left(\phi_{\mathrm{i}}\right)$ :

$$
G\left(\phi_{i}\right)=0,7502 \cdot e^{0,0387 \phi_{i}}
$$

Para bocas de descarga circular ou quadrada, de silos com fluxo de funil, a determinação de $b_{f}$ é suficiente para garantir que não haverá formação de obstruções em arco e em tubo. Enquanto bocas de descarga retangulares precisam da determinação da outra dimensão $\left(b_{p}\right)$ para evitar a obstrução em arco.

Para determinar $b_{p}$, ROBERTS (1987d) recomenda um fator fluxo $f f=1,7$. Isto permite um ângulo de inclinação da tremonha $\alpha=30^{\circ}$ para o maior efetivo ângulo de atrito interno.

Como $\alpha=30^{\circ}$, da figura 17 para boca de descarga retangular, temos que $H(\alpha)=1,15$.

Portanto,

$$
b_{p}=\frac{1,15 \sigma_{c r i t}}{\gamma_{i}}
$$

Obs.: $\sigma_{\text {crit }}$ será obtido com fator fluxo $f f=1,7$. 


\section{4 - AÇÕES}

\section{1 - FUNDAMENTOS}

No projeto de uma estrutura, seja ela de concreto armado, aço, madeira ou qualquer outro material, independentemente de sua complexidade arquitetônica ou estrutural, deve-se exigir que a mesma desempenhe as funções para que foi concebida com eficiência, aliando economia, durabilidade e segurança estrutural.

Pode-se dizer que uma estrutura apresenta segurança estrutural se ela for capaz de resistir ilesa a todas as ações que vierem a solicitá-la desde o período construtivo até o final de sua vida útil.

Vários métodos foram desenvolvidos na tentativa de buscar um valor que possa servir como medida desta segurança. Atualmente o método que vem sendo adotado pelas normas é o método dos estados limites, que leva em consideração conceitos probabilísticos na verificação da segurança.

Estados limites são situações em que a estrutura apresenta comportamento inadequado ou inadmissível, ou seja, são estados em que a estrutura está imprópria para o uso.

A NBR 8681 (2003) define os estados limites últimos como aqueles relacionados ao colapso, ou a qualquer outra forma de ruína estrutural, que determine a paralisação do uso da estrutura. Como estados limites de serviço, aqueles que pela sua ocorrência, repetição ou duração, causam efeitos estruturais que não respeitam as condições especificadas para o uso normal da construção, ou que são indícios do comprometimento da durabilidade da estrutura.

A determinação das ações é importante para a determinação dos esforços atuantes, dimensionamento, estabilidade e segurança estrutural. Estas ações são normalmente devidas a causas externas que ocasionam esforços internos e deformações na estrutura. Como exemplo pode-se citar o peso próprio dos elementos estruturais e construtivos, dilatações térmicas, vento, etc... 
Segundo FUSCO (1976) o termo ação, designa qualquer influência ou conjunto de influências capaz de produzir estados de tensão na estrutura. Usualmente, as forças e as deformações são consideradas como se fossem as próprias ações.

Para a verificação da segurança torna-se necessário realizar a combinação das ações atuantes. Essas combinações devem ser feitas de diferentes maneiras, de forma que possam ser determinados os efeitos mais desfavoráveis para a estrutura. Devem ser estabelecidas tantas combinações de ações quantas forem necessárias para que a segurança seja verificada em relação a todos os possíveis estados limites da estrutura.

Conforme CALIL Jr. \& NASCIMENTO (1997), no projeto de silos devem ser consideradas as seguintes ações:

Ações Permanentes: são as constituídas pelo peso próprio da estrutura, da plataforma e dos equipamentos mecânicos instalados na cobertura e suspensos pela tremonha.

Ações Variáveis: são as constituídas pelas pressões de carregamento e descarga do produto armazenado, pressões de insuflação de ar, dilatação térmica do produto, deformações na fundação, dispositivos vibradores, efeitos climáticos, vento, etc...

Ações Excepcionais: são as devidas ao possível impacto de veículos na estrutura de suporte ou com o silo e pressões decorrentes da explosão de pós.

No projeto de silos, as principais ações a serem consideradas são as provenientes dos produtos armazenados que exercem pressões nas paredes verticais e no fundo do silo. Na parede vertical atuam pressões perpendiculares, denominadas pressões horizontais e pressões de atrito do produto com a parede. No fundo do silo atuam pressões denominadas pressões verticais (figura 20).

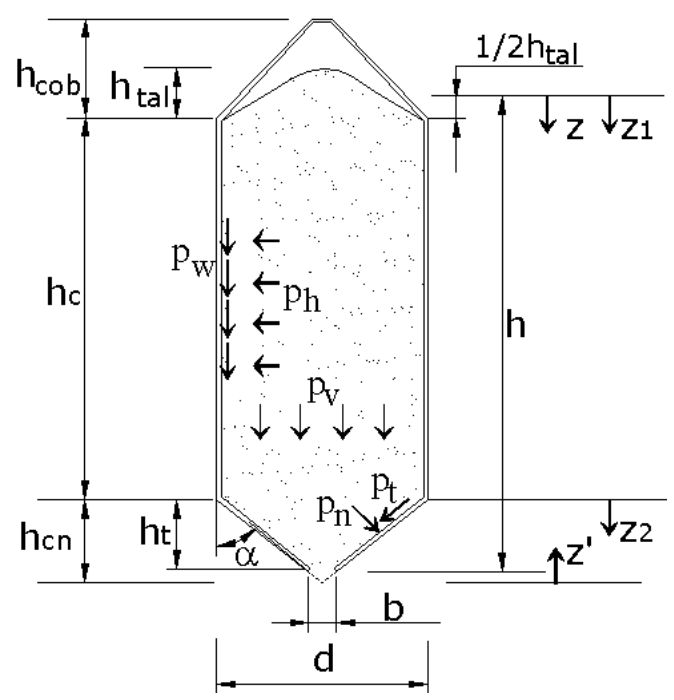

Figura 20 - Pressões atuantes 
A pressão de atrito é distribuída na superfície das paredes e equilibra parte do peso do produto, resultando em esforços de compressão nas paredes. A existência deste atrito faz com que as pressões horizontais que o produto exerce nas paredes não aumentem indefinidamente com a altura como as pressões hidrostáticas, mas apresentem um crescimento que tende exponencialmente a um valor máximo.

Para o melhor entendimento dos conceitos para a estimativa das curvas de pressões nas paredes dos silos, torna-se indispensável a compreensão de que o campo de tensões iniciais, que atua enquanto o silo está sendo carregado na condição inicialmente vazio e com a boca de descarga fechada, é totalmente diferente do campo de tensões dinâmicas que atua quando é realizada alguma descarga do produto armazenado. Esta diferença nos campos de tensões, entre as situações de carregamento e descarga, leva a formação de picos de pressões consideráveis que atuam nas paredes do silo quando a situação de fluxo é obtida.

Conforme CALIL Jr. (1990), o problema da estimativa das curvas de pressões está essencialmente em sua variabilidade tanto no tempo como no espaço. A magnitude das pressões horizontais aumenta de maneira considerável na fase de descarga do produto; no entanto, o percentual deste aumento em relação à fase de carregamento ainda é alvo de discussões e pesquisas.

\subsection{PRESSÕES ESTÁTICAS E PRESSÕES DE FLUXO}

O projeto estrutural de um silo necessita, entre outras coisas, do conhecimento da distribuição de pressões e das tensões de cisalhamento sobre as paredes (causadas pelo produto armazenado) e de como esta distribuição varia durante o carregamento, armazenagem e descarga.

As pressões que o produto exerce sobre a estrutura do silo podem geralmente ser divididas em três categorias: aquelas devidas ao carregamento inicial, aquelas que são resultado do fluxo do produto armazenado e aquelas devidas à transição entre estes dois estados. Pressões iniciais se desenvolvem quando o silo inicialmente vazio é carregado sem que qualquer produto seja retirado. Pressões de fluxo se desenvolvem, quando algum produto é retirado do silo. Pressões de transição se desenvolvem no nível da transição em silos com fluxo de massa e na transição efetiva para silos com fluxo de funil.

A determinação das pressões nas paredes dos silos tem sido examinada por um grande número de pesquisadores, entre eles, JANSSEN (1895), WALKER (1969), WALTERS (1973), JENIKE et al (1973), ARNOLD et al (1975), ROBERTS (1987), obtendo-se várias teorias e procedimentos para o assunto. 
CLAGUE \& WRIGHT apud GAYLORD \& GAYLORD (1984) realizaram 20 ensaios em silos metálicos com tremonhas cônicas e em bisel utilizando limalha de ferro. Relataram que a correlação entre a pressão média obtida e os valores dados pela teoria de WALKER (1966) foram variáveis para silos esbeltos. As pressões dinâmicas na transição, excederam, algumas vezes, os valores previstos pela teoria de WALKER (1966) e geralmente foram 5 vezes maiores que os previstos pela de JANSSEN (1895). Outra conclusão foi que as pressões nas tremonhas em bisel tendem a ser mais baixas que aquelas em tremonhas cônicas e também menores que as previstas pela teoria de WALKER (1966). Encontraram flutuações de pressão em relação a pressão média de $\pm 30 \%$.

GAYLORD \& GAYLORD (1984) compararam os valores experimentais obtidos por CLAGUE \& WRIGHT (1972) com as teorias de JENIKE \& JOHANSON (1977) e WALKER (1966). Concluíram que o equacionamento de JANSSEN (1895) com K=0,4 fornece valores próximos dos determinados experimentalmente para as pressões de carregamento no corpo do silo. Para as pressões de descarga no corpo do silo, WALKER (1966) tende a subestimar as pressões e JENIKE \& JOHANSON (1977) praticamente duplica as pressões em comparação com os valores experimentais. Com relação às pressões de carregamento na tremonha, JENIKE \& JOHANSON (1977) resultam em valores próximos aos encontrados nos ensaios, enquanto que WALKER (1966) superestima. No entanto, com relação as pressões de descarga na tremonha, tanto WALKER (1966) como JENIKE \& JOHANSON (1977) resultaram em pressões concordantes com os ensaios, exceto que o valor na transição, utilizando JENIKE \& JOHANSON (1977) pode ser muito grande.

JENIKE \& JOHANSON apud GAYLORD \& GAYLORD (1984) realizaram ensaios em modelos em escala reduzida de silos utilizando areia como produto armazenado. Concluíram que o equacionamento de JANSSEN (1895) com K=0,4 foi o que mais se aproximou dos valores encontrados nos ensaios para as pressões de carregamento no corpo do silo. Para as pressões de descarga, ao utilizar a teoria de JENIKE \& JOHANSON (1977) obtiveram o dobro daquelas da teoria de WALKER (1966). Para as pressões de carregamento na tremonha, JENIKE \& JOHANSON (1977) resultaram em valores mais adequados do que quando foi utilizada a teoria de WALKER (1966). Porém, para as pressões de descarga na tremonha, tanto WALKER (1966) como JENIKE \& JOHANSON (1977) proporcionaram valores consistentes com os obtidos nos ensaios. Encontraram flutuações de pressão em relação a pressão média na ordem de 30 a $40 \%$.

REIMBERT \& REIMBERT apud GAYLORD \& GAYLORD (1984) conduziram dois ensaios em um silo com $4,0 \mathrm{~m}$ de largura por $10 \mathrm{~m}$ de altura $(\mathrm{h} / \mathrm{d}=2.5)$ obtendo 
diferentes resultados para as pressões de descarga como mostra a figura 21 onde se observa a variação na determinação das pressões de descarga em apenas dois ensaios.

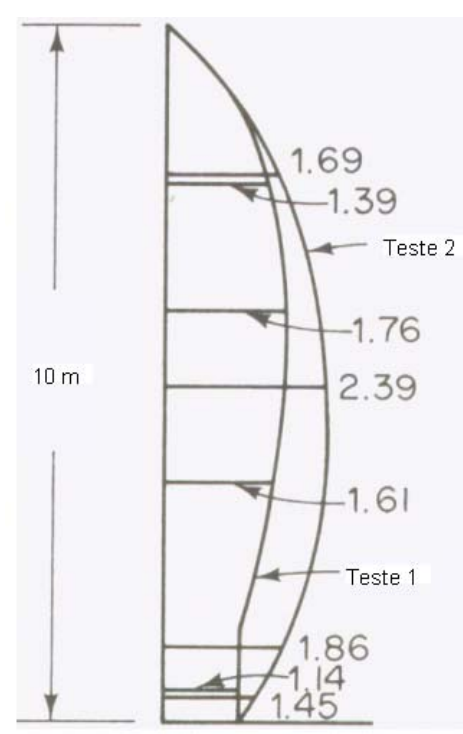

Figura 21 - Razão da pressão de fluxo pela pressão inicial Fonte: GAYLORD \& GAYLORD (1984)

ARNOLD et al apud ROBERTS (1987b) publicaram vários trabalhos levando em conta o então corrente estado da arte e sugerem procedimentos para predizer as pressões em silos com fluxo de massa, recomendando o seguinte:

Para condições estáticas:

Corpo do Silo: Método de JANSSEN (1895) com K = 0,4

Tremonha: Método de JENIKE (1977) ou

$$
\text { Método de WALKER (1969) com } K=\left[1+\frac{\mu}{\operatorname{tg} \alpha}\right]^{-1}
$$

ou

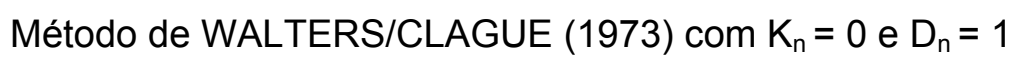

\section{Para condições de fluxo}

Corpo do Silo: Método da energia mínima de deformação com as modificações sugeridas por Jenike em 1977.

Tremonha: Método de JENIKE (1977) ou método de WALTERS/CLAGUE (1973).

A seguir se apresentam as teorias conforme os principais pesquisadores: 


\subsubsection{Teoria de JANSSEN}

JANSSEN em 1895 propôs uma teoria conhecida como método da camada elementar, que consiste basicamente na consideração do equilíbrio de uma massa de produto em repouso, válida somente para a condição de carregamento.

Esta teoria continua sendo utilizada até hoje pela maioria das normas internacionais de silos para o cálculo da pressão estática ou inicial de carregamento em silos de seções cilíndricas e poligonais. Até mesmo para o cálculo das pressões dinâmicas, isto é, durante o fluxo, um dos métodos mais utilizados pelas mesmas, é aplicar coeficientes, chamados de sobrepressão, aos valores obtidos para a condição estática.

As hipóteses em que esta teoria é baseada são:

- As pressões horizontais são constantes no mesmo plano horizontal.

- O valor de $\phi_{\mathrm{w}}$ (ângulo de atrito do produto com a parede) é constante.

- O peso específico do produto é uniforme.

- As paredes do silo são totalmente rígidas.

- A relação entre as pressões horizontais e verticais, $K$, é constante em toda a altura do silo, sendo:

$$
K=\frac{p_{h}}{p_{v}}
$$

O valor empírico para $K$ de:

$$
K=\frac{1-\operatorname{sen} \phi_{i}}{1+\operatorname{sen} \phi_{i}}=\operatorname{tg}^{2}\left(\frac{\pi}{4}-\frac{\phi_{i}}{2}\right)
$$

sempre assumido como sendo parte da equação de Janssen, foi de fato introduzido por Koenen em 1896, sendo determinado com base no coeficiente de pressão ativa, $K_{a}$, da teoria de Coulomb-Rankine para empuxos de terra. CALIL (1990).

Segundo AYUGA (1995), nenhuma dessas hipóteses é exata para silos, mas o resultado obtido é suficientemente preciso para silos altos em estado estático e produtos pouco compressíveis como os grãos.

De acordo com PIEPER \& WENZEL apud GAYLORD \& GAYLORD (1984), o valor dado pela equação 25 fornece pressões verticais muito grandes, as quais subestimam a pressão horizontal sobre a parede. Seus experimentos mostram que usando $K=1-\operatorname{sen} \phi_{i}$ resultam valores melhores para as pressões de carregamento. 
Porém, de acordo com JENIKE et al (1973) $K=0,4$ fornece resultados mais coerentes com os obtidos em ensaios experimentais.

Baseado na análise de 8 ensaios, HOMES apud GAYLORD \& GAYLORD (1984), obteve bons resultados usando a equação de Janssen com $\phi_{w}=0.67 . \phi_{i}$ e $K=0,45$.

A formulação de JANSSEN, consiste no equilíbrio de uma camada elementar de produto de altura $d z$ com peso específico $\gamma$ sujeito às pressões verticais $p_{v}$ e $p_{v}+d p_{v}$ e as devidas ao atrito produzido pela força horizontal $p_{h}$ sobre as paredes (figura 22). Se $A$ é a área da seção transversal do silo e $U$ é o perímetro, então:

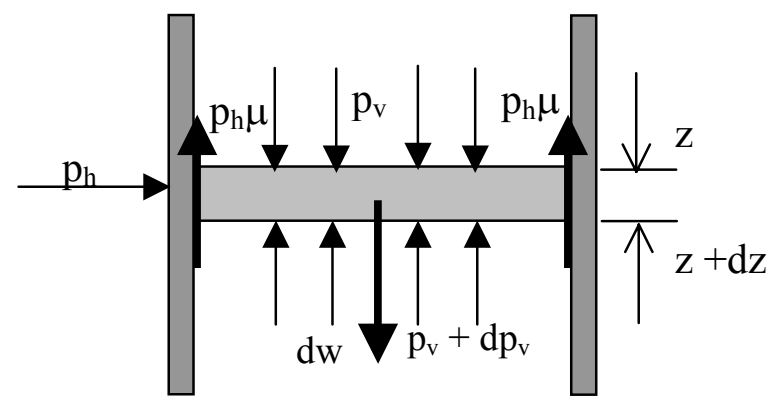

Figura 22 - Camada elementar adotada por Janssen.

$$
p_{h} \cdot \mu \cdot d z \cdot U+\left(p_{v}+d p_{v}-p_{v}\right) A-\gamma A d z=0
$$

Fazendo $K . d p_{v}=d p_{h}$ e separando as variáveis:

$$
\frac{\mathrm{A}}{\mathrm{U}} \cdot \frac{1}{\mathrm{~K}} \cdot \frac{1}{\mu} \cdot \frac{\mathrm{dp}_{\mathrm{h}}}{\frac{\gamma}{\mu} \cdot \frac{\mathrm{A}}{\mathrm{U}}-\mathrm{p}_{\mathrm{h}}}=\mathrm{dz}
$$

Integrando, temos que:

$$
\frac{-\mathrm{A}}{\mathrm{U}} \cdot \frac{1}{\mathrm{~K}} \cdot \frac{1}{\mu} \cdot \ln \left(\frac{\gamma}{\mu} \cdot \frac{\mathrm{A}}{\mathrm{U}}-\mathrm{p}_{\mathrm{h}}\right)=\mathrm{z}-\mathrm{cte}
$$

Aplicando as condições de contorno em $z=0$, temos

$$
\mathrm{p}_{\mathrm{h}}(z)=\frac{\gamma}{\mu} \cdot \frac{\mathrm{A}}{\mathrm{U}}\left(1-\mathrm{e}^{-\mathrm{zK} \mu \frac{\mathrm{U}}{\mathrm{A}}}\right)
$$

conhecida como fórmula de JANSSEN para o cálculo teórico da pressão horizontal, a partir da qual é obtida a pressão vertical:

$$
p_{v}=\frac{p_{h}}{K}
$$


e a pressão de atrito na parede:

$$
p_{w}=\mu \cdot p_{h}
$$

O parâmetro $\mu$ constante da formulação de JANSSEN é obtido por:

$$
\mu=\operatorname{tg} \phi_{w}
$$

A pressão de atrito na parede $p_{w}$ causa esforço de compressão na parede e pode ser integrada verticalmente para o cálculo da força de compressão resultante sobre a parede $P_{w}(z)$ por unidade de perímetro de parede atuando na profundidade $z$, fornecendo a seguinte equação:

$$
P_{w}(z)=\mu \int p_{h} d z=\gamma A / U\left[z-\frac{A}{\mu K U}\left(1-e^{-\mu K z U / A}\right)\right]=\frac{A}{U}(\gamma z-p v)
$$

ou seja, é igual ao peso total do produto menos a resultante da pressão vertical $p v$, dividido pelo perímetro.

\subsubsection{Teoria de WALKER apud GAYLORD \& GAYLORD}

Em 1966 na Inglaterra, Walker desenvolve sua teoria sobre o fluxo de produtos para silos com fluxo de massa. Sua teoria também é baseada nas forças que atuam sobre uma camada elementar.

\section{Pressões estáticas no corpo do silo}

Walker assumiu que o campo inicial de pressões no corpo do silo é um campo ativo de Rankine, mas com o coeficiente de empuxo (relação entre pressões) dado pelo efetivo ângulo de atrito interno. Sendo as pressões iniciais dadas por:

$$
\begin{aligned}
& p_{v_{c, e}}=\gamma \cdot z \\
& p_{h_{c, e}}=K \cdot p_{v_{c, e}}
\end{aligned}
$$

onde:

$$
K=\frac{1-\operatorname{sen} \phi_{e}}{1+\operatorname{sen} \phi_{e}}
$$




\section{Pressões estáticas na tremonha}

No campo de tensões na tremonha admite-se que a pressão principal maior está na vertical. Dois casos são considerados:

$1^{\circ}$ caso: Se $\operatorname{sen} \phi_{e} \geq \frac{\operatorname{sen} \phi_{w}}{\operatorname{sen}\left(\phi_{w}+2 \alpha\right)}$, as pressões na tremonha são dadas por:

$$
\begin{aligned}
p_{n t, e} & =\gamma \cdot z \cdot \frac{\operatorname{tg} \alpha}{\operatorname{tg} \alpha+\operatorname{tg} \phi_{w}} \\
p_{t t, e} & =p_{n t, e} \cdot \operatorname{tg} \phi_{w}=p_{n t, e} \cdot \mu \\
2^{\circ} \text { caso: } \operatorname{Se} \operatorname{sen} \phi_{e} \leq \frac{\operatorname{sen} \phi_{w}}{\operatorname{sen}\left(\phi_{w}+2 \alpha\right)}, \text { as pressões na tremonha são dadas por: } & \\
p_{n t, e} & =\gamma \cdot z \cdot \frac{1-\operatorname{sen} \phi_{e} \cos 2 \alpha}{1+\operatorname{sen} \phi_{e}} \\
p_{t t, e} & =\gamma \cdot z \cdot \frac{\operatorname{sen} \phi_{e} \operatorname{sen} 2 \alpha}{1+\operatorname{sen} \phi_{e}}
\end{aligned}
$$

\section{Pressões de descarga no corpo do silo}

Já para o caso da descarga, Walker assume que o campo ativo de Rankine, estabelecido durante o carregamento, é alterado durante o fluxo devido ao atrito do produto com a parede.

Walker mostrou que por meio do equilíbrio de uma camada horizontal do produto e da geometria do círculo de Mohr que as pressões $p_{v_{c, d}}$ e $p_{h_{c, d}}$ são dadas pelas equações de Janssen com $\mu K$ dado por:

$$
\mu K=\frac{\operatorname{sen} \phi_{e} \operatorname{sen} \varepsilon_{1}}{1-\operatorname{sen} \phi_{e} \cos \varepsilon_{1}}
$$

onde

$$
\varepsilon_{1}=\frac{\pi}{2}+\phi_{w}+\cos ^{-1} \frac{\operatorname{sen} \phi_{w}}{\operatorname{sen} \phi_{e}}
$$

\section{Pressões de descarga na tremonha}

Walker admitiu que o produto na tremonha esteja num estado de deslizamento e promova as maiores pressões possíveis sobre a parede da tremonha.

$$
\frac{p_{n_{t, d}}}{p_{v_{t, d}}}=\frac{1+\operatorname{sen} \phi_{e} \cos \varepsilon_{2}}{1-\operatorname{sen} \phi_{e} \cos \left(2 \alpha+\varepsilon_{2}\right)}
$$

onde

$$
\varepsilon_{2}=\phi_{w}+\operatorname{sen}^{-1} \frac{\operatorname{sen} \phi_{w}}{\operatorname{sen} \phi_{e}}
$$


Considerando o equilíbrio de forças verticais numa camada horizontal de produto a uma distância z' acima do vértice (ápice) da tremonha e assumindo que a pressão vertical seja uniformemente distribuída, temos a seguinte equação:

$$
\begin{aligned}
& p_{v_{t, d}}=\frac{\gamma \cdot h_{c n}}{\left(K_{w}-1\right)} \frac{z^{\prime}}{h_{c n}}+\left(p_{v_{t r}}-\frac{\gamma \cdot h_{c n}}{K_{w}-1}\right)\left(\frac{z^{\prime}}{h_{c n}}\right)^{K_{w}} \\
& \text { onde } \\
& K_{w}=\frac{1+m}{\operatorname{tg} \alpha} \cdot \frac{\operatorname{sen} \phi_{e} \operatorname{sen}\left(2 \alpha+\varepsilon_{2}\right)}{1-\operatorname{sen} \phi_{e} \cos \left(2 \alpha+\varepsilon_{2}\right)} \\
& \mathrm{m}=0 \text { para tremonhas em cunha; } \\
& \mathrm{m}=1 \text { para tremonhas cônicas ou piramidais; } \\
& z^{\prime}=\text { distância a partir do vértice da tremonha } \\
& h_{c n}=\text { altura do cone } \\
& p_{v t r}=\text { pressão vertical dinâmica na transição }
\end{aligned}
$$

\subsubsection{Teoria de WALTERS}

WALTERS (1973a,1973b) aprofunda o estudo realizado por Walker em 1966 para silos com fluxo de massa, analisando as tensões desenvolvidas durante 0 carregamento e aquelas durante a descarga nas paredes verticais dos silos. A grande vantagem do uso de sua teoria é que é necessária apenas a determinação do ângulo de atrito com a parede e do efetivo ângulo de atrito interno para usar seus equacionamentos.

Sua teoria pode ser aplicada para o menor dos seguintes limites:

$$
\begin{aligned}
& 2 \alpha<\pi-\phi e-\phi w-\cos ^{-1}\left(\frac{\operatorname{sen} \phi w}{\operatorname{sen} \phi e}\right) \\
& 2 \alpha<\phi e-\phi w+\cos ^{-1}\left(\frac{\operatorname{sen} \phi w}{\operatorname{sen} \phi e}\right)
\end{aligned}
$$

Valores maiores de $\alpha$ não são considerados pois WALTERS (1973b) considera que se $\alpha$ ultrapassar esses limites, o fluxo de massa não ocorrerá. Portanto a aplicabilidade dessa teoria se restringe a pequenas inclinações de tremonhas,não podendo ser aplicada para a maioria dos casos na prática. 


\section{Pressões estáticas no corpo do silo}

$$
\begin{aligned}
p_{v_{c e}}= & \frac{1}{4 B D c e}\left(1-e^{-4 B D c e . z 1}\right) \\
p_{h_{c e}}= & \frac{1}{4 \operatorname{tg} \phi w}\left(1-e^{-4 B D c e . z 1}\right) \\
p_{w_{c e}}= & \frac{1}{4}\left(1-e^{-4 B D c e . z 1}\right)
\end{aligned}
$$

nas quais

$$
\begin{aligned}
& B D_{c e}=\frac{\operatorname{tg} \phi_{w} \cdot \cos ^{2} \phi_{e}}{\left(1+\operatorname{sen}^{2} \phi_{e}\right)+2 \xi \operatorname{sen} \phi_{e}} \\
& \xi=\left[\frac{2}{3 v}\left(1-(1-v)^{3 / 2}\right)\right] \\
& v=\left(\frac{\operatorname{tg} \phi_{w}}{\operatorname{tg} \phi_{e}}\right)^{2}
\end{aligned}
$$

Pressões dinâmicas no corpo do silo

$$
\begin{aligned}
p_{v_{c d}}= & \frac{1}{4 B D c d}\left(1-e^{-4 B D c d . z 1}\right) \\
p_{h_{c d}}= & \frac{1}{4 \operatorname{tg} \phi_{w}}\left(1-e^{-4 B D c d . z 1}\right) \\
p_{w_{c d}}= & \frac{1}{4}\left(1-e^{-4 B D c d . z 1}\right)
\end{aligned}
$$

nas quais

$$
\begin{aligned}
& B D_{c d}=\frac{\operatorname{tg} \phi_{w} \cdot \cos ^{2} \phi_{e}}{\left(1+\operatorname{sen}^{2} \phi_{e}\right)-2 \xi \operatorname{sen} \phi_{e}} \\
& \xi=\text { equação (53) } \\
& v=\text { equação (54) }
\end{aligned}
$$

\section{Pressões na transição}

Walters sugere que a relação $\frac{B D_{c d}}{B D_{c e}}$ seja usada como fator de segurança aplicado às pressões sobre a parede para determinar os picos de pressão na mudança. Portanto:

$$
p_{h t r, c}=\frac{B D_{c d}}{B D_{c e}} \cdot p_{h_{c e}}\left(h_{t r}\right)
$$




\section{Pressões na tremonha para condições estáticas}

$$
\begin{aligned}
& \beta_{e}=\frac{1}{2}\left[\frac{\pi}{2}+\phi_{w}+\cos ^{-1}\left(\frac{\operatorname{sen} \phi_{w}}{\operatorname{sen} \phi_{e}}\right)\right] \\
& \eta_{e}=\operatorname{tg}^{-1}\left[\frac{\operatorname{sen} \phi_{e} \cos \left(2 \alpha+2 \beta_{e}-\pi / 2\right)}{1-\operatorname{sen} \phi_{e} \operatorname{sen}\left(2 \alpha+2 \beta_{e}-\pi / 2\right)}\right] \\
& v=\left(\frac{\operatorname{tg} \eta_{e}}{\operatorname{tg} \phi_{e}}\right)^{2} \\
& \xi=\left[\frac{2}{3 v}\left(1-(1-v)^{3 / 2}\right)\right] \\
& B_{t e}=\frac{\operatorname{sen} \eta_{e} \cos ^{2} \phi_{e}}{\cos \eta_{e}\left(1+\operatorname{sen}^{2} \phi_{e}\right)+2\left[\left(\operatorname{sen}^{2} \phi_{e}-\operatorname{sen}^{2} \eta_{e}\right)\right]^{1 / 2}} \\
& D_{t e}=\frac{\cos \eta_{e} \cdot\left(1+\operatorname{sen}^{2} \phi_{e}\right)+2 \sqrt{\operatorname{sen}^{2} \phi_{e}-\operatorname{sen}^{2} \eta_{e}}}{\cos \eta_{e}\left(1+\operatorname{sen}^{2} \phi_{e}+2 \xi \operatorname{sen} \phi_{e}\right)} \\
& X=2 .\left(\frac{B_{t e} D_{t e}}{\operatorname{tg} \alpha}+D_{t e}-1\right) \\
& p_{v_{t e}}=\frac{1-2 z_{2} \cdot \operatorname{tg} \alpha}{2 \operatorname{tg} \alpha \cdot(X-1)}\left[1-\left(1-2 \cdot z_{2} \operatorname{tg} \alpha\right)^{X-1}\right]+p_{v_{c e}}\left(h_{t r}\right) \cdot\left(1-2 z_{2} \operatorname{tg} \alpha\right)^{X} \\
& p_{t e}=\frac{\operatorname{sen} \phi_{e} \operatorname{sen}(2 \beta e)}{1-\operatorname{sen} \phi_{e} \cos \left(2 \alpha+2 \beta_{e}\right)} D_{t e} \cdot p_{v_{t e}}\left(z_{2}\right) \\
& p_{n t e}=\frac{p_{t e}}{\operatorname{tg} \phi_{w}}
\end{aligned}
$$

\section{Pressões na tremonha para condições dinâmicas}

$$
\begin{aligned}
& \beta_{d}=\frac{1}{2}\left[\frac{\pi}{2}+\phi_{w}-\cos ^{-1}\left(\frac{\operatorname{sen} \phi_{w}}{\operatorname{sen} \phi_{e}}\right)\right] \\
& \eta_{d}=\operatorname{tg}^{-1}\left[\frac{\operatorname{sen} \phi_{e} \cos \left(\pi / 2-2 \alpha-2 \beta_{d}\right)}{1+\operatorname{sen} \phi_{e} \operatorname{sen}\left(\pi / 2-2 \alpha-2 \beta_{d}\right)}\right]
\end{aligned}
$$




$$
\begin{gathered}
v=\left(\frac{\operatorname{tg} \eta_{d}}{\operatorname{tg} \phi_{e}}\right)^{2} \\
\xi=\left[\frac{2}{3 v}\left(1-(1-v)^{3 / 2}\right)\right] \\
B_{t d}=\frac{\operatorname{sen} \eta_{d} \cos ^{2} \phi_{e}}{\cos \eta_{d}\left(1+\operatorname{sen}^{2} \phi_{e}\right)-2\left[\left(\operatorname{sen}^{2} \phi_{e}-\operatorname{sen}^{2} \eta_{d}\right)\right]^{1 / 2}} \\
D_{t d}=\frac{\cos \eta_{d} \cdot\left(1+\operatorname{sen}^{2} \phi_{e}\right)-2 \sqrt{\operatorname{sen}^{2} \phi_{e}-\operatorname{sen}^{2} \eta_{d}}}{\cos \eta_{d}\left(1+\operatorname{sen}^{2} \phi_{e}-2 \xi \operatorname{sen} \phi_{e}\right)} \\
p_{v t d}=\frac{1-\left(\frac{B_{t d} D_{t d}}{\operatorname{tg} \alpha}+D_{t d}-1\right)}{2 \operatorname{tg} \alpha \cdot(X-1)} \\
p_{t d}=\frac{\operatorname{sen} \phi_{e} \operatorname{sen}\left(2 \beta_{d}\right)}{1-\operatorname{sen} \phi_{e} \cos \left(2 \alpha+2 \beta_{d}\right)} D_{t d} \cdot p_{v t d}\left(z_{2}\right) \\
p_{n t d}=\frac{p_{t d}}{\operatorname{tg} \phi_{w}}\left[1-\left(1-2 \cdot z_{2} \operatorname{tg} \alpha\right)^{X-1}\right]+p_{v t d}\left(h_{t r}\right) \cdot\left(1-2 z_{2} \operatorname{tg} \alpha\right)^{X}
\end{gathered}
$$

\subsubsection{Teoria de CARSON \& JENKYN}

Em 1993, preocupados com o grande número de acidentes ocorridos em silos devidos a incorreta determinação das condições de carregamento pelos projetistas, CARSON \& JENKYN (1993) descrevem procedimentos a serem seguidos para o projeto de silos.

Segundo os autores, se o ponto de carregamento do silo coincide com a linha central do silo, as cargas desenvolvidas sobre as paredes do silo serão geralmente menores que aquelas induzidas pelo fluxo e, portanto de menor interesse para o projeto estrutural. Se por alguma razão existe interesse em considerar estas cargas, utilizar o equacionamento proposto por Janssen com $K=0,4$.

Para o caso de tremonhas cônicas, não importando o tipo de fluxo que ocorre durante a descarga, as pressões iniciais ou de carregamento que atuam normalmente nas paredes da tremonha são dadas por: 


$$
\begin{gathered}
p_{n}=\gamma\left[\frac{h_{c n}-z^{\prime}}{n_{i}}+\left(\frac{p_{v}}{\gamma}-\frac{h_{c n}}{n_{i}}\right)\left(1-\frac{z^{\prime}}{h_{c n}}\right)^{n_{i}+1}\right] \\
n_{i}=2\left(1+\frac{\operatorname{tg} \phi_{w}}{\operatorname{tg} \alpha}\right)-3
\end{gathered}
$$

onde:

$$
\begin{aligned}
& z^{\prime}=\text { inicia com valor zero no vértice (ápice) da tremonha. } \\
& p_{v}=\text { dado pela equação de Janssen com } K=0,4 \text { e } z=\text { transição. }
\end{aligned}
$$

Já para as pressões de descarga em tremonhas cônicas com fluxo de massa, CARSON \& JENKYN (1993) recomendam usar o seguinte equacionamento:

$$
\begin{aligned}
& p_{n}=\gamma \cdot K_{f}\left[\frac{h_{c n}-z^{\prime}}{n_{f}}+\left(\frac{p_{v}}{\gamma}-\frac{h_{c n}}{n_{f}}\right)\left(1-\frac{z^{\prime}}{h_{c n}}\right)^{n_{f}+1}\right] \\
& \left.K_{f}=\frac{1}{\left[1,5\left(1+\frac{\operatorname{tg} \phi_{w}}{\operatorname{tg} \alpha}\right)-\frac{1}{6\left(\sigma^{\prime} / \gamma B\right.}\right) \operatorname{tg} \alpha}\right] \\
& n_{f}=2 K_{f}\left(1+\frac{\operatorname{tg} \phi_{w}}{\operatorname{tg} \alpha}\right)-3
\end{aligned}
$$

onde:

$$
\begin{aligned}
& p_{v}=\text { dado pela equação de Janssen com } K=0,25 \text { e } z=\text { transição } . \\
& \sigma^{\prime} / \gamma_{B}=\text { dado pelos gráficos do Boletim } 123 \text { de JENIKE (1964) }
\end{aligned}
$$

Devido à rápida mudança do estado de tensões que ocorre na transição do corpo do silo para a tremonha, é esperado um aumento de pressão sobre a parede do corpo do silo. Para levar em conta esta possibilidade, recomenda-se que o pico de pressão seja estendido ao longo da parede vertical como mostrado na figura 23. CARSON \& JENKYN (1993) propõem o seguinte procedimento: primeiramente, desenhar um arco circular centrado no vértice teórico da tremonha cônica passando pela linha da base do cone (tremonha). A altura do ponto mais alto do arco é aproximadamente a máxima altura que o pico de pressão alcançaria. A distribuição de pressão abaixo desta altura pode ser considerada linear. 


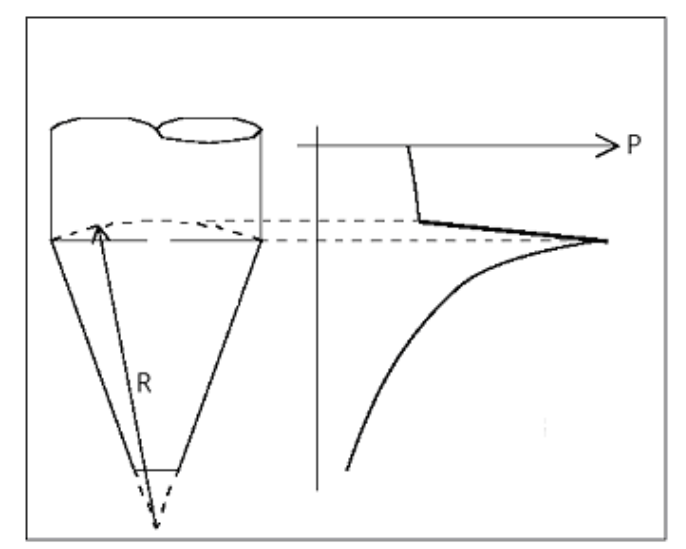

Figura 23 - Pico de pressão em tremonhas com fluxo de massa. Fonte: CARSON \& JENKIN (1993)

Para silos com fluxo de funil, é adequado considerar que as pressões de projeto atuando normalmente as paredes da tremonha são as mesmas que ocorrem durante a condição de carregamento. Isto presume, é claro, que a dimensão da saída seja tal que não ocorra a formação de obstruções e o produto possa ser descarregado.

Para o corpo do silo com fluxo de funil, há duas situações a considerar:

$1^{\circ}$ ) se o canal de fluxo não intercepta a parede do silo, é seguro assumir que as pressões atuando contra as paredes serão as mesmas do carregamento. (Janssen com $K=0,4$ )

$2^{\circ}$ ) Se o canal de fluxo intercepta a parede do corpo do silo na mesma altura em toda a circunferência, então o canal de fluxo é centrado e pode-se assumir o campo de tensão de Janssen acima da efetiva transição.

$\mathrm{Na}$ efetiva transição, onde o canal de fluxo encontra a parede, existe um rápido aumento da pressão na parede devido a convergência pela qual o produto está passando. Dentro do próprio canal de fluxo, é razoável assumir que as pressões variarão com se fosse uma tremonha com fluxo de massa, mas com o ângulo do canal de fluxo e também com ângulo de atrito com a parede substituído pelo ângulo de atrito interno. Como esta distribuição de pressão é transmitida para as paredes do silo não está muito bem definido. É seguro, mas provavelmente um pouco conservador, assumir que a pressão que atua as paredes do corpo do silo é a mesma pressão que atua no canal de fluxo. 


\subsubsection{Teoria de JENIKE \& JOHANSON}

As pesquisas desenvolvidas por Andrew W. Jenike e Jerry R. Johanson formam a base da teoria de armazenamento e fluxo dos produtos armazenados. Por meio de estudos, identificaram e definiram os dois principais tipos de fluxo, estabeleceram critérios para o fluxo, determinaram as principais propriedades físicas dos produtos armazenados, assim como, projetaram equipamentos para suas medições, além de desenvolver teorias para determinar as ações atuantes sobre as paredes dos silos.

Para determinar as ações atuantes na descarga do produto, JENIKE et al (1973) utilizaram a segunda lei da termodinâmica, a qual declara que a energia interna de um sistema tende a ser minimizada. No entanto, JENIKE et al (1973) mostram por meio de experimentos, que as pressões iniciais sobre a parede do cilindro são melhor representadas pelo campo de Janssen, o qual possui energia de deformação definida.

Durante o fluxo do produto no corpo do silo, a presença de pequenas imperfeições nas paredes, causa grandes mudanças nas pressões e na energia de deformação. Estas imperfeições controlam a formação de camadas de contorno nas paredes do corpo do silo. Em muitos casos, as camadas são instáveis e de curta duração. A formação de uma camada causa uma mudança no campo de Janssen para o campo de energia mínima, sendo que, sua dissolução causa o retorno para o campo de Janssen, ou seja, onde as camadas de contorno não foram formadas ou foram dissolvidas, o campo inicial de tensões de Janssen pode ser aplicado. Porém, nos locais onde as camadas de contorno existem, ocorrem picos de pressão que se aproximam da energia mínima de deformação. Portanto, as pressões de fluxo são determinadas assumindo que a energia de deformação dentro do produto armazenado em fluxo tende para um mínimo.

A mudança entre estes campos de tensões ocorre a alguma profundidade no corpo do silo. Portanto, o campo inicial de tensões de Janssen pode ser aplicado entre o topo do corpo do silo e a mudança; abaixo deste nível deve ser aplicado o campo de tensões pela energia mínima de deformação.

Como a mudança do campo de tensões estático para o dinâmico pode ocorrer para pequenas imperfeições nas paredes, a localização da mudança é de difícil determinação. Portanto a determinação das pressões de fluxo pela energia mínima de deformação necessita da avaliação de uma envoltória de todos os possíveis picos de pressão.

A determinação das envoltórias da pressão horizontal sob condições de fluxo no corpo do silo utilizando a energia mínima de deformação é bastante simplificada 
por meio dos gráficos apresentados por JENIKE (1973). Porém, esses gráficos não cobrem algumas formas geométricas de silos.

Para explicar como as pressões atuam nas paredes da tremonha, JENIKE \& JOHANSON (1968) desenvolveram vários estudos mostrando que as pressões do produto armazenado dentro da tremonha tende a diminuir para zero no vértice da tremonha. Quando estas pressões diminuem linearmente na tremonha dá-se o nome de campo radial de pressões. Neste campo, todas as pressões ao longo de um determinado raio são proporcionais à distância do vértice da tremonha.

Em geral, o campo de pressões radiais na tremonha não concorda com o campo de pressões do corpo do silo. $\mathrm{Na}$ interface desses dois campos, um campo de pressões transitório se desenvolve. Esse campo consiste de uma onda de sobrepressão sobreposta as pressões radiais, que decai rapidamente para o vértice da tremonha.

Essa teoria, além de determinar o campo de tensões que atua na tremonha, também é utilizada para expressar se o fluxo ocorrerá ao longo das paredes ou não (critério fluxo/não fluxo). Conseqüentemente, é até hoje uma das teorias mais usadas para o projeto da tremonha.

JENIKE (1987) reescreve a teoria apresentada em 1968 para o campo radial de pressões devido a erros na determinação das zonas estagnadas em silos com fluxo de funil. BENINK (1989) mostra que as diferenças entre as duas teorias para as tensões na parede de tremonhas cônicas são pequenas, enquanto que para tremonhas em cunha, as tensões são as mesmas pelas duas teorias.

Segundo ROBERTS (1995), na primeira teoria, o contorno entre fluxo de massa e fluxo de funil foi baseado na condição de que as pressões ao longo da linha central da tremonha tornam-se zero. Na teoria revisada o contorno é baseado na condição de que a velocidade torna-se zero na parede. Isto levou a novos limites para fluxo de funil, os quais, fornecem valores maiores para o ângulo de inclinação com a vertical da tremonha que aqueles determinados pela teoria anterior, particularmente para grandes valores do ângulo de atrito com a parede.

Infelizmente, o procedimento proposto por Jenike causa certas dificuldades aos calculistas para a maioria das situações práticas de projeto. Um dos problemas encontrados é que o método utiliza vários gráficos, que não cobrem algumas formas geométricas, para a determinação de alguns dos parâmetros propostos na teoria.

A teoria de JENIKE et al (1973) explica o campo de tensões no produto armazenado por meio da definição de três estados de acordo com o tipo de fluxo: 


\section{SILOS COM FLUXO DE MASSA}

(a)

estático (inicial ou de carregamento, figura 24(a)) inicialmente, quando o produto vai sendo carregado para dentro da célula com a saída fechada ou o alimentador parado, o produto rola um sobre o outro, sedimentando na forma de um cone. Durante a sedimentação, o produto contrai verticalmente dentro do silo e principalmente na tremonha. Este produto encontra-se num estado ativo de tensões e a direção da tensão principal maior, $\sigma_{1}$, tende a alinhar-se com a vertical. A pressão inicial é representada por Janssen na parte cilíndrica e por uma distribuição linear na tremonha. Iss o assume que o produto é carregado para dentro do silo sem um impacto significativo e a uma razão relativamente baixa;

(b) em fluxo (dinâmico ou de descarga, figura 24(b)) - durante o fluxo, com o produto fluindo para fora da boca de descarga, ocorre uma expansão vertical e uma contração lateral, estabelecendo-se um estado passivo de tensões. A direção da tensão principal maior, $\sigma_{1}$, tende a alinhar-se com a direção horizontal;

(c) transição (figura 24(c)) - instantes após a abertura da boca de descarga, ocorre à passagem do estado ativo para o passivo de tensões. Esta mudança inicia-se no produto logo acima da boca de descarga e propaga-se para cima em direção a sua superfície livre. O tempo (fração de segundo) em que os dois estados de tensão ativo e passivo coexistem é denominado de mudança. No local onde a mudança ocorre, um pico de pressão (sobrepressão) é exercido sobre as paredes do silo. Essa sobrepressão de descarga se desloca para cima no mínimo até o nível no qual o canal intercepta o corpo do silo, isto é, no nível da transição em silos com fluxo de massa e na transição efetiva em silos com fluxo de funil. $O$ volume preto de produto entre os dois carregamentos não pertence a qualquer um deles. Acima do nível da mudança assume-se que o campo de pressões não 
é perturbado, portanto o estado de tensões ativo ainda permanece.

Deve ser notado que quando a descarga do produto é parada, o campo de tensões da figura 24(c) permanece. O campo de tensões não retorna àquele da figura 24(a), a menos que o silo seja completamente descarregado e carregado novamente.

GAYLORD \& GAYLORD (1984) mostram que para um exemplo de $\phi_{\mathrm{e}}=50^{\circ} \mathrm{e}$ $\phi_{\mathrm{w}}=25^{\circ}$ a pressão horizontal de fluxo, em silo com fluxo de massa, imediatamente abaixo da transição é 6,7 vezes a pressão inicial imediatamente acima. Contudo, se $\phi_{\mathrm{e}}=25^{\circ}$ e as outras variáveis permanecem as mesmas, a taxa da pressão de pico pela pressão inicial cai para 2,83 conforme WALTERS (1966) e para 2,58 conforme JENIKE \& JOHANSON (1973). Portanto, os picos de pressão parecem ser muito sensíveis ao efetivo ângulo de atrito interno.

No caso de tremonhas com fluxo de massa, as cargas iniciais governam o projeto estrutural da tremonha até aproximadamente $2 / 3$ do fundo, enquanto que as cargas de fluxo até o $1 / 3$ final (mais próximo da transição). Segundo CARSON \& JENKYN (1993) para a maioria das tremonhas com fluxo de massa, seu projeto estrutural pode ser baseado nas cargas iniciais. 


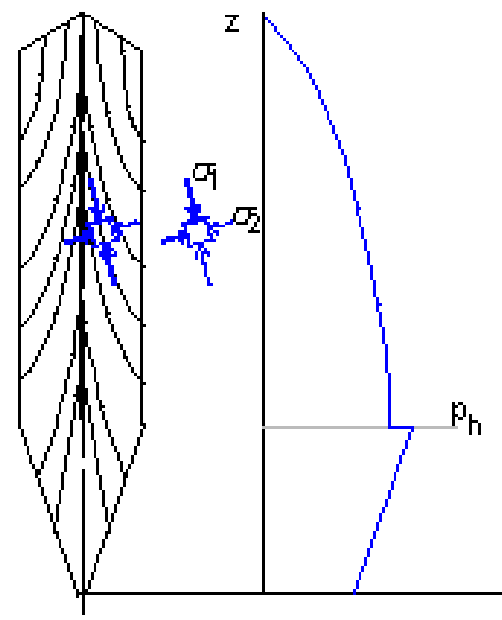

(a) Inicial

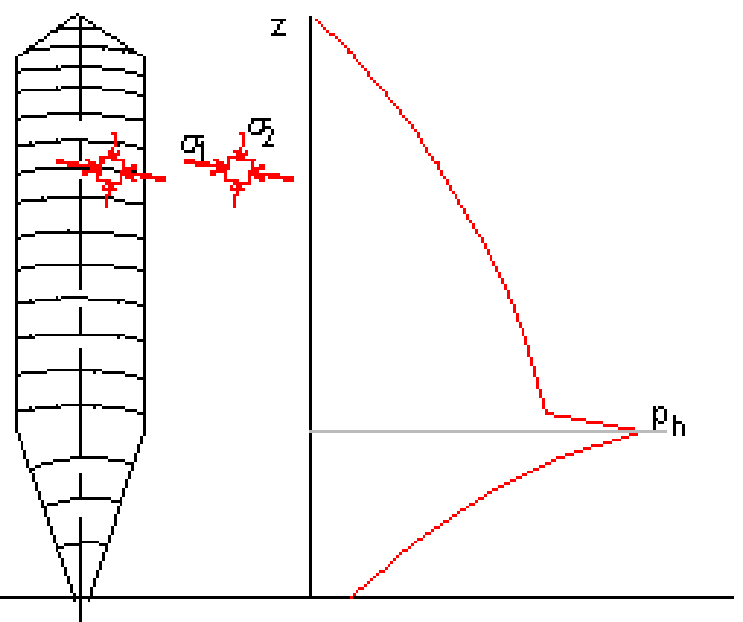

(b) Em fluxo

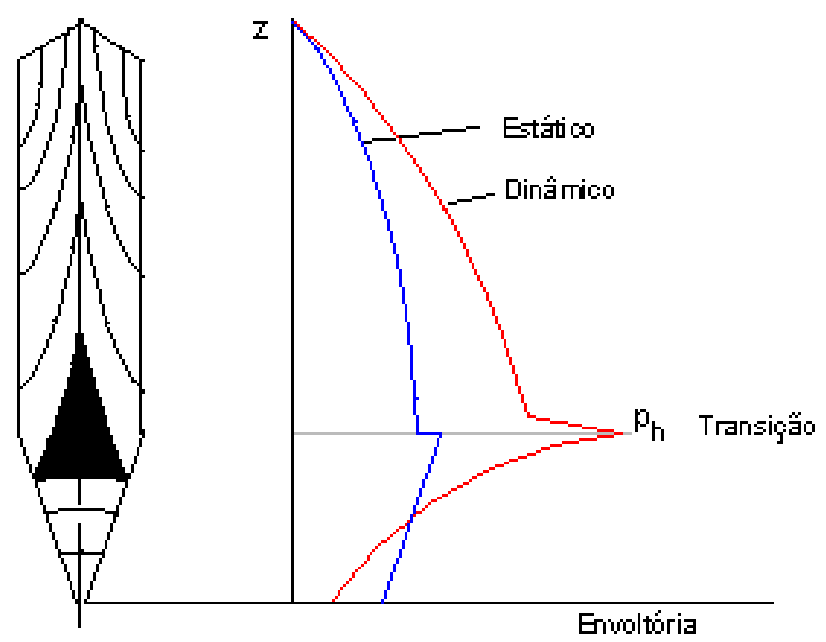

(c) Na transiçẫo

Figura 24 - Estados de Tensão - Fluxo de Massa

A seguir se apresenta a teoria de Jenike para a determinação das pressões baseando-se principalmente nas suas publicações de 1968, 1973 e 1977.

\section{Pressões no Corpo do Silo}

\section{Condições Estáticas}

Recomenda utilizar o equacionamento proposto por JANSSEN (1895) com $K=0,4$. 


\section{Condicões de Fluxo}

A figura 25 ilustra a distribuição de pressão para a situação na qual o produto abaixo da mudança está expandindo verticalmente no desenvolvimento do canal de fluxo, enquanto o produto acima está ainda na condição inicial (Janssen). O pico de pressão resultante na mudança é determinado por meio da minimização da energia de deformação recuperável no campo de fluxo abaixo da mudança. A solução é dada por JENIKE et al (1973) na forma de 3 equações simultâneas. Contudo, segundo GAYLORD \& GAYLORD (1984), elas podem ser simplificadas para o seguinte equacionamento para $\mathrm{p}_{\mathrm{h}}$ :

$$
\frac{p_{h}}{R \gamma / \mu}=1+\frac{\left(\frac{\omega \cdot p_{v_{c e}}(z)}{\gamma}-\partial\right) \cdot\left[(1+\partial) e^{\omega\left(h_{t r}-z\right)}-(1-\partial) e^{-\omega\left(h_{t r}-z\right)}\right]-2\left(1-\partial^{2}\right)}{(1+\partial) e^{\omega\left(h_{t r}-z\right)}+(1-\partial) e^{-\omega\left(h_{t r}-z\right)}}
$$

Obs.: JENIKE (1977) recomenda que as pressões dadas pela equação 85 sejam reduzidas em $15 \%$ para levar em conta o fato de que os picos de pressão teóricos são inevitavelmente arredondados na prática.

Para silos circulares:

$$
\begin{aligned}
& \partial=K \sqrt{\frac{2}{1+K}} \\
& \omega=\frac{\mu K}{R \partial}
\end{aligned}
$$

Para silos retangulares

$$
\partial=K(\text { aproxidamente) }
$$

$$
\omega=\frac{\mu}{R}
$$

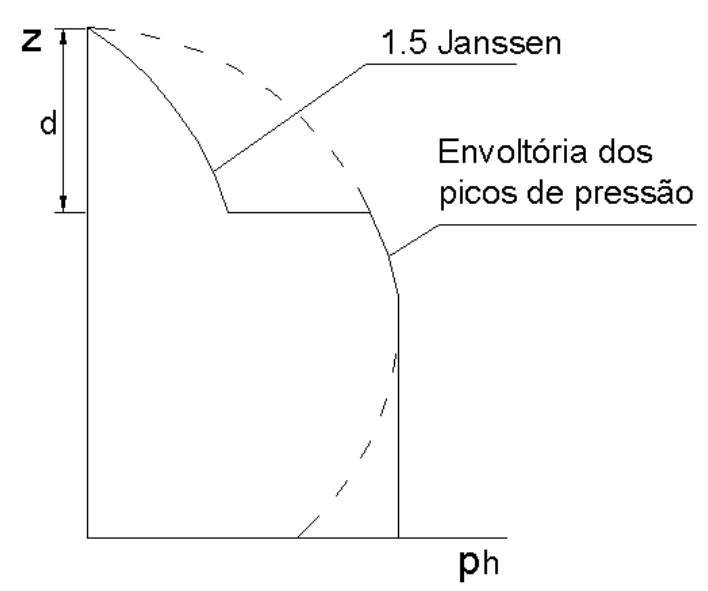

Figura 25 - Pressões em silo com fluxo de massa 
A envoltória dos picos de pressão é encontrada por meio da determinação dos picos de pressão $\left(p_{h}\right)$ em vários níveis $(z)$. Porém, a equação 85 não resulta igual a zero para $z=0$. De acordo com JENIKE (1977), isto é devido ao efeito da mudança não se manifestar na região em que $z=d$. JENIKE (1977) recomenda que para valores de $z \leq d$ onde $d$ é o diâmetro do corpo do silo ou largura, as pressões na parede sejam determinadas pela multiplicação da equação de Janssen por 1,5 com $K$ dado pelo maior valor de:

$$
\begin{aligned}
& K=0,4 \\
& K=\frac{1-\operatorname{sen} \phi_{e}}{1+\operatorname{sen} \phi_{e}}
\end{aligned}
$$

Outra modificação da envoltória dos picos de pressão é necessária devido a pressão horizontal dada pela equação 85 reduzir-se para a pressão lateral de Janssen no final do corpo do silo devido ao produto na tremonha não ter sido levado em consideração na obtenção da equação. Com efeito, a solução é baseada na suposição que o fluxo começa a se desenvolver na base do corpo do silo ao invés da saída da tremonha. Portanto, a envoltória dos picos de pressão nesse trecho, é substituída por uma linha vertical abaixo do ponto onde o valor de ph é máximo. (Figura 25)

Para a pressão vertical, GAYLORD \& GAYLORD (1984) recomendam utilizar o seguinte equacionamento:

$$
\frac{p_{v}}{\gamma / \omega}=\partial+\frac{\left(1-\partial^{2}\right)\left(e^{\omega z}-e^{-\omega z}\right)-\partial\left[(1+\partial) e^{\omega\left(h_{t r}-z\right)}+(1-\partial) e^{-\omega\left(h_{t r}-z\right)}\right]}{(1+\partial) e^{\omega h_{t r}}+(1-\partial) e^{-\omega h_{t r}}}
$$

Para a força de compressão sobre a parede utilizar a equação 33 reduzida em $15 \%$ (pg. 40) com a pressão vertical $\left(p_{v}\right)$ dado pela equação 91.

\section{Pressões na Tremonha}

JENIKE et al (1973) desenvolveram um procedimento para o cálculo das pressões na tremonha, sendo em 1977 alterado, recomendando o seguinte equacionamento:

$$
\begin{aligned}
& p_{n}=K \gamma\left[\frac{h_{c n}-z_{2}}{\nabla-1}+\left(\frac{p_{v_{c e}}\left(h_{t r}\right)}{\gamma}-\frac{h_{c n}}{\nabla-1}\right)\left(\frac{h_{c n}-z_{2}}{h_{c n}}\right)^{\nabla}\right] \\
& \nabla=(1+m)\left[\left(1+\frac{\operatorname{tg} \phi_{w}}{\operatorname{tg} \alpha}\right) K-1\right]
\end{aligned}
$$


Cabe salientar, que a equação 92 é similar ao equacionamento proposto por Walker (equações 43 e 45) com $K$ equivalente a relação $p_{n} / p_{v}$ na equação $43, \mathrm{~h}$ correspondendo ao $K_{w}$ e $p_{v t}$ ao $\gamma h_{c}$ na equação 45.

JENIKE (1977) recomenda que $K$ varie de um valor máximo de fluxo $K_{\max }$ na transição para um valor estático na parte mais baixa da tremonha e que a escolha seja feita para cada altura de forma a maximizar o valor de $p_{n}$. O valor de $K_{\max }$ é apresentado na forma de gráficos por Jenike em função de $\phi_{\mathrm{e}}, \alpha \mathrm{e} \phi_{\mathrm{w}}$.

\section{Condicões Estáticas}

Para essa condição o valor de $K$ deve ser o valor mínimo:

$$
K=K_{\min }=\frac{\operatorname{tg} \alpha}{\operatorname{tg} \phi_{w}+\operatorname{tg} \alpha}
$$

Substituindo na equação 93 temos que $\nabla=0$, sendo que a equação 92 reduzse a:

$$
\begin{gathered}
p_{n}=\gamma \cdot K_{\min } \cdot\left[\frac{p_{v_{c e}}\left(h_{t r}\right)}{\gamma}+z_{2}\right] \\
p_{v}=\frac{p_{n}}{K_{\min }}=\gamma \cdot\left[\frac{p_{v_{c e}}\left(h_{t r}\right)}{\gamma}+z_{2}\right]
\end{gathered}
$$

\section{Condič̃es de Fluxo}

A pressão normal na parede da tremonha é dada pela equação (92) com o valor máximo de $K$ :

$$
K=K_{\text {max }}
$$

onde $K_{\max }$ é obtido de forma gráfica em JENIKE (1977) ou pode ser determinado usando as seguintes equações:

$$
K_{\max }=\left[\frac{\sigma_{w} / \gamma B}{q\left(\frac{4}{\pi}\right)^{m}}\right]
$$

onde

$$
\begin{aligned}
& \frac{\sigma_{w}}{\gamma B}=\frac{Y\left(1+\operatorname{sen} \phi_{e} \cdot \cos 2 \beta\right)}{2(X-1) \operatorname{sen} \alpha} \\
& q=\left(\frac{\pi}{3}\right)^{m} \cdot \frac{1}{4 \operatorname{tg} \alpha}\left[2\left(\frac{\sigma_{w}}{\gamma B}\right)\left(\operatorname{tg} \alpha+\operatorname{tg} \phi_{w}\right)-\frac{1}{1+m}\right]
\end{aligned}
$$




$$
\begin{aligned}
& 2 \beta=\phi_{w}+\operatorname{sen}^{-1}\left(\frac{\operatorname{sen} \phi_{w}}{\operatorname{sen} \phi_{e}}\right) \\
& X=\frac{2^{m} \operatorname{sen} \phi_{e}}{1-\operatorname{sen} \phi_{e}}\left[\frac{\operatorname{sen}(2 \beta+\alpha)}{\operatorname{sen} \alpha}+1\right] \\
& Y=\frac{\langle 2[1-\cos (\beta+\alpha)]\rangle^{m}(\beta+\alpha)^{1-m} \operatorname{sen} \alpha+\operatorname{sen} \beta \cdot \operatorname{sen}^{1+m}(\beta+\alpha)}{\left(1-\operatorname{sen} \phi_{e}\right) \operatorname{sen}^{2+m}(\beta+\alpha)}
\end{aligned}
$$

onde

$\mathrm{m}=1$ para tremonha cônica ou de eixo simétrico;

$\mathrm{m}=0$ para tremonha em cunha;

na equação (102) o numerador $(\alpha+\beta)$ deve ser em radianos.

Obs.: A tensão de cisalhamento é dada por:

$$
p_{t}=p_{n} \cdot \operatorname{tg} \phi_{w}
$$

\section{SILOS COM FLUXO DE FUNIL}

Quando o fluxo começa, o produto acima da boca de descarga expande verticalmente para cima formando um canal de fluxo dentro de uma massa parada de produto (figura 26). Se o silo é suficientemente alto, o cone expande para as paredes cilíndricas do silo. Nas paredes em contato com a massa parada de produto, as pressões são amortecidas e na região onde o canal de fluxo intercepta a parede (transição efetiva), se desenvolvem picos de pressão. Como o local da transição efetiva ainda não esta completamente compreendido, é necessário levar em consideração no cálculo das pressões a envoltória dos picos de pressão em toda a altura da parede do silo.

Em vários silos altos, geralmente com $\mathrm{h} / \mathrm{d}>5$, é possível assumir que a posição mais alta da transição efetiva nunca alcançara o topo do corpo do silo. Nesse caso, a região superior do silo pode ser projetada como para silos com fluxo de massa.

Para silos com h/d<2, JENIKE (1973) sugere que seja usada a equação de Janssen pois o canal de fluxo raramente intercepta a parede, e mesmo se isso ocorrer, o pico de pressão seria insignificante.

O ângulo de inclinação do funil desenvolvido na descarga ( $\alpha$ s) (Figura 26) varia de acordo com as propriedades físicas do produto, geometria e rugosidade das paredes do silo. Em ensaios realizados num silo protótipo, BENINK (1989), determinou valores entre $30^{\circ}$ e $60^{\circ}$, dependendo do produto armazenado. FREITAS (2001) realizando ensaios num silo real utilizando milho como produto armazenado, encontrou o valor de $30^{\circ}$. 


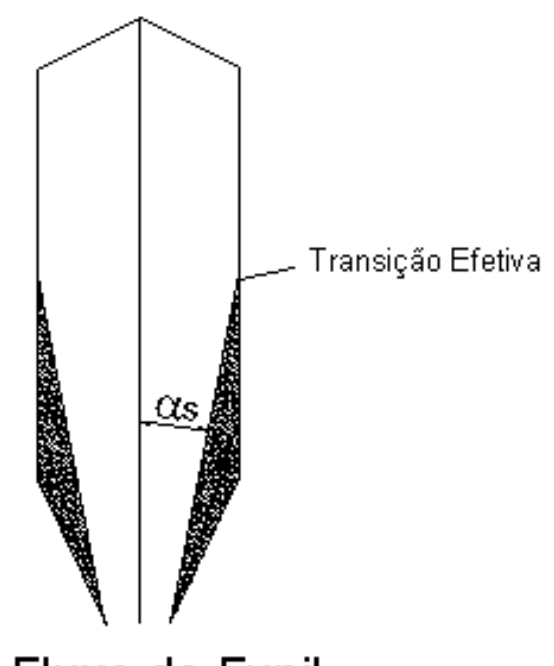

Fluxo de Funil

Figura 26 - Estado de Tensão - Fluxo de Funil.

\section{Pressões no Corpo do Silo}

\section{Pressão de Pico na Transição Efetiva}

Deve ser determinado para vários valores de $z$ com o objetivo de determinar a envoltória dos picos de pressão. JENIKE (1973) apresenta para $2<\mathrm{h} / \mathrm{d}<5$ gráficos para determinação dos picos de pressão que também podem ser obtidos pela seguinte equação:

$$
p_{h}(z)=\lambda \cdot p_{v}(z)
$$

sendo:

$$
\begin{aligned}
& p_{v}(z)=\text { equação de Janssen com } \mathrm{k}=0,4 \\
& \lambda=\frac{(24 \operatorname{tg}(\alpha s)+\pi / q) \cdot\left(1-\operatorname{sen} \phi_{e} \operatorname{tg}(\alpha s)\right)}{16\left(\operatorname{sen} \phi_{e}+\operatorname{tg}(\alpha s)\right)} \text { para tremonhas de eixo simétrico. } \\
& q=\frac{\pi}{24 \cdot \operatorname{sen}(\alpha s)}\left[\frac{2 Y}{(X-1) \operatorname{sen}(\alpha s)}\left(\operatorname{tg}(\alpha s)+\operatorname{sen} \phi_{e}\right)-1\right] \\
& X=\text { equação (101) com } \alpha \text { s no lugar de } \alpha \text {. } \\
& Y=\text { equação (102) com } \alpha \text { s no lugar de } \alpha \text {. } \\
& \text { Sendo } \beta \text { dado por: } \\
& \beta=\frac{1}{2}\left[\phi_{e}+\operatorname{sen}^{-1}\left(\cos \phi_{e}\right)\right]
\end{aligned}
$$




\section{Força de Compressão}

Pode ser obtida diretamente por meio dos gráficos publicados por JENIKE (1973) ou pelo seguinte equacionamento:

$$
\begin{aligned}
\frac{P_{w \max }}{\gamma d^{2+m} L^{1-m}} & =\left(\frac{\pi}{4}\right)^{m} \cdot\left(\frac{h}{d}-\frac{A e^{x}+B e^{-x}+N}{2(1+m)}\right) \\
M & =\sqrt{2(1-v)} \\
v & =0,3 \text { para tremonhas de eixo simétrico } \\
N & =\frac{2 v}{\mu M^{2(1-m)}} \\
x & =\frac{\mu h}{M^{m} R} \\
\vartheta & =\frac{v}{1-v} \\
A & =\frac{-\left(\vartheta \cdot M^{m}-1\right)(-N) e^{-x}+M^{m}\left(\mu^{-1}-\vartheta N\right)}{\left(\vartheta M^{m}+1\right) e^{x}-\left(\vartheta M^{m}-1\right) e^{-x}} \\
B & =-A-N
\end{aligned}
$$

\section{Pressões na Tremonha}

Para a determinação das pressões na tremonha JENIKE (1973) assumiu que o campo de pressões determinado para o corpo do silo se estende para dentro da tremonha.

$$
\begin{aligned}
& p_{n}=p_{h} \cdot\left[\left(\frac{\operatorname{sen}^{2} \alpha}{k}+\cos ^{2} \alpha\right)+\left(\frac{4 r}{d} \mu \operatorname{sen} \alpha \cdot \cos \alpha\right)\right] \\
& p_{t}=p_{h} \cdot\left[\left(\frac{1}{k}-1\right) \operatorname{sen} \alpha \cdot \cos \alpha+\frac{2 r}{d} \mu\left(\cos ^{2} \alpha-\operatorname{sen}^{2} \alpha\right]\right.
\end{aligned}
$$

onde

$r=$ coordenada radial

$p_{h}=$ pressão horizontal de Janssen para $\mathrm{z}=\mathrm{h}$ 


\subsubsection{Método dos Elementos Finitos}

Mais recentemente, a possibilidade de aplicação de métodos numéricos para obter soluções aproximadas de muitos problemas complexos, tem causado interesse por parte de pesquisadores, na utilização do método dos elementos finitos para a determinação das pressões atuantes e fluxo do produto armazenado. Segundo ZIENKIEWICZ OC, TAYLOR RL apud MARTÍNEZ (2002) o uso do método dos elementos finitos permite a solução do problema do processo de descarga para geometrias variadas e a elaboração de modelos constitutivos, simulando comportamentos plásticos e viscosos do produto, assim como, o contato entre o produto e a parede.

Segundo MARTíNEZ (2002), ROTTER et al tem desenvolvido trabalhos abordando os processos de carregamento e descarga em silos. No estado de carregamento eles têm empregado o comportamento constitutivo elástico, enquanto que na descarga o critério de Mohr-Coulomb.

JOFRIET et al (1997) propuseram uma classe especial de relações constitutivas para produtos isotrópicos e sem coesão. Eles empregaram relações elasto-plásticas utilizando o critério de ruptura de Drucker-Prager.

Segundo BENINK (1989), os resultados dependem grandemente das equações constitutivas utilizadas. Infelizmente essas equações ainda não são baseadas numa adequada descrição do comportamento de ruptura, especialmente o inicio da falha (deslizamento). Por outro lado, bons resultados da distribuição de pressão durante o estado de fluxo estável são obtidos.

Para tentar superar essas dificuldades, o método de elementos discretos (DEM) tem recentemente sido aplicado a estes problemas, porém o potencial para aplicações práticas ainda é desconhecido. Esse método trata do comportamento mecânico do grão individualmente, e embora muitos pesquisadores utilizem partículas esféricas, alguns trabalhos com partículas não esféricas também tem sido desenvolvidos. No DEM, a equação de Newton do movimento para cada partícula reproduz as equações de equilíbrio da mecânica do contínuo, e o modelo descreve o contato das partículas reproduzindo as equações constitutivas. 


\subsection{NORMAS INTERNACIONAIS ANALISADAS}

A seguir será apresentado um resumo das recomendações propostas pelas mais importantes normas internacionais utilizadas no projeto de silos: ISO 11697 (1995), EUROCODE 1/Part 4 (1995), AS 3774 (1996) e DIN 1005-6 (2000), para a determinação das pressões exercidas pelos produtos armazenados sobre as paredes laterais e o fundo, sob condições estáticas e dinâmicas de silos verticais esbeltos, assim como, das pressões adicionais.

Conforme as normas internacionais, os silos podem ser classificados geralmente de acordo com as seguintes características:

- geometria do silo

- tipo de fluxo

- tipo de fundo (plano ou elevado)

Em relação à geometria, os silos são classificados segundo a relação entre a altura efetiva do produto armazenado (h) e o maior diâmetro inscrito (d). No entanto, as normas internacionais não são unânimes em relação a essa classificação, como mostrado na tabela 2.

TABELA 2 - Classificação dos silos segundo a relação $\mathrm{h} / \mathrm{d}$

\begin{tabular}{c||c||c||c}
\hline \multicolumn{1}{c||}{ NORMA } & \multicolumn{3}{c}{ CLASSIFICAÇÃO } \\
\cline { 2 - 4 } & Baixo & Medianamente esbelto & Esbelto \\
\hline AUSTRALIANA AS -1996 & $\mathrm{h} / \mathrm{d}<1$ & $1 \leq \mathrm{h} / \mathrm{d} \leq 3$ & $\mathrm{~h} / \mathrm{d}>3$ \\
EUROCODE (ENV) -1995 & $\mathrm{h} / \mathrm{d}<1,5$ & -- & $\mathrm{h} / \mathrm{d} \geq 1,5$ \\
ISO-1995 & $\mathrm{h} / \mathrm{d}<1,5$ & -- & $\mathrm{h} / \mathrm{d} \geq 1,5$ \\
DIN 1055-6 - 2000 & $\mathrm{h} / \mathrm{d}<1,5$ & -- & $\mathrm{h} / \mathrm{d} \geq 1,5$ \\
\hline
\end{tabular}

Segundo SAFARIAN \& HARRIS (1985) apud FREITAS (2001), entre os pesquisadores também não há consenso em relação ao que seja uma célula alta ou baixa. Alguns fazem essa classificação em relação às proporções da célula e outros em relação à posição do lugar geométrico de deslizamento do produto. Em geral a relação $\mathrm{h} / \mathrm{d}<1,5$, onde $\mathrm{h}$ é a altura como indicado na figura 20 e d o diâmetro ou lado da célula, classifica a célula como baixa e, caso contrário, como alta, sendo o proposto neste trabalho. 


\subsubsection{Pressões no Corpo do Silo}

\subsubsection{Pressões Estáticas ou Iniciais ou de Carregamento}

Todas as normas analisadas adotam a formulação proposta por JANSSEN (1895) para o cálculo das pressões horizontais, pressões verticais e pressões de atrito com a parede, variando apenas o valor do coeficiente de majoração utilizado para a obtenção da pressão vertical na base em silos com fundo plano (inclinação $\leq 20^{\circ}$ ).

A tabela 3 apresenta de forma resumida as prescrições conforme as normas analisadas.

TABELA 3 - Pressões iniciais e parâmetro K.

\begin{tabular}{c|c|c|c|c|c|c}
\hline \multirow{2}{*}{ Norma } & \multicolumn{2}{|c|}{ Pressões Estáticas } & \multicolumn{2}{|c|}{ Silos com fundo plano } & & \multirow{2}{*}{$\mathbf{K}$} \\
\cline { 2 - 5 } & $\mathbf{p}_{\mathrm{h}}$ & $\mathbf{p}_{\mathrm{v}}$ & $\mathbf{p}_{\mathrm{w}}$ & Pressão Vertical na Base & $\mathbf{P}_{\mathbf{w}}$ & \\
\hline ISO 11697 & Eq.(29) & Eq.(30) & Eq.(31) & Eq.(30) multiplicada por 1,35 & Eq.(33) & $1,1\left(1-\operatorname{sen} \phi_{e}\right)$ \\
EUROCODE & Eq.(29) & Eq.(30) & Eq.(31) & Eq.(30) multiplicada por 1,2 & Eq.(33) & $1,1\left(1-\operatorname{sen} \phi_{e}\right)$ \\
AS & Eq.(29) & Eq.(30) & Eq.(31) & Obs. (1) & Eq.(33) & $\frac{1+\operatorname{sen}^{2} \phi_{e}-2 \sqrt{\left(\operatorname{sen}^{2} \phi_{e}-\mu^{2} \cos ^{2} \phi_{e}\right)}}{4 \mu^{2}+\cos ^{2} \phi_{e}} \geq 0,35$ \\
DIN & Eq.(29) & Eq.(30) & Eq.(31) & Eq. (30) multiplicada por 1,2 & Eq.(33) & $1,1\left(1-\operatorname{sen} \phi_{e}\right)$ \\
\hline
\end{tabular}

Obs. (1)

A norma Australiana apresenta formulações diferentes para a pressão vertical na base em silos com fundo plano, de acordo com o tipo da seção transversal do silo.

Para silos cilíndricos, a pressão vertical (figura 27b) na base ( $\mathrm{p}_{\mathrm{eb}}$ ) será determinada pela seguinte equação:

$$
\begin{aligned}
& p_{v_{e b}}(r)=1,25 p_{v}\left[1-1,6\left(\frac{r}{d}\right)^{2}\right] \\
& p_{v}=\text { equação } 30 \text { aplicada na base do silo } \\
& r=\text { coordenada radial no silo circular } \\
& d=\text { diâmetro do silo }
\end{aligned}
$$

A base de silos cilíndricos de fundo plano, também deverá ser projetada para resistir a trações devidas ao cisalhamento horizontal que atua do centro para as extremidades (figura 27c). Este esforço de cisalhamento $\left(p_{w b}\right)$ ocorre devido ao atrito do produto armazenado com o material do fundo do silo, sendo dado pela seguinte equação: 


$$
p_{w b}(r)=0,3 p_{v}\left[\left(\frac{2 r}{d}\right)-\left(\frac{2 r}{d}\right)^{2}\right]
$$

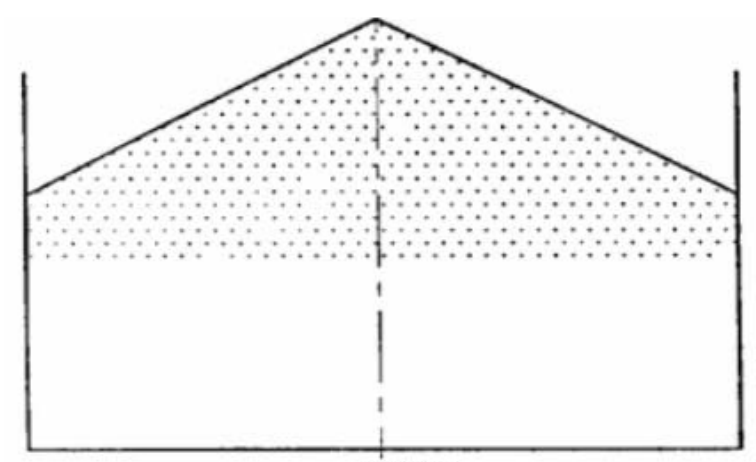

(a) Silo

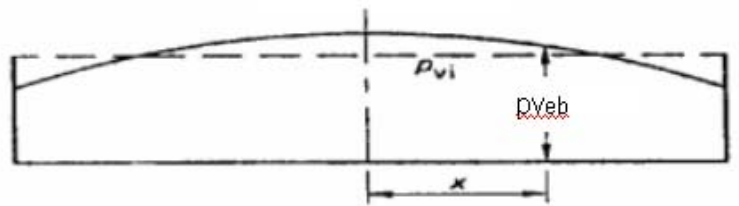

(b) Distribuição da pressão vertical

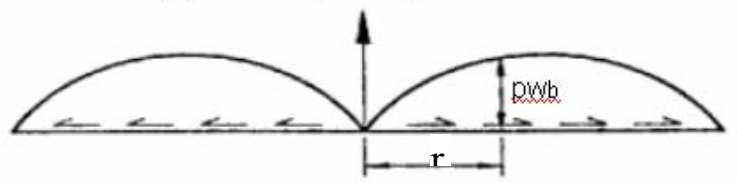

(c) Distribuição da tração horizontal na base

Figura 27 - Distribuição das pressões em silos com fundo plano conforme norma AS 3774.

\subsubsection{Pressões Dinâmicas ou de Descarga}

As normas, de uma forma geral, utilizam coeficientes de majoração, também chamados de coeficientes de sobrepressão, aplicados às pressões estáticas para a determinação das pressões dinâmicas.

\section{Norma ISO $11697-1995$}

Para silos com fluxo de massa, as pressões de descarga serão obtidas multiplicando as pressões de carregamento (equações 29, 31 e 33) por um coeficiente de sobrepressão $C$.

Para silos esbeltos $(h / d \geq 1,5)$, C vale 1,35 . Este valor aplica-se apenas para os produtos listados conforme as classes que a norma apresenta em tabela própria.

Para produtos não tabelados, C pode ser calculado pela seguinte equação:

$$
\mathrm{C}=1,35+0,02\left(\phi_{\mathrm{e}}-30^{\circ}\right) \geq 1,35
$$

As cargas resistidas pelos apoios do silo serão determinadas do equilíbrio de força usando a $p_{\text {ve }}$ na transição multiplicada pelo fator empírico de 1,35. 


\section{Norma EUROCODE 1/Part 4 - 1995}

As pressões de descarga serão obtidas multiplicando as pressões de carregamento (equações 29 e 33) por coeficientes de sobrepressão $C_{w}$ e $C_{h}$.

$$
\begin{aligned}
& \mathrm{Pw}_{\mathrm{d}}=\mathrm{C}_{\mathrm{w}} \cdot \mathrm{P}_{\mathrm{we}} \\
& \mathrm{p}_{\mathrm{hd}}=\mathrm{C}_{\mathrm{h}} \cdot \mathrm{p}_{\mathrm{h}}
\end{aligned}
$$

nas quais

$\mathrm{C}_{\mathrm{w}}=1,1$ e $\mathrm{C}_{\mathrm{h}}=\mathrm{C}_{\mathrm{o}}$

$\mathrm{C}_{\mathrm{o}}=$ valor tabelado pela norma em função do produto armazenado. Para produtos não tabelados, Co pode ser determinado por:

$$
\mathrm{C}_{\mathrm{o}}=1,35+0,02 \cdot\left(\phi_{\mathrm{e}}-30^{\circ}\right) \geq 1,35
$$

As cargas resistidas pelos apoios do silo serão determinadas do equilíbrio de força usando a $p_{v e}$ na transição multiplicada pelo fator empírico de 1,2 e pelo peso de produto na tremonha.

\section{Norma AS $3774-1996$}

A pressão horizontal de descarga será determinada pela seguinte equação:

$$
p_{h d}=c_{d} \cdot p_{h}
$$

na qual $c_{d}$ é o maior valor de

$$
\begin{aligned}
& c_{d}=\left[7,6\left(\frac{h}{d}\right)^{0,06}-6,4\right] \cdot c_{c} \\
& c_{d}=1,2 c_{c} \\
& p_{\mathrm{h}}=\text { equação (29) } \\
& c_{c}=1,0 \text { para silos com fluxo simétrico } \\
& c_{c}=1,2 \text { para silos com fluxo planar }
\end{aligned}
$$

Em silos com fluxo de funil a norma permite uma redução no coeficiente $c_{d}$. No nível da transição efetiva, $c_{d}$ será o maior valor obtido pelas equações 124 e 125 . No nível da boca de descarga será o valor obtido pela equação 125. Para níveis intermediários, poderá ser usada uma interpolação linear entre estes dois valores. A posição mais baixa da transição efetiva, a partir da boca de descarga, é dada por:

$$
h_{t e}=0,4 \cdot d \cdot \operatorname{tg} \phi_{i}
$$


A pressão de atrito será obtida pela seguinte equação:

$$
p_{w_{d}}=c_{q} p_{w}
$$

na qual

$\mathrm{p}_{\mathrm{w}}=$ equação 31

$\mathrm{C}_{\mathrm{q}}=1,2$ para silos com geometria de fluxo simétrico.

$c_{q}=1,4$ para silos com geometria de fluxo planar.

A força vertical por unidade de perímetro na descarga $\left(P_{w_{d}}\right)$, é determinada usando a equação 33 multiplicada pelos coeficientes $c_{q}$ utilizados na equação 127 .

\section{$\underline{\text { Norma DIN 1055-6 - } 2000}$}

As pressões de descarga serão obtidas multiplicando as pressões de carregamento (equações 29 e 33) por coeficientes de sobrepressão $C_{w}$ e $C_{h}$.

$$
\begin{aligned}
& \mathrm{P}_{\mathrm{wd}}=\mathrm{C}_{\mathrm{w}} \cdot \mathrm{p}_{\mathrm{w}} \\
& \mathrm{p}_{\mathrm{hd}}=\mathrm{C}_{\mathrm{h}} \cdot \mathrm{p}_{\mathrm{h}} \\
& \text { nas quais } \\
& \mathrm{C}_{\mathrm{w}}=1,1 \text { e } \mathrm{C}_{\mathrm{h}}=\mathrm{C}_{\mathrm{o}} \\
& \mathrm{C}_{\mathrm{o}}=\text { valor tabelado pela norma em função do produto armazenado. Para }
\end{aligned}
$$

produtos não tabelados, $\mathrm{C}_{0}$ será obtido por:

Para $\phi_{\mathrm{e}}<30^{\circ}, \mathrm{C}_{\mathrm{o}}=1,35$

Para $\phi_{\mathrm{e}} \geq 30^{\circ}, \mathrm{C}_{\mathrm{o}}=1,35+0,02 .\left(\phi_{\mathrm{e}}-30^{\circ}\right)$

As cargas resistidas pelos apoios do silo serão determinadas do equilíbrio de força usando a $p_{v e}$ na transição multiplicada pelo fator empírico de 1,2 e pelo peso de produto na tremonha.

\subsubsection{Pressões na Tremonha}

As pressões normais a tremonha são calculadas pela soma dos carregamentos devido ao enchimento da tremonha e pelos carregamentos resultantes da sobrecarga vertical diretamente acima da transição. Em silos com fluxo de massa uma pressão normal uniforme $\left(p_{s}\right)$ é aplicada na transição do corpo do silo com a tremonha.

A tabela 4 apresenta de forma resumida as prescrições conforme as normas analisadas. 
TABELA 4 - Pressões sobre a parede da tremonha

\begin{tabular}{c|c|c|c|c|c|c|c}
\hline NORMA & $\mathrm{p}_{\mathrm{n} 1}$ & $\mathrm{p}_{\mathrm{n} 2}$ & $\mathrm{p}_{\mathrm{n} 3}$ & $\mathrm{p}_{\mathrm{n}}$ & $\mathrm{p}_{\mathrm{t}}$ & $\mathrm{p}_{\mathrm{s}}$ & Obs \\
\hline ISO & $1,5 \cdot p_{h}\left(\frac{1}{K} \cos ^{2} \Omega+\operatorname{sen}^{2} \Omega\right)$ & $\frac{1,5}{K} p_{h} \cos ^{2} \Omega$ & $3,0 \frac{A}{U} \frac{\gamma K}{\sqrt{\mu}} \operatorname{sen}^{2} \Omega$ & $p_{n 1}+p_{n 2}+p_{n 3}$ & $\mu p_{n}$ & $2 p_{h}$ & Figura (28) \\
\hline EUROCODE & $p_{v}\left(1,2 \cos ^{2} \Omega+1,5 \operatorname{sen}^{2} \Omega\right)$ & $1,2 p_{v} \cos ^{2} \Omega$ & $3,0 \frac{A}{U} \frac{\gamma K}{\sqrt{\mu}} \operatorname{sen}^{2} \Omega$ & $p_{n 3}+p_{n 2}+\left(p_{n 1}-p_{n 2}\right) \frac{x}{\ln }$ & $\mu p_{n}$ & $2 p_{h}$ & Figura (28) \\
\hline AS & ------ & $---p_{n}=k_{n} \cdot p_{v n}$ & $\mu p_{n}$ & -------- & Figura (29) \\
\hline DIN & $p_{v}\left(1,2 \cos ^{2} \Omega+K \operatorname{sen}^{2} \Omega\right.$ & $1,2 p_{v} \cos ^{2} \Omega$ & $3,0 \frac{A}{U} \frac{\gamma K}{\sqrt{\mu}} \operatorname{sen}^{2} \Omega$ & $p_{n 3}+p_{n 2}+\left(p_{n 1}-p_{n 2}\right) \frac{x}{\ln }$ & $\mu p_{n}$ & $2 p_{h}$ & Figura (28) \\
\hline
\end{tabular}

$\mathrm{p}_{\mathrm{n}}=$ pressão normal sobre a parede da tremonha

$\mathrm{p}_{\mathrm{t}}=$ pressão de atrito sobre a parede da tremonha

$p_{\mathrm{s}}=$ pressão aplicada na transição para silos com fluxo de massa

$\mathrm{p}_{\mathrm{h}}=$ equação 29 na transição

$\mathrm{p}_{\mathrm{v}}=$ equação 30 na transição

$\Omega=90^{\circ}-\alpha$

$\phi_{e}=$ efetivo ângulo de atrito interno

$\phi_{w}=$ ângulo de atrito com a parede

Obs. (2)

A pressão normal na parede $\left(p_{n}\right)$ é dada pela seguinte equação: (figura 29)

$$
\begin{aligned}
& p_{n}=k_{n} \cdot p_{v n} \\
& k_{n}=\frac{1+\operatorname{sen} \phi_{e} \cos (2 \eta)}{1-\operatorname{sen} \phi_{e} \cos [2(\alpha+\eta)]} \\
& p_{v n}=\frac{\gamma z^{\prime}}{j-1}+\left(p v-\frac{\gamma h_{c n}}{j-1}\right)\left(\frac{z^{\prime}}{h_{c n}}\right)^{j} \\
& \eta=0,5\left[\phi_{w}+\operatorname{sen}^{-1}\left(\operatorname{sen} \phi_{w} / \operatorname{sen} \phi_{e}\right)\right] \leq 90^{\circ} \\
& j=c_{h}\left[k_{n}(\mu \cot \alpha+1)-1\right]
\end{aligned}
$$

nas quais:

$\mathrm{C}_{\mathrm{h}}$ vale 2, para tremonhas cônicas ou piramidais 


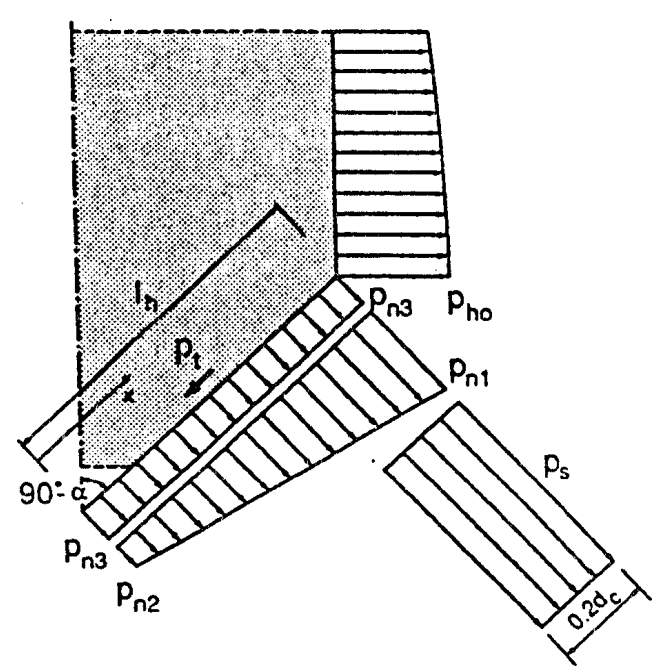

Figura 28 - Pressões sobre a tremonha conforme normas ISO, EUROCODE 1 e DIN 1055-6.

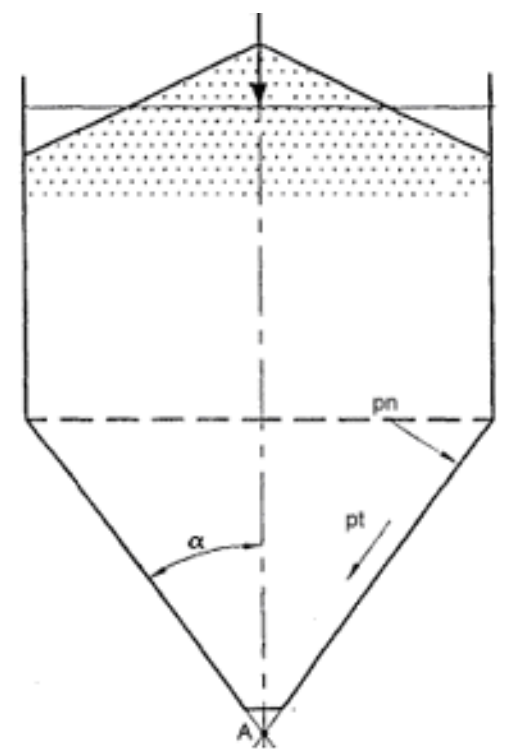

Figura 29 - Pressões sobre a tremonha conforme norma AS 3774.

\subsubsection{Pressões Adicionais}

A adoção de pressões adicionais deve-se ao fato de que pressões assimétricas são inevitáveis, mesmo para silos com carregamento concêntrico e eixo simétrico, sendo dependentes das características do produto armazenado e das imperfeições na geometria das paredes da tremonha e do silo. Do mesmo modo, heterogeneidade e mudanças probabilísticas no produto armazenado podem contribuir para flutuações na zona de fluxo. Por estas razões, os silos devem ser projetados para resistir às pressões assimétricas, tendo especial atenção aos momentos de flexão induzidos por estas pressões. 


\section{Norma ISO $11697-1995$}

A pressão adicional será considerada atuando sobre qualquer parte da parede do silo sobre uma área quadrada de lado s (figura 30):

$$
\begin{aligned}
& s=0,8 \cdot \frac{A}{U} \\
& \mathrm{p}_{\mathrm{p}}=0,2 \cdot \mathrm{p}_{\mathrm{hd}} \\
& \mathrm{p}_{\mathrm{hd}}=\text { pressão horizontal na descarga }
\end{aligned}
$$

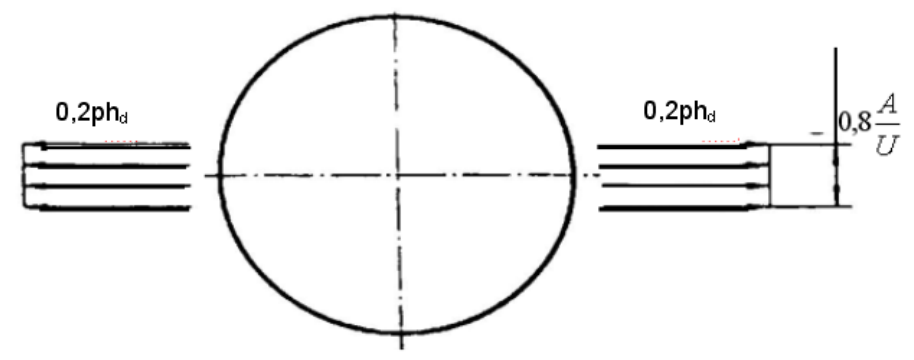

Figura 30 - Pressão adicional conforme ISO 11697.

Para o caso de descarga excêntrica menor que $0,25 \mathrm{~d}$ no caso de silos cilíndricos e menor que 0,25 a para silos retangulares, a pressão adicional (equação 138) será aumentada pelo fator $\beta$, dado pela seguinte equação:

$$
\beta=1,0+4 \frac{e}{d}
$$

Obs.: a equação 139 é valida apenas em silos onde a excentricidade (e) é menor ou igual a $0.25 \mathrm{~d}$.

$a$ = é o menor lado do retângulo;

$e=$ excentricidade da boca de descarga;

$d=$ diâmetro do silo.

\section{Norma EUROCODE 1/Part 4 - 1995}

A pressão adicional será considerada atuando sobre qualquer parte do silo, no carregamento e na descarga, sendo determinada pela seguinte equação:

$$
\begin{aligned}
& \mathrm{p}_{\mathrm{p}}=0,2 \cdot \beta \cdot \mathrm{p}_{\mathrm{he}} \quad \text { (carregamento) } \\
& \mathrm{p}_{\mathrm{p}}=0,2 \cdot \beta \cdot \mathrm{p}_{\mathrm{hd}} \quad \text { (descarga) } \\
& \beta=\begin{array}{l}
\text { equação } 139 \text { onde e é o maior valor da excentricidade devido ao } \\
\text { carregamento ou da excentricidade da boca de descarga. }
\end{array}
\end{aligned}
$$


A pressão adicional será tomada atuando sobre duas áreas quadradas opostas de lado: (figura 31).

$$
S=0,2 \cdot d
$$

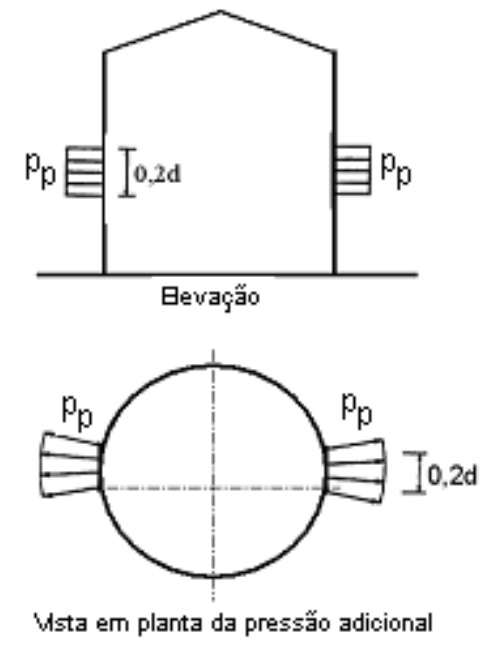

Figura 31 - Aplicação da pressão adicional

Esta norma apresenta um procedimento simplificado para levar em conta a pressão adicional para silos com diâmetro menor que 5,0m. Esse procedimento consiste em afetar as pressões atuantes por um coeficiente de ponderação.

Para silos de concreto, silos com enrijecedores e silos seção transversal não circular, a pressão são dadas por:

$$
\begin{aligned}
& p_{\text {he }}=p_{\text {he }} \cdot(1+0.2 \beta) \\
& p_{\text {hd }}=p_{\text {hd }} \cdot(1+0.2 \beta)
\end{aligned}
$$

Para silos de parede fina com seção circular, as pressões são dadas por:

$$
\begin{aligned}
& p_{\text {he }}=p_{\text {he }} \cdot(1+0.1 \beta) \\
& p_{\text {hd }}=p_{\text {hd }} \cdot(1+0.1 \beta) \\
& p_{\text {we }}=p_{\text {we }} \cdot(1+0.2 \beta) \\
& p_{w d}=p_{w d} \cdot(1+0.2 \beta)
\end{aligned}
$$

\section{Norma AS 3774 - 1996}

Esta norma prevê aumentos na pressão normal sobre a parede, quando qualquer uma das seguintes situações ocorrer: rápido carregamento, mistura pneumática, expansão do produto armazenado devido à absorção de umidade, carregamento excêntrico, sucção devido a mudanças térmicas adiabáticas, entre outras. Neste trabalho só serão tratadas as pressões adicionais devido à descarga 
excêntrica, pois é o caso mais comum e mais crítico entre as normas.

Quando um silo é projetado para ter descarga excêntrica, deverão ser consideradas pressões adicionais atuando sobre as paredes durante o fluxo. Estas pressões serão adicionadas e subtraídas, como especificado a seguir.

A parede mais afastada (diametralmente oposta à saída) estará sujeita a aumentos de pressões ao longo da altura $h_{D}$, conforme figura $32(c)$. A altura $h_{D}$ é dada pela seguinte equação:

$$
h_{D}=\left(0,5 d+e_{o}\right) \cdot \operatorname{tg} \phi_{e}
$$

O máximo aumento de pressão devido ao fluxo excêntrico será dado pela seguinte equação:

$$
p_{e x, \max }=p_{n d}\left(\frac{e_{0}}{d}-0,1\right) \geq 0
$$

Para silos circulares, o acréscimo de pressão será considerado de acordo com a distribuição proposta na figura 32(b), na qual variação da pressão será dada por:

$$
\begin{aligned}
& \text { para } \beta \text { entre } 90^{\circ} \text { e } 270^{\circ}: p_{\mathrm{ex}}=p_{\mathrm{ex}, \max }(-\cos \beta) \\
& \text { para } \beta \text { entre }-90^{\circ} \text { e } 90^{\circ}: p_{\mathrm{ex}}=0 \\
& \text { na qual, } \beta=\text { coordenada circunferencial }
\end{aligned}
$$

Para silos retangulares, o acréscimo de pressão será constante sobre o lado mais distante da boca de descarga excêntrica e igual a $p_{\text {ex,max. }}$.

A parede mais próxima da boca de descarga estará sujeita a reduções de pressões ao longo de uma altura igual ao diâmetro do silo conforme figura 32 (c). Para silos circulares, a redução de pressão será constante e se estenderá ao redor da circunferência por uma distância $d_{\mathrm{ex}} / 2$ sobre o lado mais próximo da saída.

$$
d_{e x}=1,83 d\left(1-1,43 \frac{e_{0}}{d}\right)
$$

A redução de pressão será determinada pela seguinte equação:

$$
p_{e x, r e d}=1,5 p_{n d}\left(\frac{e_{0}}{d}-0,1\right)
$$

A faixa da redução circunferencial de pressões será dada por:

$$
\beta_{e}=105-150 \frac{e_{0}}{d}
$$




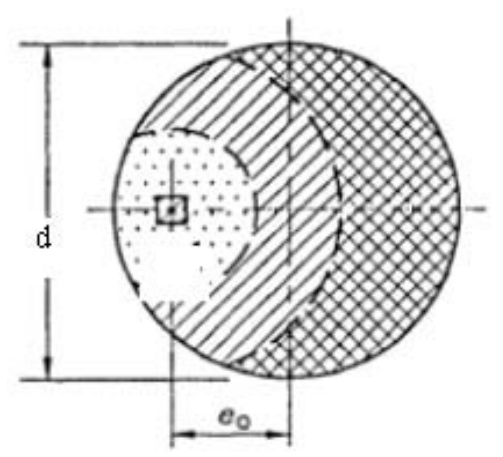

(a) Corte A - A

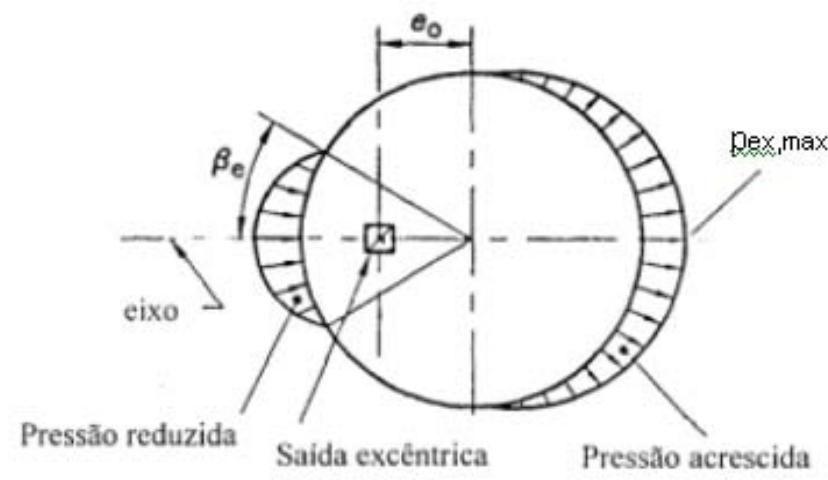

(b) variação da pressão circunferencial sobre a parede

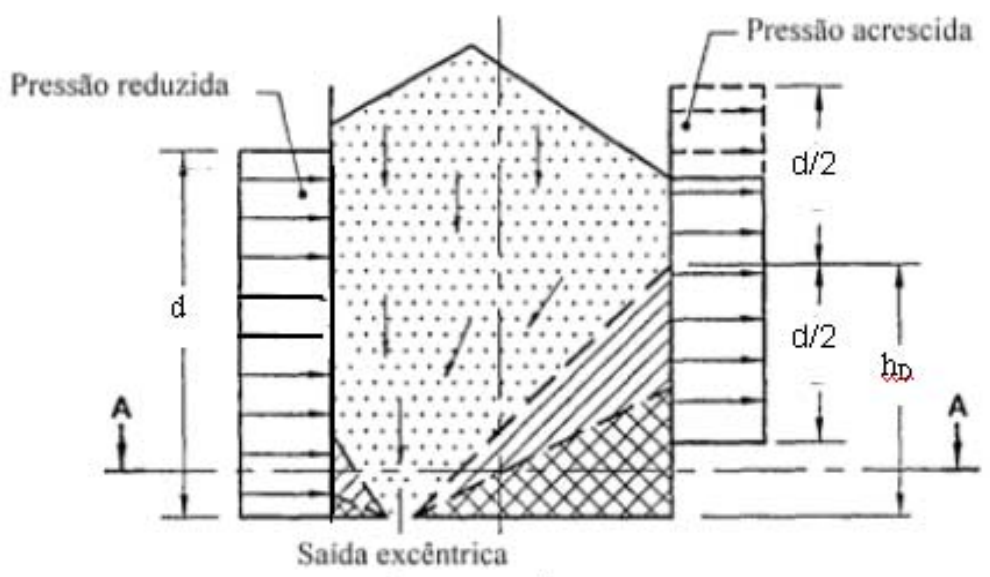

(c) Variaçẩo da pressấo sobre a parede

Figura 32 - Distribuição da pressão de descarga excêntrica

\section{Norma DIN 1055- 6 - 2000}

Adota o mesmo procedimento do EUROCODE para o cálculo das pressões adicionais no carregamento e na descarga, sendo que no procedimento simplificado não faz qualquer menção quanto ao diâmetro máximo do silo. A única alteração diz respeito à equação (139), que fornece o coeficiente $\beta$, devendo ser maior ou igual a 1 e menor ou igual a 2.

\subsection{4 - Combinações de Carregamento}

Para levar em consideração a variabilidade das propriedades do produto armazenado e para obter os valores que representam o extremo dessas propriedades, todas as normas analisadas, recomendam que os valores do coeficiente de atrito com a parede $(\mu)$ e da relação entre a pressão horizontal e a pressão vertical $(K)$ devem ter seus valores médios aumentados por um fator de conversão de 1,15 ou diminuídos 
por um fator de 0,9. Esses fatores são aplicados para produzir a combinação de carregamento mais desfavorável sobre a estrutura. Portanto, para o cálculo dos máximos carregamentos de projeto, devem ser realizadas as combinações apresentadas na tabela 5, dos parâmetros $\mathrm{K} \mathrm{e} \mu$.

TABELA 5 - Combinações dos parâmetros $\mu$ e K.

\begin{tabular}{|c|c|c|}
\hline Carregamento & $\mathbf{K}$ & $\mu$ \\
\hline $\mathbf{p h}_{\max }$ & $1,15 \mathrm{~K}_{\mathrm{m}}$ & $0,9 \mu_{\mathrm{m}}$ \\
\hline $\mathbf{p v}_{\max }$ & $0,9 \mathrm{~K}_{\mathrm{m}}$ & $0,9 \mu_{\mathrm{m}}$ \\
\hline $\mathbf{P}_{\mathbf{w}_{\max }}$ & $1,15 \mathrm{~K}_{\mathrm{m}}$ & $1,15 \mu_{\mathrm{m}}$ \\
\hline
\end{tabular}

Obs.: o índice "m" corresponde ao valor médio do parâmetro. 


\section{5 - METODOLOGIA PROPOSTA}

A pesquisa desenvolvida no presente trabalho foi constituída de três etapas principais:

1 - cálculo das pressões do produto armazenado conforme a formulação de Janssen, Walker, Walter, Jenike et al e das principais normas internacionais de modo a compara-las entre si;

2 -.elaboração de uma proposta de norma para as pressões em silos verticais esbeltos;

3 - confecção de um programa computacional de cálculo em linguagem C++ para a determinação das pressões em silos verticais esbeltos conforme a proposta de norma.

\section{1 - CÁLCULO DAS AÇÕES}

\subsection{1 - Caracterização do Produto}

Para a avaliação das pressões devidas ao produto armazenado foi realizada a determinação das propriedades físicas de uma amostra de soja e uma de painço a fim de possibilitar a comparação entre dois produtos granulares.

Os ensaios foram realizados no LaMEM/EESC/USP no equipamento de cisalhamento direto TSG 70-140 conhecido internacionalmente como Jenike Shear Tester, sendo o procedimento de ensaio utilizado o recomendado no manual Standart Shear Testing Technique for Particulate Solids Using the Jenike Shear Cell (1989) elaborado pela Federação Européia de Engenharia Química.

O ensaio foi realizado objetivando a determinação de 4 yield locus com cargas de consolidação de pré-cisalhamento iguais a $100 \mathrm{~N}, 70 \mathrm{~N}, 50 \mathrm{~N}$ e $20 \mathrm{~N}$. Para cada valor de consolidação de pré-cisalhamento, executaram-se três ensaios com cargas de consolidação de cisalhamento, correspondendo a um yield locus. A tabela 6 apresenta os níveis de carregamento de pré-cisalhamento e cisalhamento $(\mathrm{N})$. 
TABELA 6 - Níveis de carregamentos utilizados nos ensaios

\begin{tabular}{|c|c|c|c|c|c|c|c|}
\hline Yield locus 1 & Yield locus 1 & Yield locus 2 & Yield locus 2 & Yield locus 3 & Yield locus 3 & Yield locus 4 & Yield locus 4 \\
\hline $\begin{array}{c}\text { Pré } \\
\text { cisalhamento }\end{array}$ & Cisalhamento & $\begin{array}{c}\text { Pré } \\
\text { cisalhamento }\end{array}$ & Cisalhamento & $\begin{array}{c}\text { Pré } \\
\text { cisalhamento }\end{array}$ & Cisalhamento & $\begin{array}{c}\text { Pré } \\
\text { cisalhamento }\end{array}$ & Cisalhamento \\
\hline 100 & 70 & 70 & 50 & 50 & 35 & 20 & 15 \\
\hline 100 & 50 & 70 & 35 & 50 & 20 & 20 & 10 \\
\hline 100 & 35 & 70 & 20 & 50 & 10 & 20 & 5 \\
\hline
\end{tabular}

Para o ensaio do ângulo de atrito com a parede foi utilizada uma chapa de aço com rugosidade média $(\mathrm{Ra})$ de $14.8 \mu \mathrm{m}$. Os níveis de carregamentos aplicados à amostra de produto foram de $50 \mathrm{~N}, 40 \mathrm{~N}, 30 \mathrm{~N}, 20 \mathrm{~N}, 10 \mathrm{~N}$.

Por meio dos ensaios de cisalhamento do produto foram determinadas as forças de pré-cisalhamento e cisalhamento das amostras, calculando-se então as respectivas tensões de pré-cisalhamento e cisalhamento. Com os pares de valores de tensões colocados num diagrama $\sigma$ versus $\tau$, obtiveram-se os pontos de deslizamento do produto. Com a união desses pontos determinou-se a curva representativa dos lugares geométricos de deslizamento do produto e conseqüentemente o ângulo de atrito interno. Com auxílio da geometria plana, traçaram-se os círculos de tensões obtendose os efetivos lugares geométricos de deslizamento do produto e conseqüentemente o efetivo ângulo de atrito interno.

Com os pares de valores medidos de $\left(\sigma_{\mathrm{w}}, \tau_{\mathrm{w}}\right)$ no ensaio de atrito do produto com a parede plotados num diagrama $\tau_{\mathrm{w}}$ versus $\sigma_{\mathrm{w}}$, obteve-se o lugar geométrico de deslizamento do produto com a parede e conseqüentemente o ângulo de atrito cinemático com a parede.

A tabela 7 apresenta os valores das propriedades físicas determinadas para as amostras de produto.

TABELA 7 - Valores das propriedades físicas dos produtos.

\begin{tabular}{|c|c|c|c|c|c|c|c|c|c|c|c|c|}
\hline \multirow{2}{*}{ Produto } & \multicolumn{3}{|c|}{ Peso Específico $\left(\mathrm{kN} / \mathrm{m}^{3}\right)$} & \multicolumn{3}{|c|}{ Atrito Interno } & \multicolumn{3}{|c|}{ Efetivo Atrito Interno } & \multicolumn{3}{|c|}{ Aço Rugoso } \\
\hline & $\gamma_{\mathrm{i}}$ & $\gamma \mathrm{s}$ & $\gamma \mathrm{m}$ & $\phi \mathrm{ii}$ & фis & dim & фei & pes & $\phi \mathrm{em}$ & $\phi$ wi & $\phi w s$ & pws \\
\hline Painço & 6,1 & 6,2 & 6,15 & 23 & 25 & 24 & 23 & 25 & 24 & 12 & 14 & 13 \\
\hline Soja & 5,8 & 6,4 & 6,1 & 33 & 36 & 34,5 & 35 & 37 & 36 & 13 & 15 & 14 \\
\hline
\end{tabular}




\subsection{2 - Geometria do Silo}

A estrutura do silo analisado é cilíndrica, em aço, e composta por chapas laterais corrugadas e colunas (montantes), apoiadas sobre uma base de concreto, sendo que a retirada do produto é realizada por uma tremonha com forma cônica.

Para o cálculo das pressões foram consideradas duas inclinações de tremonha: $45^{\circ}$ e $35^{\circ}$. A primeira corresponde a uma inclinação muito utilizada em silos e corresponde a análise para silos com fluxo de funil. Já a segunda foi determinada pela equação (4) sugerida por McLEAN (1986), visando a obtenção de fluxo de massa para a pior situação (soja) como se pode inferir a seguir:

$$
\begin{aligned}
& \alpha_{c r i t}=0,5\left[180-\cos ^{-1}\left(\frac{\left(1-\operatorname{sen} \phi_{e}\right)}{2 \operatorname{sen} \phi_{e}}\right)-\left(\phi_{w}+\operatorname{sen}^{-1}\left(\frac{\operatorname{sen} \phi_{w}}{\operatorname{sen} \phi_{e}}\right)\right)\right] \\
& \alpha_{c r i t}=0,5\left[180-\cos ^{-1}\left(\frac{(1-\operatorname{sen} 36)}{2 \operatorname{sen} 36}\right)-\left(14+\operatorname{sen}^{-1}\left(\frac{\operatorname{sen} 14}{\operatorname{sen} 36}\right)\right)\right] \\
& \alpha_{c r i t}=36^{\circ}
\end{aligned}
$$

Valor adotado: $\alpha=35^{\circ}$.

A tabela 8 apresenta as dimensões dos silos analisados e a figura 33 apresenta um desenho esquemático.

TABELA 8 - Dimensões dos silos.

\begin{tabular}{|c|c|c|c|c|c|c|c|c|c|}
\hline \multirow{2}{*}{ Silo } & \multicolumn{9}{|c|}{ Dimensões (m) } \\
\cline { 2 - 11 } & hcob & hc & ht & htot & d & b & $\alpha$ & h & h/d \\
\hline Fluxo Massa & 2,65 & 13,8 & 6,25 & 24,05 & 9,1 & 0,4 & $35^{\circ}$ & 20,93 & 2,30 \\
\hline Fluxo Funil & 2,66 & 13,9 & 4,35 & 24,06 & 9,1 & 0,4 & $45^{\circ}$ & 19,03 & 2,09 \\
\hline
\end{tabular}



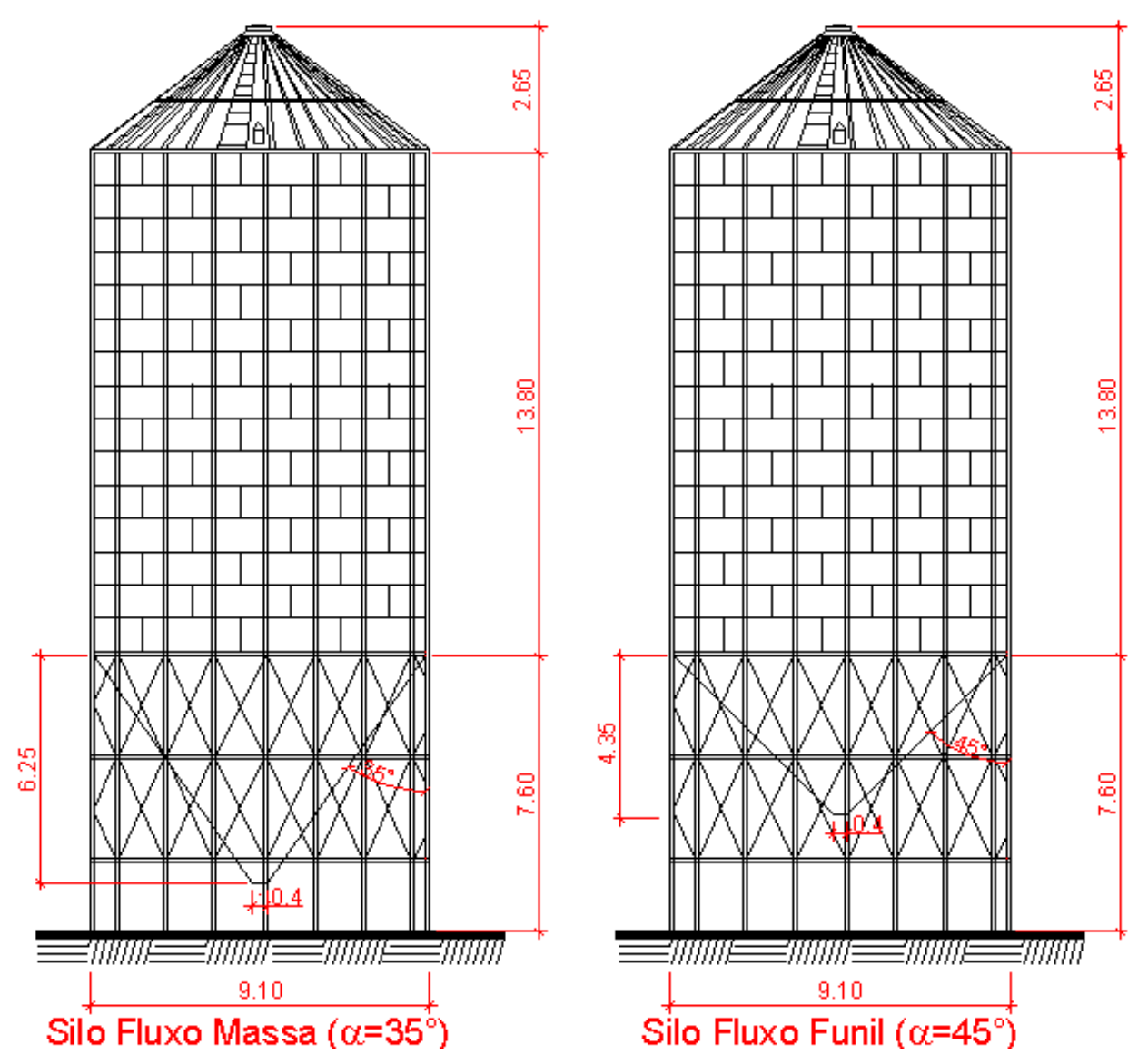

Figura 33 - Dimensões dos silos analisados.

\subsection{3 - Silo com fluxo de massa}

Para o cálculo das pressões foram utilizadas as teorias de JANSSEN (1895), WALKER (1966) e JENIKE $(1968,1973,1977)$ e as normas ISO 11697 (1995), EUROCODE 1/Part 4 (1995), AS 3774 (1996) e DIN 1005-6 (2000).

A teoria de WALTERS (1973) não pôde ser utilizada, pois se restringe a pequenas inclinações de tremonha, conforme pode ser constatado com a aplicação dos limites dados pelas equações 47 e 48.

Para o cálculo das pressões pelas teorias foram utilizados os valores médios das propriedades físicas dos produtos armazenados obtidas em laboratório. Para o cálculo das pressões segundo as normas, foram realizadas as combinações para obter os carregamentos mais desfavoráveis sobre a estrutura, conforme apresentado no item 4.3.4.

Para o cálculo das pressões no corpo do silo, tendo em vista que as paredes do silo analisadas são de chapa metálica corrugada, o ângulo de atrito com a parede foi considerado igual ao ângulo de atrito interno. Já para o cálculo das pressões na tremonha foi utilizado o ângulo de atrito com a parede apresentado na tabela 7 . 


\subsubsection{1 - Pressão Horizontal - Situação de Carregamento ou Inicial}

Os gráficos das figuras 34 e 35 ilustram as pressões horizontais iniciais conforme os autores e normas para os dois produtos analisados.

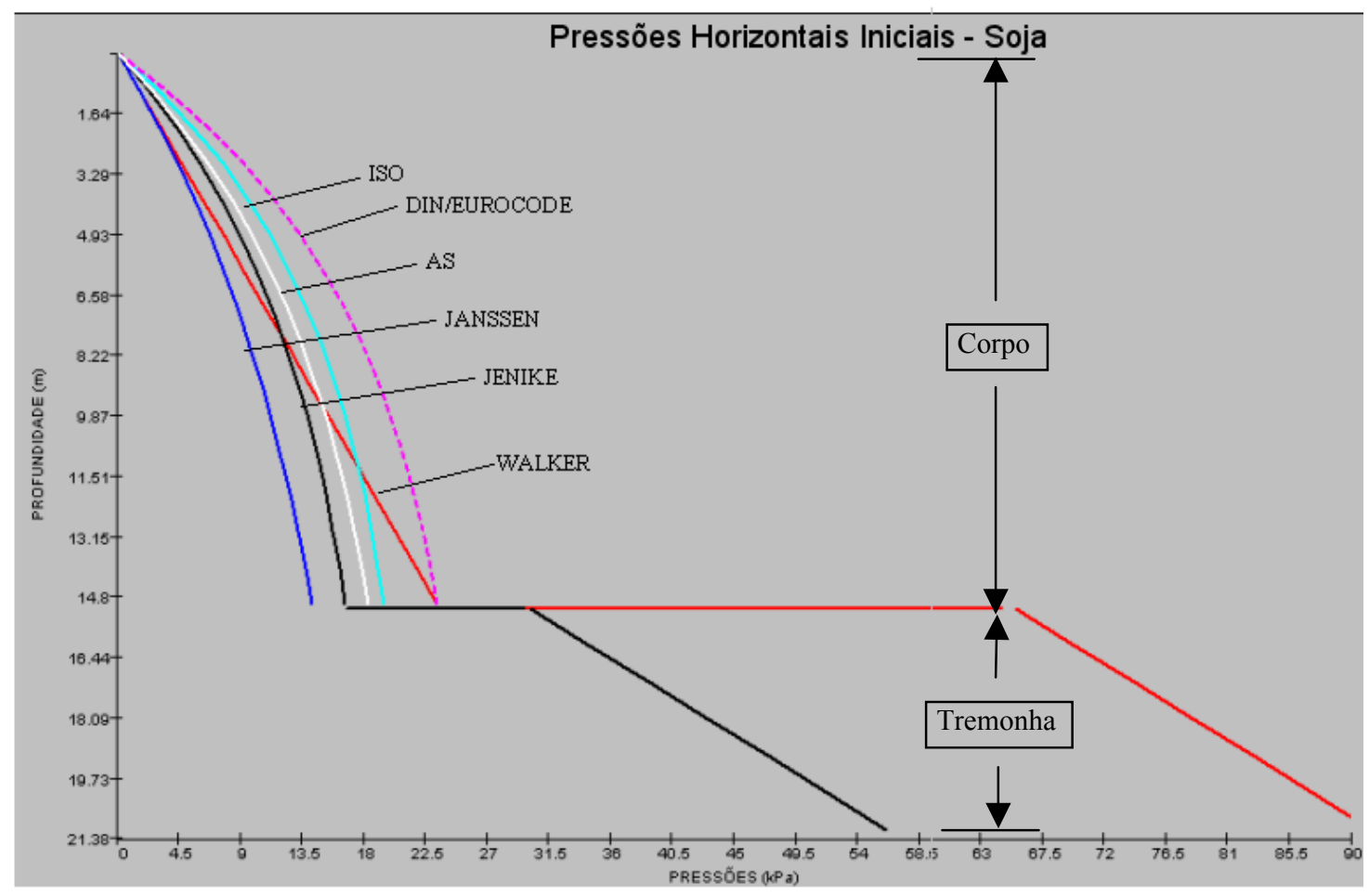

Figura 34 - Pressão horizontal inicial - Soja

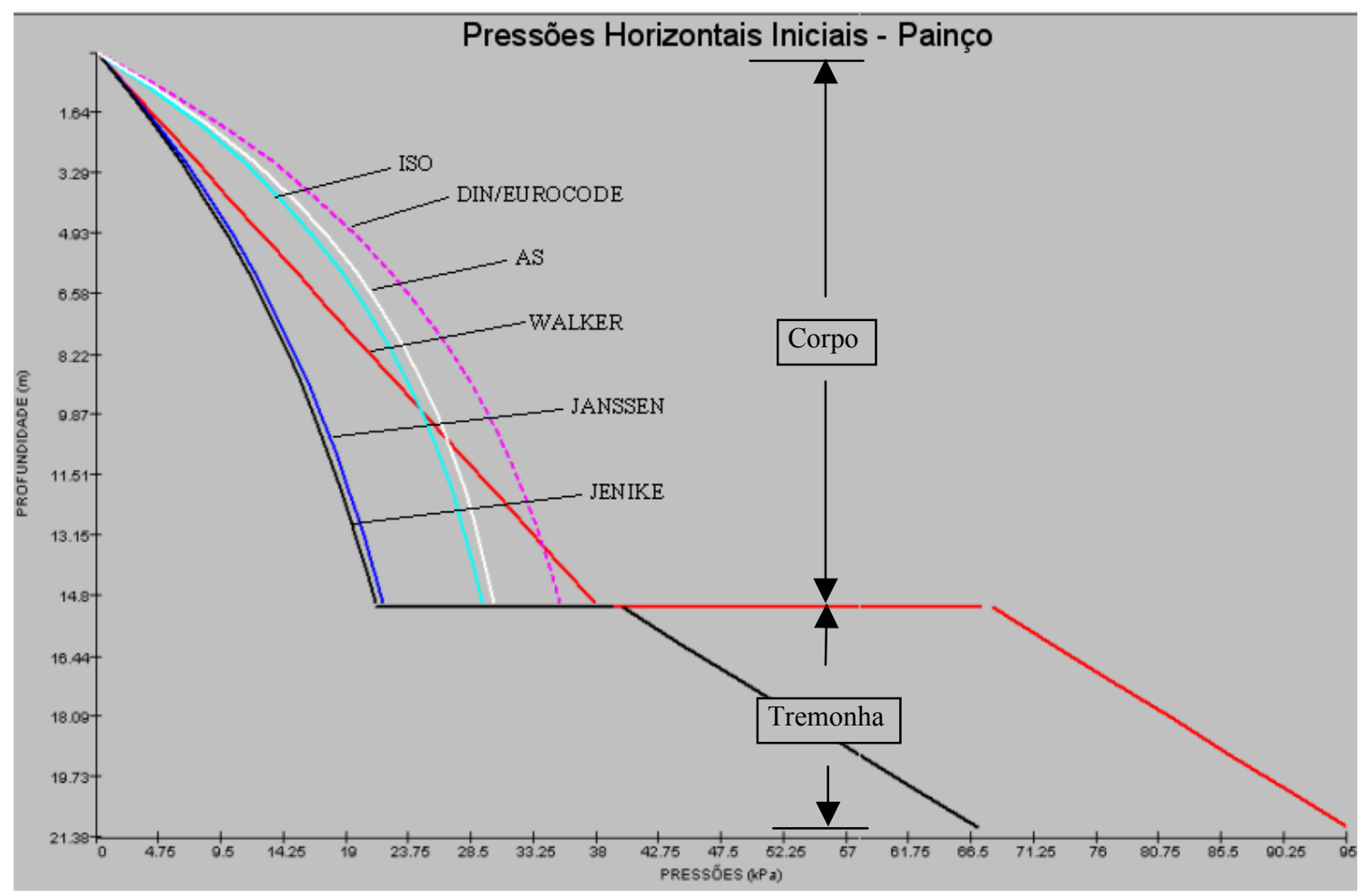

Figura 35 - Pressão horizontal inicial - Painço 
Pela análise conjunta dos gráficos 34 e 35 constata-se que as pressões horizontais iniciais sobre as paredes do silo quando se armazena painço são maiores do que quando se armazena soja. Isso é devido principalmente ao painço apresentar ângulos de atrito mais baixos, o que ocasiona maiores pressões horizontais.

As normas DIN e EUROCODE apresentam pressões no corpo do silo coincidentes e também são as fornecem maiores valores em relação às outras normas e teorias estudadas. Como todas normas adotam a formulação de JANSSEN, o motivo pelo qual as normas DIN e EUROCODE apresentam pressões mais elevadas em relação as demais (ISO e AS) é devido as mesmas recomendarem a adoção de pressões adicionais também na fase de carregamento. Em relação às teorias estudadas, as normas resultam na maioria das vezes em valores superiores devido a: formulação utilizada no cálculo de $K$; combinações com as propriedades físicas para obter os carregamentos máximos e; adoção de pressões adicionais em alguns casos.

Com relação às pressões horizontais iniciais na tremonha, observa-se que a teoria de WALKER é sempre superior e em torno de $50 \%$ a teoria de JENIKE. Conforme constatado por GAYLORD \& GAYLORD (1984), a teoria de WALKER superestima as pressões iniciais na tremonha.

Para a soja, a teoria de JANSSEN é a que apresenta menores pressões e na profundidade máxima do corpo do silo, a teoria de WALKER é a que apresenta maiores pressões, sendo que, até meia altura do corpo do silo, aproximadamente, as maiores pressões são obtidas pela teoria de JENIKE.

Para o painço, as teorias de JANSSEN e JENIKE são as que apresentam menores valores no corpo do silo. Essas duas teorias são praticamente coincidentes nessa situação devido ao ângulo de atrito interno do painço resultar em um valor para o parâmetro $K$ muito próximo a 0,4 que é o valor recomendado pela teoria de JENIKE para o cálculo das pressões iniciais (Tabela 9). Observa-se também, que a teoria de WALKER é sempre superior as outras duas teorias.

\subsubsection{2 - Pressão Horizontal - Situação de Descarga ou Dinâmica}

Os gráficos das figuras 36 e 37 ilustram as pressões horizontais dinâmicas conforme os autores e normas para os dois produtos analisados. 


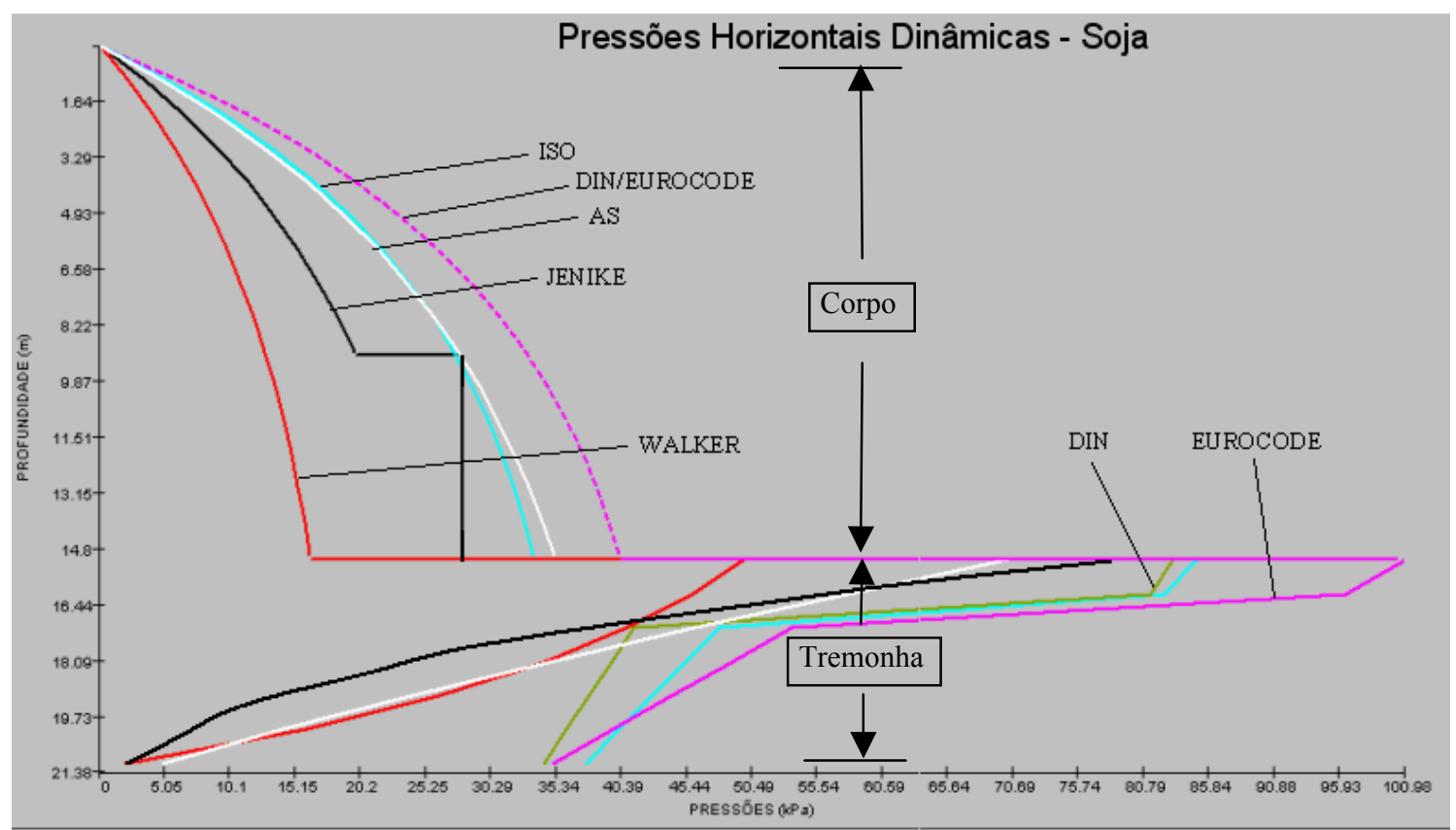

Figura 36 - Pressão horizontal dinâmica - Soja

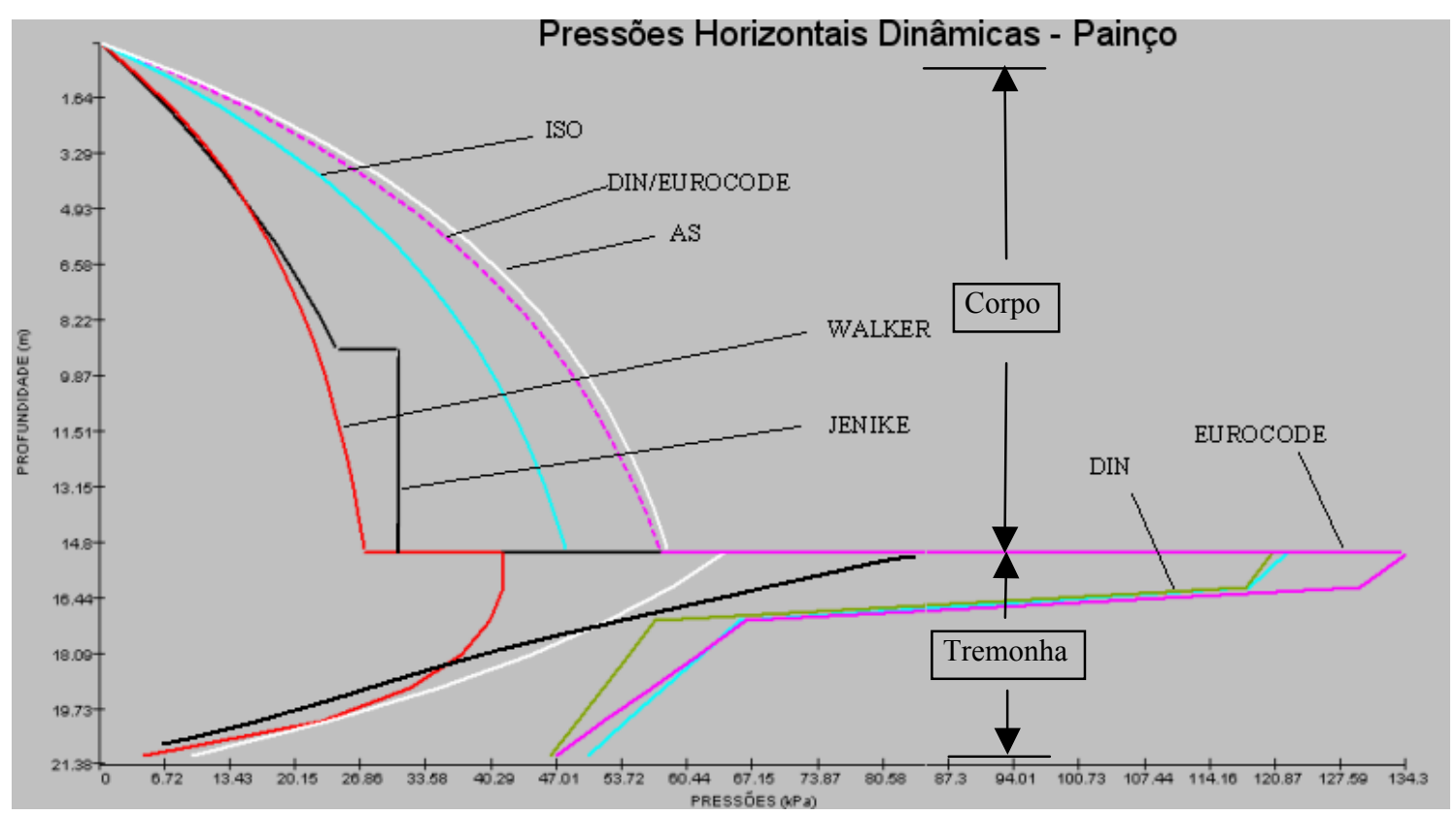

Figura 37 - Pressão horizontal dinâmica - Painço

Assim como para as condições iniciais, as pressões horizontais dinâmicas são maiores quando se armazena painço do que quando soja.

A teoria de WALKER é a que apresenta menores valores para o corpo do silo para ambos produtos. Para a soja as normas DIN e EUROCODE resultam em maiores pressões no corpo do silo, enquanto que para o painço é a norma AS. Esses valores elevados alcançados com a norma AS são devidos principalmente ao alto valor calculado para o parâmetro $K$, assim como, do coeficiente de sobrepressão (Tabela 9). 
TABELA 9 - Coeficientes de Sobrepressão e parâmetro $K$.

\begin{tabular}{|c|c|c|c|c|}
\hline \multirow{2}{*}{ Norma/Teoria } & \multicolumn{2}{|c|}{ Coef. Sobrepressão (C) } & \multicolumn{2}{|c|}{ K } \\
\cline { 2 - 5 } & Soja & Painço & Soja & Painço \\
\hline EUROCODE & 1,47 & 1,35 & 0,453 & 0,653 \\
\hline DIN & 1,47 & 1,35 & 0,453 & 0,653 \\
\hline ISO & 1,47 & 1,35 & 0,453 & 0,653 \\
\hline AS & 1,6 & 1,6 & 0,380 & 0,716 \\
\hline JENIKE & --- & --- & 0,400 & 0,400 \\
\hline WALKER & --- & --- & 0,260 & 0,422 \\
\hline
\end{tabular}

Pela tabela 9 constata-se que o coeficiente de sobrepressão recomendado pela norma AS tem o mesmo valor para ambos os produtos devido ao seu equacionamento ter somente como variável a relação altura/diâmetro. Para as normas ISO, DIN e EUROCODE, o efetivo ângulo de atrito interno é o principal parâmetro que influencia no equacionamento, sendo que quanto maior seu valor maior será o coeficiente de sobrepressão.

Outra constatação, diz respeito a preocupação das normas ISO, DIN e EUROCODE em resultar valores elevados para a pressão horizontal. Isso fica evidente ao analisarmos o parâmetro $K$ em conjunto com o coeficiente de sobrepressão C.

Ao se comparar os picos de pressões na transição pela teoria de JENIKE em relação à de WALKER constata-se que a $1^{\mathrm{a}}$ é 1,56 vezes maior que a $2^{\mathrm{a}}$ para a soja e 2 vezes para o painço.

Na tabela 10 é apresentada a relação entre a pressão horizontal calculada para a tremonha pela pressão horizontal calculada para o corpo do silo na transição.

TABELA 10 - Comparativo de pressões na transição.

\begin{tabular}{|c|c|c|}
\hline \multirow{2}{*}{ Norma/Teoria } & \multicolumn{2}{|c|}{ Produto } \\
\cline { 2 - 3 } & Soja & Painço \\
\hline EUROCODE & 2,46 & 2,34 \\
\hline DIN & 2,02 & 2,12 \\
\hline ISO & 2,54 & 2,52 \\
\hline AS & 2,08 & 1,17 \\
\hline JENIKE & 2,88 & 2,89 \\
\hline WALKER & 3,34 & 1,61 \\
\hline
\end{tabular}

Pela análise da tabela 10 constata-se que as normas ISO, DIN e EUROCODE amplificam a pressão horizontal na transição de 2 a 2,5 vezes e a teoria de JENIKE amplifica próximo de 2,88 vezes para ambos os produtos, enquanto que WALKER decai de 3,34 (soja) para 1,61 (painço) e a norma AS decai de 2,08 (soja) para 1,17 (painço).

A norma EUROCODE é a menos suscetível a variação nas propriedades físicas e a que apresenta maiores pressões na transição. A justificativa por apresentar pressões mais elevadas se deve ao EUROCODE resultar em maiores valores para a 
pressão horizontal inicial, o que resulta em maiores valores para a pressão localizada, como também, devido ao equacionamento para a determinação da pressão no enchimento da tremonha $\left(p_{n 1}\right)$.

$\mathrm{Na}$ transição, a norma AS resultou para ambos produtos em valores intermediários as teorias de JENIKE e WALKER, sendo também, a que apresentou menores valores para as pressões entre as normas analisadas.

Na tabela 11 apresenta-se a comparação entre a pressão de pico dada pela norma EUROCODE (pressões mais elevadas) em relação as demais.

TABELA 11 - Pressão na transição: EUROCODE versus Normas e Teorias.

\begin{tabular}{|c|c|c|}
\hline \multirow{2}{*}{ Norma/Teoria } & \multicolumn{2}{|c|}{ EUROCODE } \\
\cline { 2 - 3 } & Soja & Painço \\
\hline DIN & 1,22 & 1,11 \\
\hline ISO & 1,21 & 1,10 \\
\hline AS & 1,43 & 2,08 \\
\hline JENIKE & 1,28 & 1,54 \\
\hline WALKER & 2,02 & 3,32 \\
\hline
\end{tabular}

Pela análise da tabela 11 constata-se que o aumento da pressão na transição da norma EUROCODE em relação às normas ISO e DIN é próximo de $20 \%$ para a soja e de $10 \%$ para o painço; em relação a AS chega a $43 \%$ e $108 \%$ respectivamente. Com relação à teoria de JENIKE, esse aumento vai de $28 \%$ até $54 \%$, enquanto que em relação a teoria de WALKER chega a duplicar. Isso ilustra a variabilidade (incerteza) nas recomendações para a determinação da pressão na transição do corpo do silo para a tremonha tanto por pesquisadores como pelas normas analisadas.

\subsubsection{3 - Força de Atrito - Situação de Descarga ou Dinâmica}

Os gráficos das figuras 38 e 39 ilustram as forças de atrito dinâmicas conforme os autores e normas para os dois produtos analisados. 


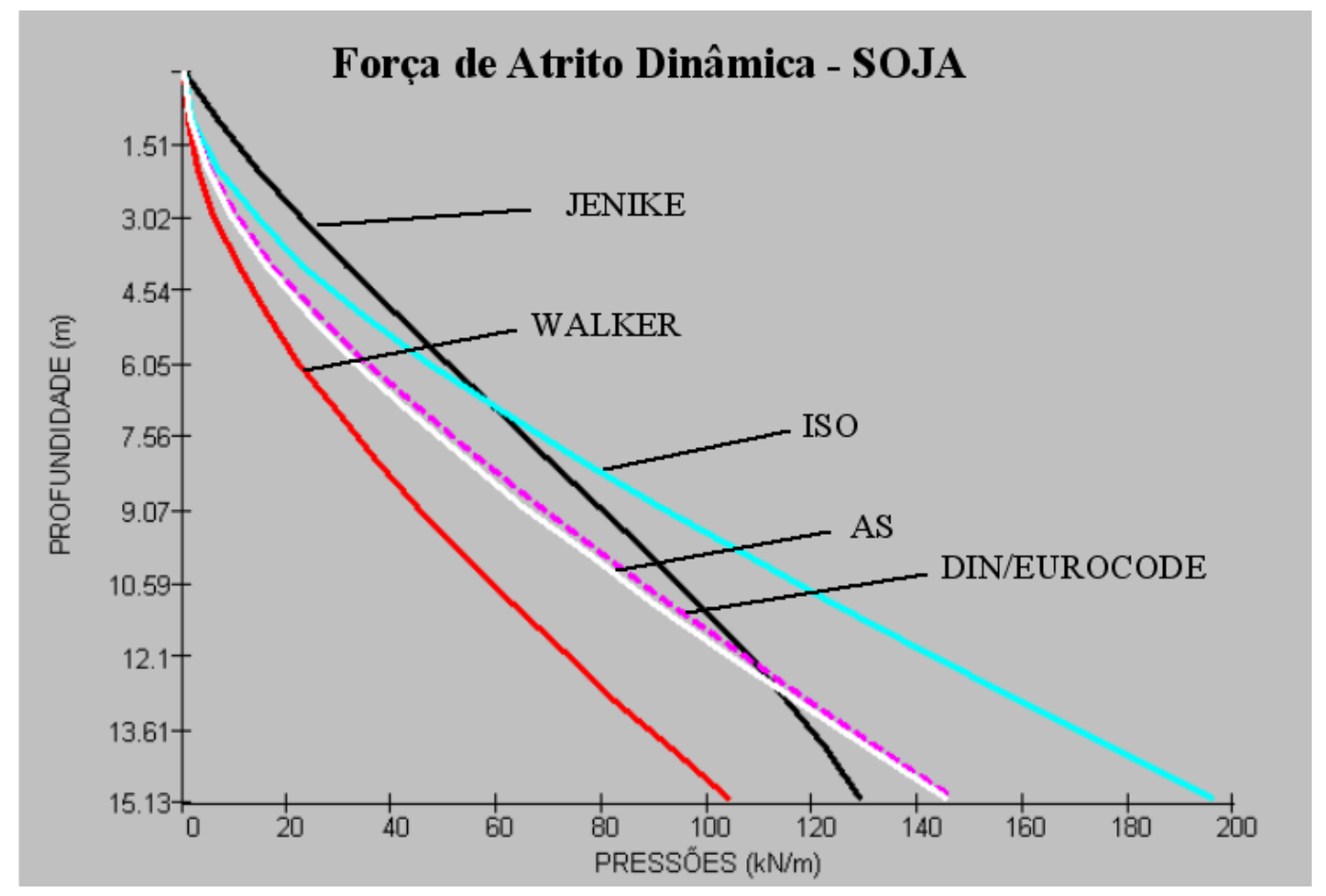

Figura 38 - Força de atrito dinâmica - Soja

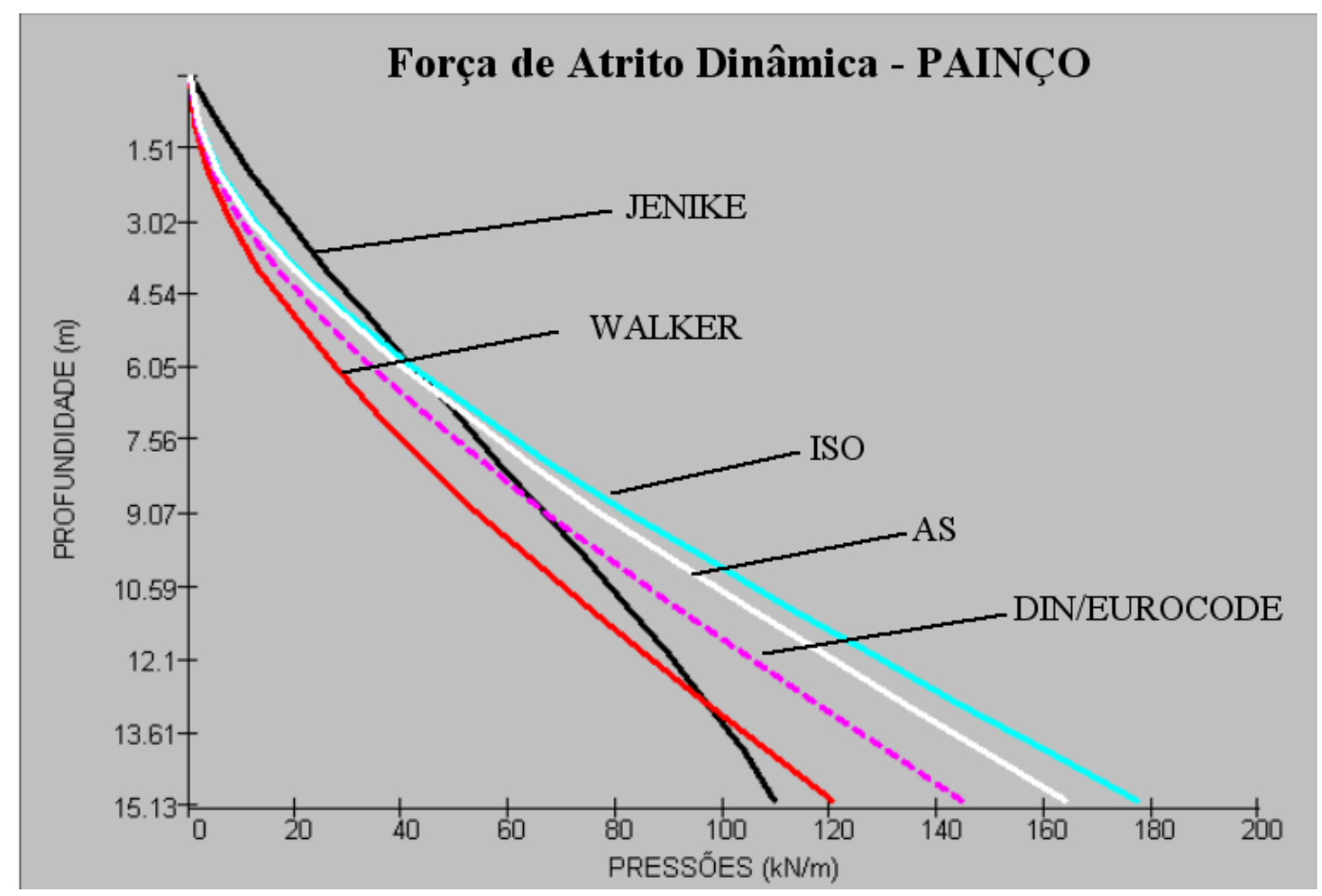

Figura 39 - Força de atrito dinâmica - Painço

Analisando-se os gráficos das figuras 38 e 39 observa-se que a força de atrito dinâmica obtida por meio da formulação de WALKER é a que apresenta menores valores e a obtida pela norma ISO os maiores para os dois produtos analisados.

Ao se comparar a norma EUROCODE com as outras normas e teorias temos a tabela 12 onde pode-se constatar grandes diferenças nos resultados da força de atrito 
dinâmica no final do corpo do silo. O coeficiente de sobrepressão aplicado as normas DIN e EUROCODE $(C=1.1)$ é o responsável pela diferença em relação às normas ISO $(C=1.35$ para o painço e $C=1.47$ para a soja) e $A S(C=1.2)$. Nota-se aqui, novamente, a grande variabilidade das recomendações tanto por pesquisadores como pelas normas.

TABELA 12 - Força de Atrito norma EUROCODE versus Normas e Teorias

\begin{tabular}{|c|c|c|}
\hline \multirow{2}{*}{ Norma/Teoria } & \multicolumn{2}{|c|}{ EUROCODE } \\
\cline { 2 - 3 } & Soja & Painço \\
\hline DIN & 1,00 & 1,00 \\
\hline ISO & 0,76 & 0,81 \\
\hline AS & 1,01 & 0,88 \\
\hline JENIKE & 1,13 & 1,31 \\
\hline WALKER & 1,37 & 1,20 \\
\hline
\end{tabular}

Determinou-se também, a pressão vertical na base para o caso do silo ter fundo plano $(\mathrm{h} / \mathrm{d}=1.66)$. Os resultados são ilustrados na tabela 13.

TABELA 13 - Pressões verticais no fundo do silo

\begin{tabular}{|c|c|c|}
\hline \multirow{2}{*}{ Norma/Teoria } & \multicolumn{2}{|c|}{ pVbase $(\mathrm{kPa})$} \\
\cline { 2 - 3 } & Soja & Painço \\
\hline ISO & 64 & 62 \\
\hline DIN/EUROCODE & 53 & 55 \\
\hline AS & 61 & 54 \\
\hline JANSSEN & 51 & 52 \\
\hline JENIKE & 42 & 53 \\
\hline WALKER & 91 & 91 \\
\hline
\end{tabular}

Pela análise da tabela 13 constata-se que WALKER resulta em valores muito elevados e que JENIKE é o que apresenta os menores valores. A diferença nos resultados entre as normas, para ambos os produtos, é devido aos diferentes coeficientes recomendados pelas normas $(C=1.35$ para o painço e $C=1.47$ para a soja), DIN e EUROCODE ( $C=1.2)$ e AS ( $C=$ =equacionamento variável). Mais uma vez, constata-se diferenças significativas nas recomendações propostas pelas normas internacionais.

\subsection{3 - Silo com fluxo de funil}

Para o cálculo das pressões foram utilizadas as teorias de JANSSEN (1895) e JENIKE $(1968,1973,1977)$ e as normas ISO 11697 (1995), EUROCODE 1/Part 4 (1995), AS 3774 (1996) e DIN 1005-6 (2000).

As teorias de WALKER (1966) e WALTERS (1973) não puderam ser aplicadas, pois são limitadas a silos com fluxo de massa.

Para o cálculo das pressões pelas teorias foram utilizados os valores médios das propriedades físicas dos produtos armazenados. Para o cálculo das pressões 
segundo as normas, foram realizadas as combinações para obter os carregamentos mais desfavoráveis sobre a estrutura, conforme apresentado no item 4.3.4.

Do mesmo modo, para o cálculo das pressões no corpo do silo, tendo em vista que as paredes do silo analisadas são de chapa metálica corrugada, o ângulo de atrito com a parede foi considerado igual ao ângulo de atrito interno. Já para o cálculo das pressões na tremonha foi utilizado o ângulo de atrito com a parede apresentado na tabela 7.

A seguir se apresentam nos gráficos nas figuras 40 e 41 as pressões horizontais conforme os autores e normas para os dois produtos analisados.

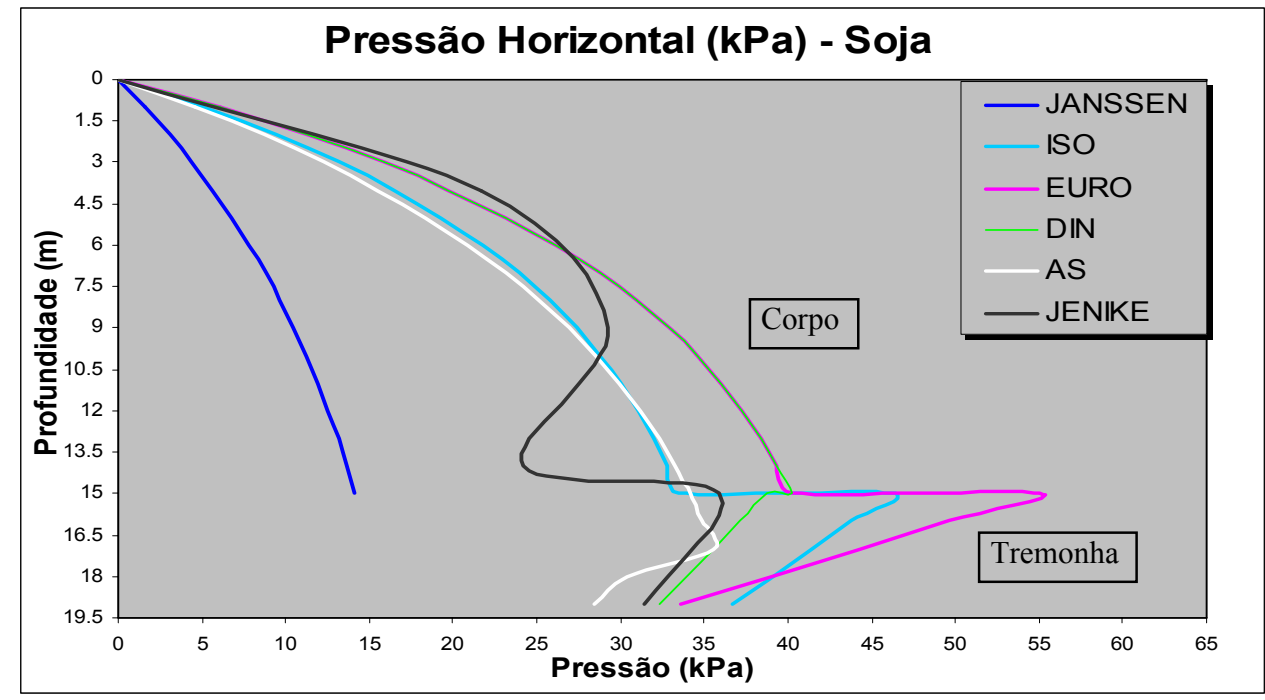

Figura 40 - Pressão Horizontal - Fluxo de Funil - Soja

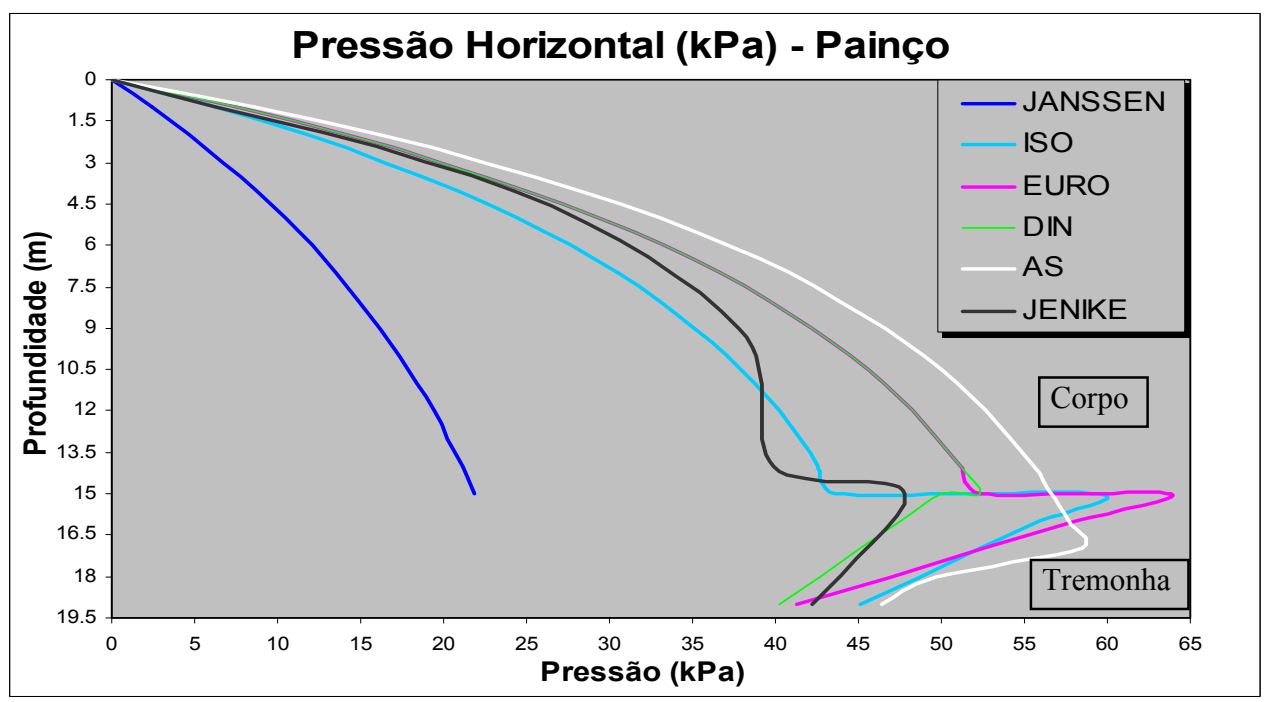

Figura 41 - Pressão Horizontal - Fluxo de Funil - Painço

Como ocorreu na análise do silo com fluxo de massa, as pressões horizontais dinâmicas são maiores quando se armazena painço do que quando soja.

Apesar de várias pesquisas apontarem que o pico de pressão em silos com fluxo de funil não ocorre na transição do corpo para a tremonha, as normas ISO e 
EUROCODE ainda consideram picos de pressão nessa região. Isso demonstra a preocupação (incertezas) na ocorrência do tipo de fluxo.

Como as normas analisadas não fazem diferenciação para as pressões no corpo do silo em função do tipo de fluxo, as pressões são as mesmas que para análise do silo com fluxo de massa. A única exceção é a norma AS que recomenda que no ponto onde ocorre a transição efetiva, o coeficiente de sobrepressão seja máximo e a partir daí reduzido, porém não fornece a localização da transição efetiva.

$\mathrm{Na}$ transição, para ambos produtos, a norma EUROCODE é a que fornece maiores valores, enquanto que o menor valor é dado pela teoria de JENIKE para o painço e pela norma AS para a soja.

Com o objetivo de avaliar a magnitude da pressão localizada aplicada na transição em silos com fluxo de massa é apresentada na tabela 14 os valores da relação da pressão na transição no silo com fluxo de massa pela pressão na transição do silo com fluxo de funil.

TABELA 14 - Relação entre pressões na transição: fluxo massa versus fluxo funil

\begin{tabular}{|c|c|c|}
\hline \multirow{2}{*}{ Norma/Teoria } & \multicolumn{2}{|c|}{ Produto } \\
\cline { 2 - 3 } & Soja & Painço \\
\hline EUROCODE & 1,84 & 2,06 \\
\hline DIN & 2,08 & 2,26 \\
\hline ISO & 1,85 & 2,02 \\
\hline AS & 2,05 & 1,10 \\
\hline JENIKE & 2,16 & 1,87 \\
\hline
\end{tabular}

Pela análise da tabela 14, constata-se que a aplicação da pressão localizada praticamente duplica o valor da pressão na transição do corpo do silo para a tremonha.

\section{2 - PROPOSTA DE NORMA BRASILEIRA}

Com base no estudo desenvolvido propõe-se a adoção das recomendações propostas pela norma DIN 1055-6 - 2000 para a avaliação das pressões adicionais e da norma EUROCODE 1/Part 4 - 1995 para a determinação das pressões de carregamento e descarga em silos verticais esbeltos $(h / d>1.5)$ pelos seguintes motivos:

- são as normas mais utilizadas atualmente na determinação das pressões devidas ao produto armazenado;

- englobam o efeito de pressões assimétricas (adicionais) tanto no carregamento como na descarga. Além disso, facilitam a sua determinação 
ao propor um procedimento simplificado, sendo que a norma DIN1055-6 não limita sua aplicação em função do diâmetro do silo.

- tanto a norma DIN1055-6 como principalmente o EUROCODE 1/Part 4 foram conservadoras tanto para as pressões horizontais no corpo do silo como para as pressões na tremonha.

Em anexo são apresentadas as recomendações para a determinação das ações devidas ao produto armazenado para silos verticais esbeltos baseadas nas normas DIN1055-6 e EUROCODE 1/Part 4. Além disso, são propostas combinações de ações fundamentadas na NBR 8681:2003, AS 3774:1996 e CALIL \& NASCIMENTO (1997).

\section{3 - PROGRAMA DE CÁlCULO}

Com base na proposta de norma brasileira foi desenvolvido um programa para a determinação das pressões devidas ao produto armazenado em silos verticais esbeltos.

$\mathrm{Na}$ implementação do programa foi utilizado o compilador Borland C++ Builder 5.0 tendo em vista que seu uso tem aumentado amplamente, e hoje está entre as linguagens mais utilizadas na indústria tecnológica.

A opção por este tipo de linguagem foi devida a linguagem $\mathrm{C}++$ ser grandemente utilizada em ensino e pesquisa, apesar de muitos acreditarem não ser esta a linguagem mais clara existente. No entanto, segundo STROUSTRUP apud LINDQUIST(2002) ela é:

- limpa o suficiente para um ensino bem sucedido de conceitos básicos;

- prática, eficiente e flexível o suficiente para atender aos projetos necessários;

- suficientemente acessível para organizações e colaborações nos seus diversos ambientes de execução e desenvolvimento;

- suficientemente compreensível para ser um veículo para ensinar conceitos avançados e técnicas, e

- comercial o suficiente para ser utilizada fora do ambiente acadêmico.

A estrutura do programa baseia-se em uma única tela de entrada de dados e saída de resultados conforme ilustrado na figura 42. Na entrada de dados devem ser informadas todas as características geométricas do silo e as propriedades físicas do produto armazenado. 


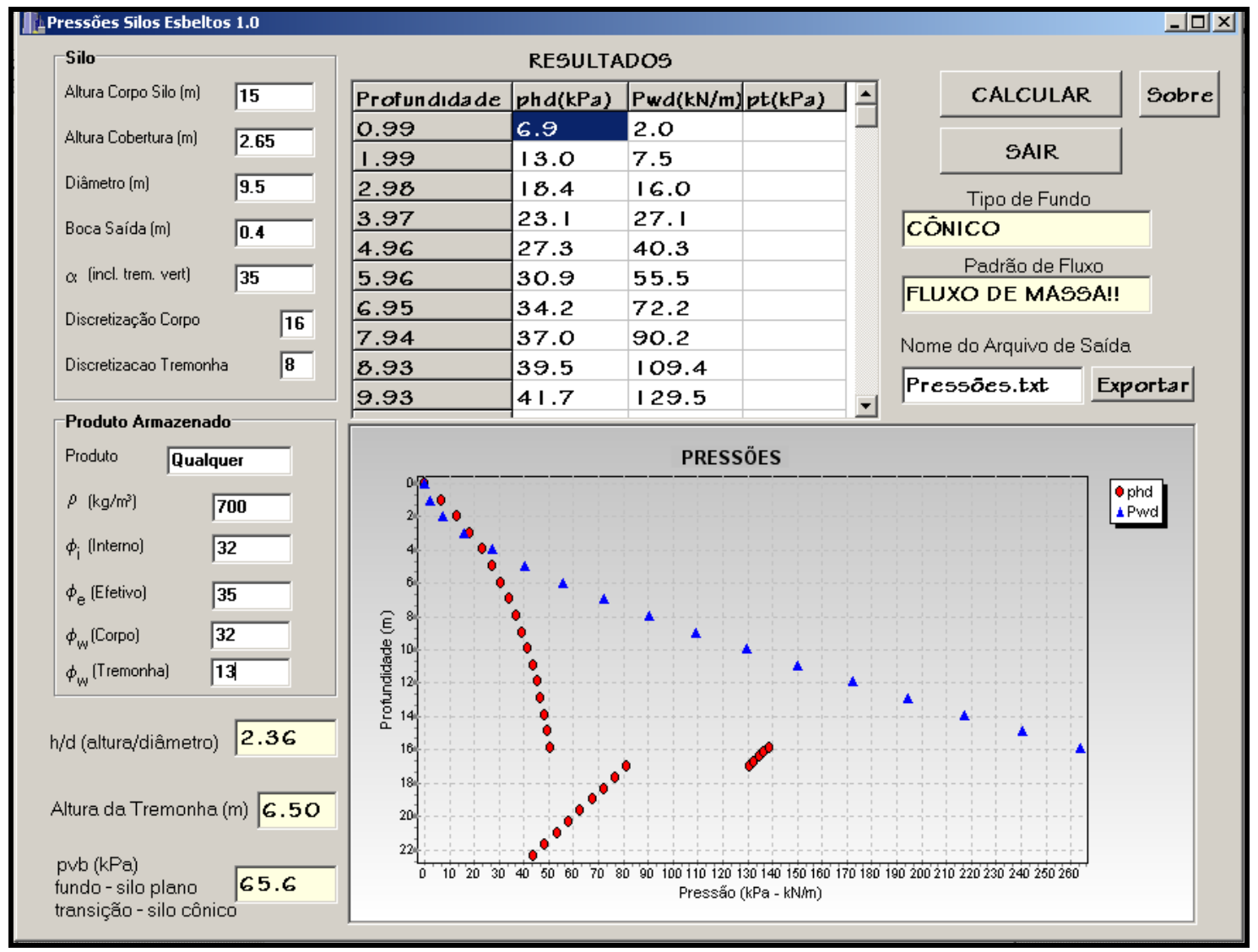

Figura 42 - Tela do programa para cálculo de pressões

O programa calcula as pressões devidas ao produto armazenado para silos com fundo plano e fundo cônico (tremonha). Sendo que para esse último caso, as pressões são calculadas em função do padrão de fluxo que vai ocorrer. A estimativa do padrão de fluxo foi realizada pelo equacionamento proposto por McLEAN (1986) apresentado no capitulo de Fluxo.

A saída de dados é realizada por meio da apresentação dos resultados (pressões) na forma de tabela e também na forma gráfica. Os dados de entrada e os resultados podem ser gravados em um arquivo com extensão “. txt” para arquivamento ou impressão por meio do botão "Exportar".

Possui ainda, uma tela adicional acessada por meio do botão "Sobre", a qual fornece informações sobre o programa, bem como, suas limitações de aplicação. 


\section{6 - CONCLUSÕES}

Apesar dos avanços no cálculo das ações do produto armazenado em silos, ainda existem muitos pontos a serem esclarecidos, especialmente com respeito à descarga do produto.

A pressão de pico da formulação de Jenike considera altos esforços de tração no anel no ponto da transição. Esses efeitos, devidos à ação do produto armazenado, não são adequadamente considerados na distribuição de pressão quando se utiliza o equacionamento de JANSSEN, particularmente se é pretendido um projeto no regime elástico. Esses picos, algumas vezes maiores que as pressões no corpo do silo, são levados em conta pelas normas, por meio da adoção de pressões localizadas na transição do corpo do silo com a tremonha.

Além de ter a simplicidade de uma equação analítica, o equacionamento de JANSSEN é apontado por muitos pesquisadores, como JENIKE \& JOHANSON (1973), ARNOLD et al (1980), BENINK (1989), CARSON \& JENKIN (1993) entre outros, como o que melhor descreve as pressões de carregamento. Como desvantagem pode-se citar a não validade na determinação das pressões de descarga das pressões na seção da tremonha.

Para as pressões de descarga, ainda não há consenso entre os pesquisadores sobre qual teoria é a mais adequada para determinar corretamente as pressões. Concordância existe no sentido de que as pressões de descarga dependem do tipo de fluxo (massa ou funil) que se desenvolve durante a retirada do produto do silo.

A aplicação da teoria de WALTERS se restringe a pequenas inclinações de tremonhas devido aos valores limites de $\alpha$ que validam sua teoria, portanto não pode ser aplicada para a maioria dos casos na prática. Isso explica, também, a ausência de comparações com essa teoria em artigos publicados.

Outro ponto relevante refere-se ao fato de que o comportamento de fluxo e de pressões é condicionado pelas propriedades físicas dos produtos armazenados. Portanto, recomenda-se que para cada produto a ser armazenado, sejam realizados ensaios de caracterização, pois os custos com os ensaios são irrisórios, tendo em vista o custo de uma instalação de armazenamento. Já os custos para recuperação de uma estrutura, que não foi corretamente projetada, são incalculáveis. 
As recomendações propostas pelas normas internacionais são baseadas na teoria de JANSSEN (1895) para as estimativas das pressões iniciais ou de carregamento. Cabe salientar que o fato de todas normas utilizarem a formulação de JANSSEN não implica que elas apresentem as mesmas pressões de carregamento para um mesmo produto armazenado, pois a equação de JANSSEN é função de três variáveis: densidade, coeficiente de atrito com a parede, relação entre as pressões horizontais e verticais.

Tendo em vista a complexidade das teorias sobre silos para a determinação das pressões de descarga, as normas estudadas utilizam coeficientes de sobrepressão, aplicados às pressões estáticas para a determinação das pressões dinâmicas. Além disso, algumas normas recomendam também, a adoção de pressões adicionais a fim de levar em conta o efeito de possíveis pressões assimétricas.

O cálculo das pressões adicionais é de difícil determinação e normalmente é necessária uma análise por elementos finitos. Para simplificar o cálculo e facilitar o desenvolvimento do projeto, as normas DIN 1055-6 e EUROCODE 1 permitem a adoção de um método simplificado que consiste na adoção de um coeficiente de ponderação das ações.

Devido às diversas incertezas, principalmente das propriedades do produto armazenado, as normas variam muito na definição dos valores dos coeficientes de sobrepressão resultando em pressões bastante diferenciadas em todo o silo.

Sabe-se que o ponto crítico em silos com fluxo de funil é a transição efetiva, porém nenhuma norma analisada fornece sua localização. Apenas a norma AS apresenta formulação para o ponto mais baixo onde ela pode ocorrer.

Os métodos de cálculo apresentados para a determinação das pressões estão sujeitos a algumas limitações, com pequenas variações entre as normas, como: relação altura/diâmetro, dimensão máxima das partículas do produto armazenado, pequenas cargas de impacto no carregamento, excentricidade máxima da abertura da saída, produto de fluxo livre, entre outras.

Outra constatação diz respeito ao fato de que a maioria das normas apresenta em tabela própria os valores de $\gamma, \mu$ e K para alguns produtos. Para produtos não tabelados na norma considerada, ou no caso das propriedades físicas do produto terem sido determinadas experimentalmente, o valor de $\mathrm{K}$ será obtido através de equacionamentos próprios de cada norma.

Com o objetivo de levar em consideração possíveis mudanças nas propriedades físicas do produto armazenado, as normas analisadas procuram estabelecer combinações com alguns parâmetros, obtendo os máximos carregamentos de projeto, cobrindo esses efeitos. 
O cálculo das pressões exercidas na tremonha é um fenômeno que não é completamente compreendido, sendo, portanto, um método semi-empírico o utilizado pela maioria das normas. O método nada mais é do que a soma das pressões devidas ao peso do produto na tremonha e da pressão vertical exercida pelo produto armazenado acima da transição da tremonha com o corpo do silo.

No entanto, as normas de cálculo em silos resolvem de forma prática os problemas derivados da aplicação das teorias clássicas de cálculo, porém ainda não fornecem qualquer indicação a respeito das técnicas de cálculo por elementos finitos.

\section{Sugestões para trabalhos futuros}

1 - Estudo das pressões adicionais;

2 - Estudo das pressões em silos com descarga excêntrica;

3 - Estudo teórico e experimental das pressões em silos verticais devidas ao armazenamento de produtos coesivos;

4 - Estudo teórico e experimental da força de compressão devida ao atrito do produto em silos metálicos de chapa corrugada.

5 - Estudo do dimensionamento da abertura da boca de descarga em função dos equipamentos de transporte. 


\section{7 - REFERÊNCIAS}

AMERICAN NATIONAL STANDARDS INSTITUTE - ANSI/ASAE. EP433 (2000). Loads exerted by free-flowing grain on bins.

ANDRADE Jr., L.J. (1998) Análise Estrutural das Chapas Metálicas de Silos e de Reservatórios Cilíndricos 208p. Dissertação (Mestrado) - Escola de Engenharia de São Carlos, Universidade de São Paulo.1998.

ANDRADE Jr., L.J. (2002) Ação do Vento em Silos Cilíndricos de baixa relação altura/diâmetro.151p. Tese (Doutorado) - Escola de Engenharia de São Carlos. São Carlos. 2002.

ARAUJO, E.C. (1997) Estudo Teórico e Experimental de Tremonhas Piramidais para Silos Metálicos Elevados. 317p. Tese (Doutorado) - Escola de Engenharia de São Carlos. Universidade de São Paulo.1997.

ASSOCIAÇÃO BRASILEIRA DE NORMAS TÉCNICAS (ABNT): NBR 8681:2003: Ações e Segurança nas Estruturas. Rio de Janeiro, 2003.

AUSTRALIAN STANDARD AS 3774. (1996) Loads on bulk containers. Sydney. AS 3774 Supplement 1 (1997)." Loads on bulk containers - Commentary. Sydney.

AYUGA, F. (1995). Los empujes del material almacenado en silos. Informes de la construcción. V.46, n.436, p. 27-34, marzo/abril.

BENINK, E.J. (1989). Flow and stress analysis of cohesionless bulk materials in silos related to codes. 162p. Tese (Doutorado). Universiteit Twente. The Netherlands.

CALIL Jr., C. (1978) Silos de Madeira. 198 p. Dissertação (Mestrado em Engenharia de Estruturas) - EESC/USP, São Carlos, 1978.

CALIL Jr., C. (1984) Sobrepresiones en las paredes de los silos para almacenamiento de productos pulverulentos cohesivos. 184 p. Tese (Doutorado). Escola Politécnica de Barcelona. Espanha. Publicação do Departamento de Engenharia de Estruturas da Escola de Engenharia de São Carlos, USP. (1984) 
CALIL Jr., C. (1990). Recomendações de Fluxo e de Cargas para o Projeto de Silos Verticais. Tese de Livre Docência. EESC - USP. 198 p.

CALIL Jr., C.; NASCIMENTO, J.W.B. (1997). Ações em silos pelo método dos estados limites: proposta de norma brasileira. Engenharia Agrícola, Jaboticabal. V.16, n. 4, p.110-117.

CARSON, J. W.; JENKYN, R. T. (1993). Load Development and Structural Considerations in Silo Design. Reliable Flow of Particulate Solids II. Oslo, Norway.

COMPANHIA NACIONAL DE ABASTECIMENTO - CONAB (2004). http://www.conab.com.br/

COUTO, L.G. (1989) Contribuição ao Estudo dos Silos de Argamassa Armada para Armazenamento de Cereais. 147p. Dissertação (Mestrado) - Escola de Engenharia de São Carlos, Universidade de São Paulo. 1989.

DEUTSCHE NORM - DIN 1055-6 (2000). Basis of design and actions on structures Part 6: design loads for buildings and loads in silo bins.

ENSTAD, G. (1975). On the Theory of Arching in Mass Flow Hoppers. Chem. Eng. Science. pp 1273 a 1283.

ESTEVES Jr., P. (1989). Silos Metálicos de Chapa Corrugada. 118p. Dissertação (Mestrado) - Escola de Engenharia de São Carlos, Universidade de São Paulo. 1989.

EUROCODE 1 - ENV 1991- 4 Part 4 (1995). Actions on silos and tanks. Bruxelas.

FASSONI, D.P.(1994) Sistema Construtivo Modular em Madeira para Silos Horizontais. 150 p. Dissertação (Mestrado) - Escola de Engenharia de São Carlos. Universidade de São Paulo .1994.

FORTES FILHO, J. (1985) Uma introdução ao estudo dos silos. 427p. Dissertação (Mestrado) - Escola de Engenharia de São Carlos, Universidade de São Paulo. 1985.

FREITAS E. G. (2001) Estudo teórico e experimental das pressões em silos cilíndricos de baixa relação altura/diâmetro e fundo plano. 175p. Tese (Doutorado) - Escola de Engenharia de São Carlos. Universidade de São Paulo. 2001.

FUSCO, P. B. (1976) Estruturas de concreto: fundamentos do projeto estrutural. São Paulo, MCGraw -Hill do Brasil, 1976.

GAYLORD JR, E.H.; GAYLORD, C.N. (1984). Design of steel bins for storage of bulk solids. Prentice-Hall, INC. New Jersey. 359p. 
GOMES, F.C. (1994) Silos para armazenamento de Laranjas. 107 p. Dissertação (Mestrado) - Escola de Engenharia de São Carlos. Universidade de São Paulo. 1994.

GOMES, F.C. (2000) Estudo teórico e experimental das ações em silos horizontais. 205p. Tese (Doutorado) - Escola de Engenharia de São Carlos. Universidade de São Paulo. 2000.

INTERNATIONAL STANDART ISO - 11697 (1995). Bases for design of structures: Loads due to bulk materials.

JANSSEN, H. A. (1895) "Versuche Über Getreidedruck in Silozellen." Zeitschrift, Verein Deutscher Ingeniure, Vol. 39, pp. 1045-1049, Aug. 31,.

JENIKE, A. W. (1964). Storage and Flow of Solids. Bulletin 123. Utah Engineering Experiment Station. University of Utah. Salt Lake City. Utah. Estados Unidos. 197 p.

JENIKE, A.W.; JOHANSON, J.R. (1968). Bin loads. Journal of Structural Division. ASCE, V.94. p.1011-1041.

JENIKE, A. W; JOHANSON, J. R.; CARSON, J. W. (1973). Bin loads in 3 parts. Journal of engineering for Industry, ASCE, V.95. p.1-5, 6-12, 13-20.

JENIKE, A.W. (1985). New developments in the theory of particulate solids flow. EFCE, Serie $N^{\circ} 49$, Bergen, Norway, $7 \mathrm{p}$.

JENIKE, A.W. (1987). A theory of Flow of Particulate Solids in Converging and Diverging Channels Based on a Conical Yield Function. Powder Technology, V.50 p. 229-236.

JOFRIET, J.C.; MENG, Q.G.; NEGI, S.C. (1997). Finite-element analysis of bulk solids flow. Part 1. Development of a model-based on a secant constitutive relationship. Journal of Agricultural Engineering. Research; 67(2):141-50.

KWADE, A.; SCHULZE, D; SCHWEDES, J. (1994): Determination of the Stress Ratio in Uniaxial Compression Tests. Powder Handling \& Processing. V.61, p. 199-203

MANFRIN, I.M.S. (1994) Um Estudo dos Silos para Açúcar: Propriedades Físicas do Material Armazenado, Recomendações Construtivas, Normativas e Análise Estrutural 82 p. Dissertação (Mestrado) - Escola de Engenharia de São Carlos. Universidade de São Paulo. 1994

MARTÍNEZ, M.A.; ALFARO, I.; DOBLARÉ, M. (2002). Simulation of axisymmetric discharging in metallic silos. Analysis of the induced pressure distribuition and comparison with different standards. Engineering Structures. V. 24. p 1561-1574. 
McLEAN, A. G. (1986). Empirical Critical Flow Factor Equations. Bulk Solids Handling, V.6, No 4.

MILANI, A. P. (1993). Determinação das propriedades de produtos armazenados para o projeto de pressões e fluxo em silos. 272 p - Tese (Doutorado. - Escola de Engenharia de São Carlos. Universidade de São Paulo . 1993.

NASCIMENTO J.W. (1996) Estudo de Silos Metálicos Prismáticos para Fábricas de Ração. 152 p. Tese (Doutorado) - Escola de Engenharia de São Carlos. Universidade de São Paulo .1996.

PRESCOTT J. K., Barnum R. A. (2000). On Powder Flowability. Pharmaceutical Techonology. October 2000.

REIMBERT, M \& A. (1979). Silos: Teoría e Práctica. Editorial Américalee S.R.L. Buenos Aires. 464 p.

ROBERTS, A. W. (1987a). Introduction - Storage and flow of bulk solids: Paper 1. Storage, Flow and Handling of Bulk Solids.

ROBERTS, A. W. (1987b). Fundamental principles of storage bin and discharge system design for bulk solids handling: Paper 2. Storage, Flow and Handling of Bulk Solids.

ROBERTS, A. W. (1987c). Wall pressures in mass flow bins: Paper 7. Storage, Flow and Handling of Bulk Solids.

ROBERTS, A. W. ; McLeAN, A. G.; ARNOLD, P.C. (1987d). Determination of bin geometry. Paper 5. Storage, Flow and Handling of Bulk Solids.

ROBERTS, A. W. (1995). 100 Years of Janssen. Bulk Solids Handling. Bulk Solids Handling. V. $15 \mathrm{n}^{\circ} 3$.

ROBERTS, I. (1884). Pressure of stored grain. Engineering, Vol.34, pp.399, Oct. 27.

SCHULZE, D. (1996). Silos - Design Variants and Special Types. Bulk Solids Handling. V. 16. N ${ }^{\circ}$ 2. April/June.

SCHULZE, D.; SCHWEDES, J. (1990): Measurement of Flow Properties of Bulk Solids. Powder Technology, 61, p. 59-68

SCHWEDES, J. (1981), Measurement of Flow Properties of Bulk Solids, Proc. Int. Symp. Powder Technology, Kyoto (Japan), p. 89 - 98.

SILVA, M.C.A.T.(1993) Estudo da Variabilidade Pressões em Silos. 192p. Tese (Doutorado) - Escola Politécnica, Universidade de São Paulo.1993. 
VAZ, J. (1987). Silos Verticais de Madeira Compensada. 346p. Dissertação (Mestrado) - Escola de Engenharia de São Carlos, Universidade de São Paulo. 1987.

WALKER, D. M. (1966). An Approximate Theory for Pressures and Arching in Hoppers. Chem. Eng. Sci., V. 21, p. 975-997.

WALTERS, J. K. (1973a). A theoretical analysis of stresses in silos with vertical walls. Chemical Engineering Science, V. 28, pp. $13-21$.

WALTERS, J. K. (1973b). A theoretical analysis of stresses in axially-symmetric hoppers and bunkers. Chemical Engineering Science, V. 28, p. 779-789.

WPMPS (1989) Standart Shear Testing Technique for Particulate Solids Using the Jenike Shear Cell". The Institution of Chemical Engineers. England. 


\section{Glossário}

- lugar geométrico de deslizamento: linha dos estados críticos de deslizamento.

- yield locus: um ponto representativo de um estado crítico de deslizamento.

- estado crítico de deslizamento: estado de tensão que o produto está submetido localmente, que corresponde ao deslizamento do produto.

- ângulo de atrito com a parede: inclinação do lugar geométrico de deslizamento com a parede.

- tensão inconfinada de deslizamento (fc): resistência ao deslizamento em compressão simples, significando a tensão limite de compressão sem confinamento.

- tensão de consolidação ( $\sigma 1)$ : máxima resistência ao deslizamento em compressão com confinamento.

- função fluxo (FF): relação da tensão inconfinada de deslizamento versus tensão de consolidação.

- fator fluxo (ff): relação entre a tensão de consolidação para o produto em fluxo pela tensão atuando onde um arco estável imaginário, formado por partículas do produto, é sustentado pelas paredes da tremonha.

- eixo simétrico: o termo eixo simétrico é comumente usado para descrever a geometria do silo ou tremonha. Silos e tremonhas de eixo simétrico têm seção transversal circular ou poligonal eqüilateral em relação ao eixo vertical.

- fluxo: movimento do produto.

- fluxo de funil: tipo de fluxo caracterizado pela formação de um canal de fluxo, alinhado com a boca de descarga, cercado por uma zona na qual o produto permanece estático (zona parada ou estagnada).

- fluxo de massa: tipo de fluxo caracterizado pelo fato de que todas as partículas do produto armazenado estão em movimento durante a operação de descarga.

- transição: lugar onde ocorre o pico de pressão em silos com fluxo de massa.

- transição efetiva: lugar onde ocorre o pico de pressão em silos com fluxo de funil.

- corpo do silo: parte do silo, geralmente de forma geométrica cilíndrica ou poligonal.

- tremonha: parte inferior do silo, normalmente apresenta forma geométrica cônica. 
APÊDICE A - Proposta de Norma Brasileira para Silos Verticais Esbeltos 


\section{Proposta de Norma Brasileira para Silos Verticais Esbeltos}

\section{1 - Campo de Aplicação}

As recomendações constantes nesta proposta apresentam as seguintes limitações:

a) no carregamento do produto, as cargas de impacto devem ser mínimas;

b) o diâmetro máximo das partículas do produto armazenado deve ser menor que 0.03 vezes o diâmetro do silo;

c) o produto armazenado deve ser de fluxo livre;

d) a excentricidade devido ao carregamento $\left(e_{i}\right)$ ou da boca de descarga $\left(e_{o}\right)$ deve ser menor que 0.25 vezes o diâmetro do silo;

e) devem ser obedecidos os seguintes limites geométricos:

- relação altura/diâmetro deve ser menor que 10;

- a altura do silo deve ser menor que $100 \mathrm{~m}$;

- o diâmetro do silo deve ser menor que 50m;

f) cada silo será projetado para uma determinada gama de produtos.

\section{2 - Notações}

$A=$ área da seção transversal do corpo do silo;

$\mathrm{C}_{\mathrm{o}}=$ coeficiente de sobrepressão aplicado a pressão horizontal inicial;

$\mathrm{C}_{\mathrm{w}}=$ coeficiente de sobrepressão aplicado a pressão ou força de atrito inicial;

d = diâmetro do corpo do silo;

$\mathrm{e}=$ maior valor entre $\mathrm{e}_{\mathrm{i}}$ e $\mathrm{e}_{\mathrm{o}}$;

$\mathrm{e}_{\mathrm{i}}=$ excentricidade devido ao carregamento;

$\mathrm{e}_{\mathrm{o}}=$ excentricidade da boca de descarga;

$\mathrm{h}$ = distância da boca de descarga até a superfície equivalente;

$\mathrm{K}_{\mathrm{m}}=$ valor médio da razão da pressão horizontal pela pressão vertical;

$\mathrm{K}_{\mathrm{i}}=$ valor inferior da razão da pressão horizontal pela pressão vertical;

$\mathrm{K}_{\mathrm{s}}=$ valor superior da razão da pressão horizontal pela pressão vertical;

$\mathrm{p}_{\mathrm{hc}}=$ pressão horizontal de carregamento no corpo do silo devido ao produto armazenado;

$\mathrm{p}_{\mathrm{hd}}=$ pressão horizontal de descarga no corpo do silo devido ao produto armazenado;

$p_{n}, p_{n i}=$ pressão normal em relação a parede da tremonha, $i=1,2,3$;

$\mathrm{p}_{\mathrm{wc}}=$ pressão de atrito de carregamento no corpo do silo devido ao produto armazenado; 
$\mathrm{p}_{\mathrm{wd}}=$ pressão de atrito de descarga no corpo do silo devido ao produto armazenado;

$\mathrm{p}_{\mathrm{vc}}=$ pressão vertical de carregamento devido ao produto armazenado;

$\mathrm{p}_{\mathrm{vo}}=$ pressão vertical de carregamento na transição;

$\mathrm{p}_{\mathrm{vd}}=$ pressão vertical de descarga devido ao produto armazenado;

$\mathrm{p}_{\mathrm{vb}}=$ pressão vertical na base de silos com fundo plano;

$\mathrm{p}_{\mathrm{ae}}=$ pressão adicional no carregamento;

$\mathrm{p}_{\mathrm{ad}}=$ pressão adicional na descarga;

$\mathrm{p}_{\mathrm{s}}=$ pressão na transição para silos com fluxo de massa;

$\mathrm{P}_{\mathrm{wc}}=$ força de atrito de carregamento devido ao produto armazenado;

$\mathrm{P}_{\mathrm{wd}}=$ força de atrito de descarga devido ao produto armazenado;

$\mathrm{s}=$ dimensão da área de atuação da pressão adicional;

$\mathrm{X}$ = parâmetro utilizado para calcular as pressões na tremonha;

$z$ = profundidade abaixo da superfície equivalente no carregamento máximo;

$\alpha=$ inclinação da parede da tremonha com a horizontal;

$\beta=$ coeficiente de amplificação da pressão adicional;

$\gamma=$ peso especifico do produto armazenado;

$\mu_{m}=$ valor médio do coeficiente de atrito com a parede;

$\mu_{\mathrm{i}}=$ valor inferior do coeficiente de atrito com a parede;

$\mu_{\mathrm{s}}=$ valor superior do coeficiente de atrito com a parede;

$\phi_{\mathrm{i}}=$ efetivo ângulo de atrito interno;

$\phi_{\mathrm{w}}=$ ângulo de atrito com a parede;

\section{3 - Definições}

Superfície equivalente: nível da superfície plana que se obtém para um mesmo volume de produto armazenado em forma de cone.

Fundo plano: silo com fundo plano ou inclinação inferior a $20^{\circ}$ em relação a horizontal

Padrão de fluxo: a forma do produto fluir quando o fluxo está estabelecido;

Produto de fluxo livre: produto não coesivo;

Fluxo de funil: padrão de fluxo no qual o canal de fluxo se desenvolve, cercado por uma zona de produto estático. O canal de fluxo pode interceptar a parede ou estender-se até a superfície livre do produto. 
Fluxo de massa: padrão de fluxo no qual todas as partículas do produto armazenado estão em movimento durante a operação de descarga.

Tremonha: fundo do silo com paredes inclinadas superior a $20^{\circ} \mathrm{com}$ a horizontal.

Pressão Localizada: pressão concentrada que ocorre na transição do corpo do silo para a tremonha durante a descarga.

Pressão Adicional: pressão local atuante sobre uma determinada área em qualquer parte da parede do silo.

Silo: estrutura de contenção utilizada para armazenamento de materiais em geral.

Silo esbelto: silo onde $h / d \geq 1,5$.

Silo baixo: silo onde $\mathrm{h} / \mathrm{d}<1,5$.

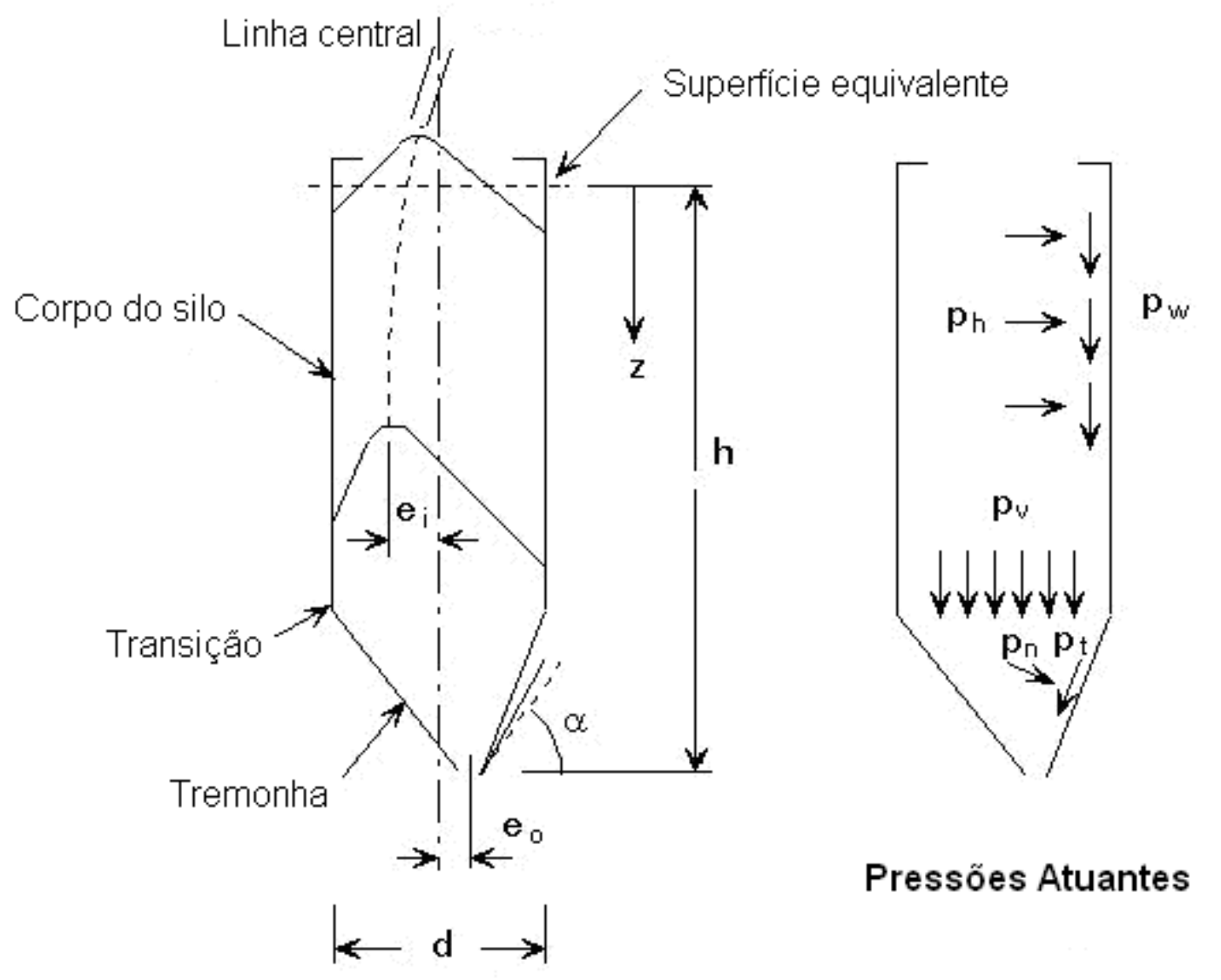

Geometria

Figura 1 - Notações 


\section{4 - Padrões de Fluxo}

A descarga do produto armazenado por gravidade pode ocorrer conforme dois tipos principais de fluxo: por fluxo de massa e fluxo de funil (figura 2). O padrão de fluxo que vai ocorrer depende principalmente das propriedades físicas do produto, assim como, da geometria e rugosidade da superfície da tremonha.

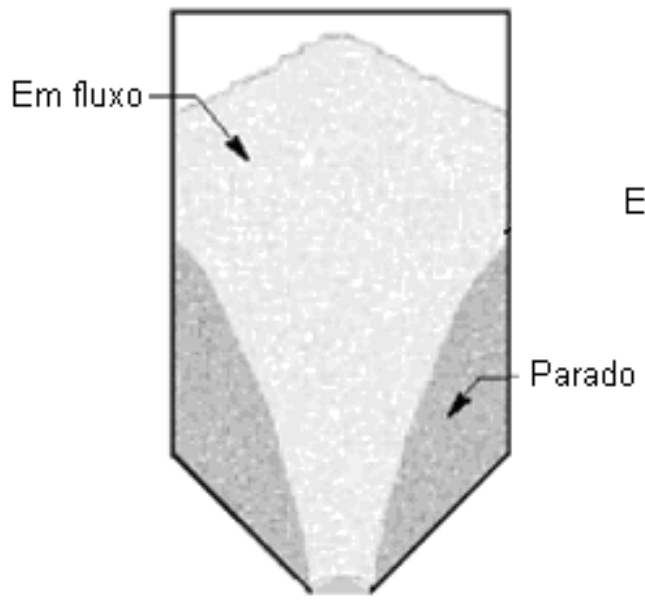

(a) Fluxo de Funil

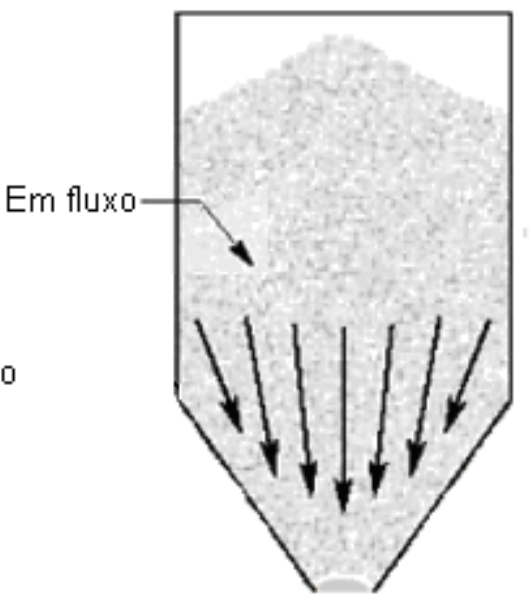

(b) Fluxo de Massa

Figura 2 - Padrões de fluxo

O padrão de fluxo que poderá ocorrer na retirada do produto armazenado do silo pode ser estimado pelos gráficos ilustrados na figura 3.
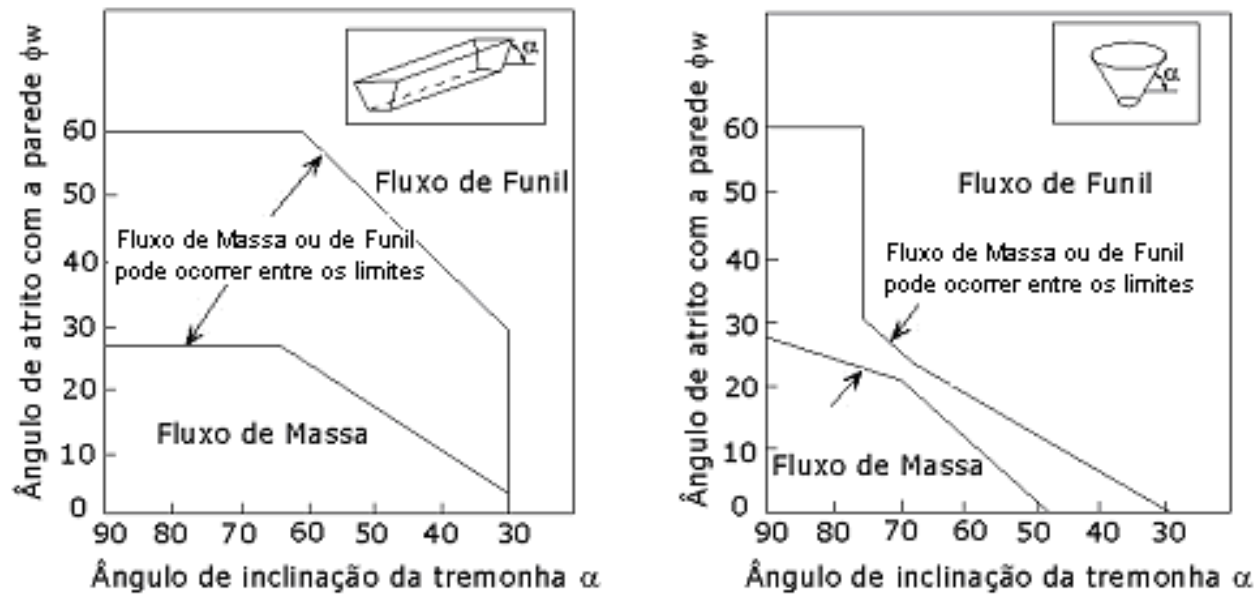

Figura 3 - Determinação gráfica do tipo de fluxo 


\section{5 - Combinações de Ações}

\subsection{Classificação das ações em silos}

No projeto e construção de silos podem ser consideradas as seguintes ações:

- Permanentes: são as constituídas pelo peso próprio da estrutura, peso de equipamentos fixos e de outras ações permanentes aplicadas.

- Variáveis: devem ser consideradas, pelo menos, três ações variáveis de naturezas diferentes:

- produto armazenado: podem ser divididas em três tipos:

a pressões de carregamento do produto;

- pressões de descarga do produto;

- ações especiais: insuflação de ar, dilatação térmica, etc..

- ações térmicas: efeitos climáticos e efeitos devido ao armazenamento de produtos quentes.

- ações do vento: deve ser considerada de acordo com a NBR 6123:1998.

- Excepcionais: devem ser consideradas, pelo menos, duas ações excepcionais:

- impacto de veículos: quando não for prevista proteção adequada de colisão de veículos com a estrutura de suporte ou com o silo, devem ser aplicadas à estrutura forças de impacto apropriadas;

- explosão de pós: os silos podem ser usados para armazenar produtos que podem causar explosões. Essas devem ser evitadas ou limitadas pela incorporação de aberturas de ventilação de ar e pelo cálculo da estrutura para resistir a alguma sobrepressão de explosão quando isto for julgado necessário.

\subsection{Valores limites das propriedades dos produtos armazenados}

Para levar em consideração a variabilidade das propriedades do produto armazenado e para obter os valores que representam o extremo dessas propriedades, recomenda-se que os valores do coeficiente de atrito com a parede $(\mu)$ e da relação entre a pressão horizontal e a pressão vertical $(K)$ tenham seus valores médios aumentados por um fator de modificação de 1,15 ou diminuídos por um fator de 0,9. Esses fatores são aplicados para produzir a combinação de carregamento mais desfavorável sobre a estrutura. Portanto, para o cálculo dos máximos carregamentos de projeto, devem ser realizadas as combinações apresentadas na tabela 1, dos parâmetros $\mathrm{Ke} \mu$. 
TABELA 1 - Combinações dos parâmetros $\mu$ e K.

\begin{tabular}{|c|c|c|}
\hline Carregamento & $\mathbf{K}$ & $\mu$ \\
\hline $\mathbf{p h}_{\max }$ & $1.15 \mathrm{~K}_{\mathrm{m}}$ & $0.9 \mu_{\mathrm{m}}$ \\
\hline $\mathbf{p v}_{\max }$ & $0.9 \mathrm{~K}_{\mathrm{m}}$ & $0.9 \mu_{\mathrm{m}}$ \\
\hline $\mathbf{P}_{\mathbf{w}_{\max }}$ & $1.15 \mathrm{~K}_{\mathrm{m}}$ & $1.15 \mu_{\mathrm{m}}$ \\
\hline
\end{tabular}

\subsection{Critérios de combinação das ações}

Para a verificação da segurança em relação aos possíveis estados limite, para cada tipo de carregamento devem ser consideradas todas as combinações de ações que possam acarretar os efeitos mais desfavoráveis nas seções críticas da estrutura.

As ações permanentes são consideradas em sua totalidade. Das ações variáveis, são consideradas apenas as parcelas que produzem efeitos desfavoráveis para a segurança.

As ações incluídas em cada uma destas combinações devem ser consideradas com seus valores representativos, multiplicados pelos respectivos coeficientes de ponderação das ações.

\subsubsection{Critérios para combinações últimas}

Devem ser considerados os seguintes critérios:

a) ações permanentes devem figurar em todas as combinações de ações;

b) ações variáveis nas combinações últimas normais: em cada combinação última, uma das ações variáveis é considerada como a principal, admitindose que ela atue com seu valor característico $\mathrm{F}_{\mathrm{k}}$; as demais ações variáveis são consideradas como secundárias, admitindo-se que elas atuem com seus valores reduzidos de combinação $\psi_{0} F_{k}$;

c) ações variáveis nas combinações últimas especiais: nas combinações últimas especiais, quando existirem, a ação variável especial deve ser considerada com seu valor representativo e as demais ações variáveis devem ser consideradas com valores correspondentes a uma probabilidade não desprezível de atuação simultânea com a ação variável especial;

d) ações variáveis nas combinações últimas excepcionais: nas combinações últimas excepcionais, quando existirem, a ação variável excepcional deve ser considerada com seu valore representativo e as demais ações variáveis devem ser consideradas com valores correspondentes a uma grande probabilidade de atuação simultânea com a ação variável excepcional. 


\subsubsection{Combinações últimas das ações}

\subsubsection{Combinações últimas normais}

As combinações últimas normais podem ser calculadas pela seguinte expressão:

$$
F_{d}=\sum_{i=1}^{m} \gamma_{g i} F_{G i, k}+\gamma_{q}\left[F_{Q 1, k}+\sum_{j=2}^{n} \psi_{0 j} F_{Q j, k}\right]
$$

onde:

$F_{G i, k}$ é o valor característico das ações permanentes;

$F_{Q 1, k}$ é o valor característico da ação variável considerada como ação principal para a combinação;

$\psi_{0 j} F_{Q j, k}$ é o valor reduzido de combinação de cada uma das demais ações variáveis.

Em casos especiais devem ser consideradas duas combinações: numa delas, admite-se que as ações permanentes sejam desfavoráveis e na outra que sejam favoráveis para a segurança.

\subsubsection{Combinações últimas especiais ou de construção}

As combinações últimas especiais ou de construção podem ser calculadas pela seguinte expressão:

$$
F_{d}=\sum_{i=1}^{m} \gamma_{g i} F_{G i, k}+\gamma_{q}\left[F_{Q 1, k}+\sum_{j=2}^{n} \psi_{0 j . e f} F_{Q j, k}\right]
$$

onde:

$F_{G i, k}$ é o valor característico das ações permanentes;

$F_{Q 1, k}$ é o valor característico da ação variável admitida como ação principal para a situação transitória considerada;

$\psi_{0 j . e f}$ é o fator de combinação efetivo de cada uma das demais variáveis que podem agir concomitantemente com a ação principal $F_{Q 1}$, durante a situação transitória.

O fator $\psi_{0 j . e f}$ é igual ao fator $\psi_{0 j}$ adotado nas combinações normais, salvo quando a ação principal $F_{Q 1}$ tiver um tempo de atuação muito pequeno, caso em $\psi_{0 j . e f}$ pode ser tomado como o correspondente $\psi_{2 j}$. 


\subsubsection{Combinações últimas excepcionais}

As combinações últimas excepcionais podem ser calculadas pela seguinte expressão:

$$
F_{d}=\sum_{i=1}^{m} \gamma_{g i} F_{G i, k}+F_{Q . e x c}+\gamma_{q} \sum_{j=1}^{n} \psi_{0 j . e f} F_{Q j, k}
$$

onde:

$F_{\text {Q.exc }}$ é o valor da ação transitória excepcional.

\subsubsection{Combinações de utilização das ações}

Nas combinações de utilização são consideradas todas as ações permanentes, inclusive as deformações impostas permanentes e as ações variáveis correspondentes a cada um dos tipos de combinações.

\subsubsection{Combinações quase permanentes de utilização}

Nas combinações quase permanentes de utilização, todas as ações variáveis são consideradas com seus valores quase permanentes $\psi_{2} F_{Q k}$.

$$
F_{d, u t i}=\sum_{i=1}^{m} F_{G i, k}+\sum_{j=1}^{n} \psi_{2 j} F_{Q j, k}
$$

\subsubsection{Combinações freqüentes de utilização}

Nas combinações freqüentes de utilização, a ação variável principal $F_{Q 1}$ é tomada com seu valor freqüente $\psi_{1} F_{Q 1, k}$ e todas as demais ações variáveis são tomadas com seus valores quase-permanentes $\psi_{2} F_{Q k}$.

$$
F_{d, u t i}=\sum_{i=1}^{m} F_{G i, k}+\psi_{1} F_{Q 1, k}+\sum_{j=2}^{n} \psi_{2 j} F_{Q j, k}
$$

\subsubsection{Combinações raras de utilização}

Nas combinações raras de utilização, a ação variável principal $F_{Q 1}$ é tomada com seu valor característico $F_{Q 1, k}$ e todas as demais ações são tomadas com seus valores freqüentes $\psi_{1} F_{Q k}$.

$$
F_{d, u t i}=\sum_{i=1}^{m} F_{G i, k}+F_{Q 1, k}+\sum_{j=2}^{n} \psi_{1 j} F_{Q j, k}
$$


TABELA 2 - Coeficientes de ponderação das ações para estados limite.

\begin{tabular}{|c|c|c|c|}
\hline \multicolumn{2}{|c|}{ Ações } & Estado Limite Último & Estado Limite de Utilização \\
\hline \multicolumn{2}{|c|}{ Permanentes } & 1.3 & 1.0 \\
\hline \multirow{3}{*}{ Produto } & Carregamento & 1.4 & 1.0 \\
\cline { 2 - 4 } & Descarga & 1.2 & 1.1 \\
\cline { 2 - 4 } & Especiais & 1.2 & 1.1 \\
\hline \multicolumn{2}{|c|}{ Vento } & 1.4 & 1.0 \\
\hline \multicolumn{2}{|c|}{ Térmica } & 1.2 & 1.0 \\
\hline
\end{tabular}

TABELA 3 - Valores dos fatores de combinação $\left(\psi_{0}\right)$ e de redução $\left(\psi_{1}\right.$ e $\left.\psi_{2}\right)$ para as ações variáveis.

\begin{tabular}{|l|c|c|c|}
\hline \multicolumn{1}{|c|}{ Ações em Silos } & $\psi_{0}$ & $\Psi_{1}$ & $\Psi_{2}$ \\
\hline Variações uniformes de temperatura em relação à média anual local & 0.6 & 0.5 & 0.3 \\
\hline Pressão dinâmica do vento & 0.5 & 0.2 & 0.0 \\
\hline Pressões devidas ao produto armazenado & 1.0 & 0.9 & 0.8 \\
\hline Deformações impostas & 0.7 & 0.5 & 0.3 \\
\hline
\end{tabular}

TABELA 4 - Sugestões de combinações das ações em silos.

\begin{tabular}{|c|c|c|c|c|c|c|}
\hline \multicolumn{2}{|c|}{ Ações } & Combinação 1 & Combinação 2 & Combinação 3 & Combinação 4 & Combinação 5 \\
\hline \multicolumn{2}{|c|}{ Permanentes } & $\bar{x}$ & $x$ & $\bar{X}$ & $\bar{X}$ & $\bar{x}$ \\
\hline \multirow{3}{*}{ Produto } & Carregamento & $\bar{x}$ & & 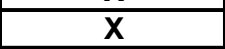 & & \\
\hline & Descarga & & $\bar{X}$ & & $\bar{x}$ & \\
\hline & Especiais & $\bar{X}$ & $\bar{X}$ & $\bar{X}$ & $\bar{X}$ & \\
\hline \multicolumn{2}{|r|}{ Vento } & & & $\bar{X}$ & $\bar{X}$ & $\bar{X}$ \\
\hline \multicolumn{2}{|c|}{ Térmica } & $\mathbf{X}$ & $\mathbf{X}$ & $\mathbf{X}$ & $\mathbf{X}$ & \\
\hline
\end{tabular}

\section{6 - Pressões de Carregamento}

Após o carregamento do silo, as pressões podem ser calculadas por:

$$
\begin{aligned}
& \mathrm{p}_{\mathrm{hc}}(z)=\frac{\gamma}{\mu} \cdot \frac{\mathrm{A}}{\mathrm{U}}\left(1-\mathrm{e}^{-\mathrm{zK} \mu \frac{\mathrm{U}}{\mathrm{A}}}\right) \\
& p_{v c}=\frac{p_{h c}}{K} \\
& p_{w c}=\mu \cdot p_{h c}
\end{aligned}
$$

Onde o parâmetro $\mu$ é obtido por:

$$
\mu=\operatorname{tg} \phi_{w}
$$

Sendo o valor empírico para o parâmetro $K$ dado pela seguinte relação:

$$
K=\frac{1-\operatorname{sen} \phi_{i}}{1+\operatorname{sen} \phi_{i}}=\operatorname{tg}^{2}\left(\frac{\pi}{4}-\frac{\phi_{i}}{2}\right)
$$


A pressão de atrito na parede $p_{w c}$ causa esforço de compressão na parede e pode ser integrada verticalmente para o cálculo da força de compressão resultante sobre a parede $P_{w c}(z)$ por unidade de perímetro de parede atuando na profundidade $z$, resultando a seguinte equação:

$$
P_{w c}(z)=\mu \int p_{h c} d z=\gamma A / U\left[z-\frac{A}{\mu K U}\left(1-e^{-\mu K z U / A}\right)\right]=\frac{A}{U}\left(\gamma z-p_{v c}\right)
$$

\section{7 - Pressões de Descarga}

As pressões de descarga podem ser determinadas multiplicando-se as pressões de carregamento (equações 1 e 6 ) por coeficientes de sobrepressão $C_{w}$ e $C_{o}$.

$$
\begin{aligned}
& p_{h d}=C_{o} \cdot p_{h c} \\
& P_{w d}=C_{w} \cdot P_{w c}
\end{aligned}
$$

nas quais

$$
\begin{aligned}
& C_{o}=1,35+0,02 \cdot\left(\phi_{e}-30^{\circ}\right) \geq 1,35 \\
& C_{w}=1,1
\end{aligned}
$$

Obs.: as cargas resistidas pelos apoios do silo podem ser determinadas do equilíbrio de força usando a $p_{v c}$ na transição multiplicada pelo fator empírico de 1,2 e pelo peso de produto na tremonha.

A pressão vertical atuando em silos com fundo plano $\left(\alpha \leq 20^{\circ}\right)$ pode ser determinada por:

$$
p_{v b}=1,2 \cdot p_{v c}
$$

\section{8 - Pressões na Tremonha}

As pressões normais a tremonha podem ser calculadas pela soma dos carregamentos devidos ao enchimento da tremonha $\left(p_{n 1}\right.$ e $\left.p_{n 2}\right)$ e pelos carregamentos resultantes da sobrecarga vertical diretamente acima da transição $\left(p_{n 3}\right)$.

Em silos com fluxo de massa uma pressão normal uniforme $\left(p_{s}\right)$ será aplicada na transição do corpo do silo com a tremonha. (figura 4)

$$
\begin{aligned}
& p_{n 1}=p_{v o}\left(1,2 \cos ^{2} \alpha+1,5 \operatorname{sen}^{2} \alpha\right) \\
& p_{n 2}=1,2 p_{v o} \cos ^{2} \alpha \\
& p_{n 3}=3,0 \frac{A}{U} \frac{\gamma K}{\sqrt{\mu}} \operatorname{sen}^{2} \alpha
\end{aligned}
$$




$$
\begin{aligned}
& p_{n}=p_{n 3}+p_{n 2}+\left(p_{n 1}-p_{n 2}\right) \frac{x}{\ln } \\
& p_{t}=\mu p_{n} \\
& p_{s}=2 p_{h c}
\end{aligned}
$$

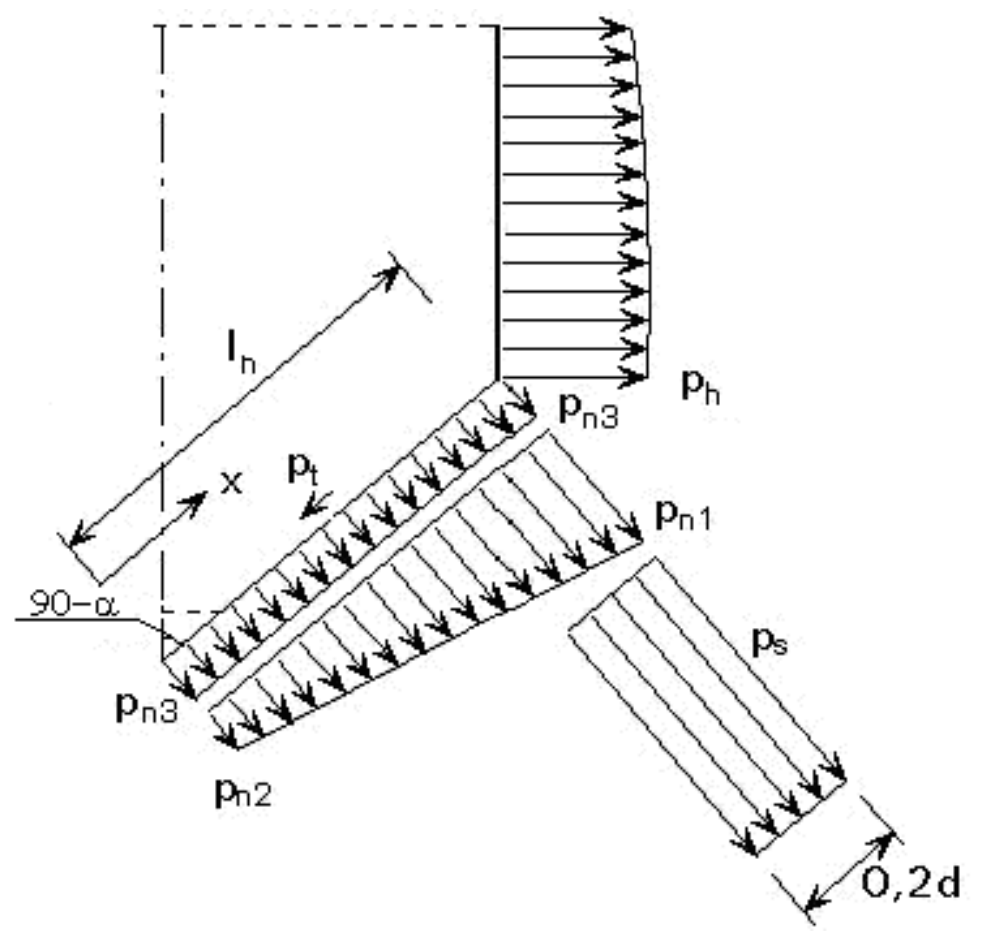

Figura 4 - Pressões sobre a tremonha.

\section{9 - Pressões Adicionais}

A adoção de pressões adicionais deve-se ao fato de que pressões assimétricas são inevitáveis, mesmo para silos com carregamento concêntrico e simetria axial, sendo dependentes das propriedades do produto armazenado e das imperfeições na geometria das paredes da tremonha e do silo. Do mesmo modo, heterogeneidade e mudanças probabilísticas no produto armazenado podem contribuir para flutuações na zona de fluxo. Por estas razões, os silos devem ser projetados para resistir às pressões assimétricas, tendo especial atenção aos momentos de flexão induzidos por estas pressões.

A pressão adicional pode ser considerada atuando sobre qualquer parte do silo, no carregamento e na descarga, sendo determinadas pelas seguintes equações:

$$
\begin{array}{ll}
p_{a c}=0,2 \cdot \beta \cdot p_{h c} & \text { (carregamento) } \\
p_{a d}=0,2 \cdot \beta \cdot p_{h d} & \text { (descarga) }
\end{array}
$$


onde $\beta$ é dado por:

$\beta=1,0+4 \cdot \frac{e}{d}$

$e=$ maior valor entre $e_{i}$ e $e_{o}$.

A pressão adicional pode ser considerada atuando sobre duas áreas quadradas opostas de lado: (figura 5).

$$
S=0,2 \cdot d
$$

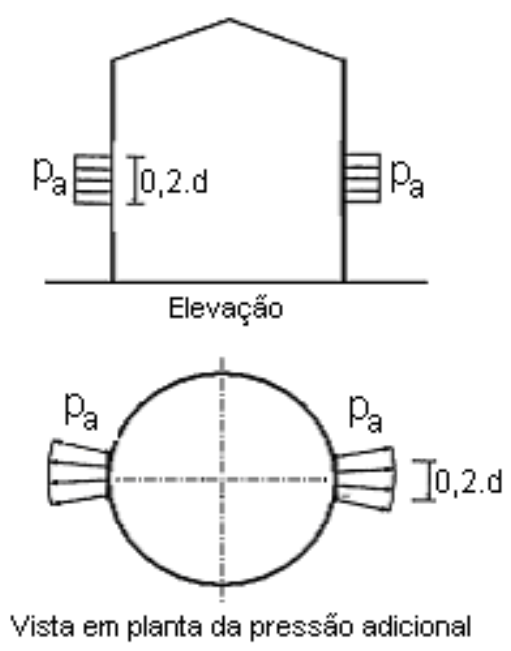

Figura 5 - Aplicação da pressão adicional.

\section{1 - Procedimento Simplificado}

Dada a incerteza da atuação das pressões adicionais, permite-se utilizar uma aproximação, que consiste em afetar as pressões atuantes por um coeficiente de ponderação.

Para silos de concreto, silos com enrijecedores e silos seção transversal não circular, as pressões podem ser determinadas por:

$$
\begin{aligned}
& \mathrm{p}_{\mathrm{hc}}=\mathrm{p}_{\mathrm{hc}} \cdot(1+0.2 \beta) \\
& \mathrm{p}_{\mathrm{hd}}=\mathrm{p}_{\mathrm{hd}} \cdot(1+0.2 \beta)
\end{aligned}
$$

Para silos de parede fina com seção circular, as pressões podem ser determinadas por:

$$
\begin{aligned}
& \mathrm{p}_{\mathrm{hc}}=\mathrm{p}_{\mathrm{hc}} \cdot(1+0.1 \beta) \\
& \mathrm{p}_{\mathrm{hd}}=\mathrm{p}_{\mathrm{hd}} \cdot(1+0.1 \beta) \\
& \mathrm{P}_{\mathrm{wc}}=\mathrm{P}_{\mathrm{wc}} \cdot(1+0.2 \beta) \\
& \mathrm{P}_{\mathrm{wd}}=\mathrm{P}_{\mathrm{wd}} \cdot(1+0.2 \beta)
\end{aligned}
$$




\section{0 - Referências}

ASSOCIAÇÃO BRASILEIRA DE NORMAS TÉCNICAS (ABNT): NBR 6123:1988: Forças devidas ao vento em edificações. Rio de Janeiro, 1988.

ASSOCIAÇÃO BRASILEIRA DE NORMAS TÉCNICAS (ABNT): NBR 8681:2003: Ações e Segurança nas Estruturas. Rio de Janeiro, 2003.

DEUTSCHE NORM - DIN 1055-6 (2000). Basis of design and actions on structures Part 6: design loads for buildings and loads in silo bins.

EUROCODE 1 - ENV 1991- 4 Part 4 (1995). Actions on silos and tanks. Bruxelas.

JANSSEN, H. A. (1895) "Versuche Über Getreidedruck in Silozellen." Zeitschrift, Verein Deutscher Ingeniure, Vol. 39, pp. 1045-1049, Aug. 31,. 